\title{
Alstoscholarisine K, an Antimicrobial Indole from Gall- Induced Leaves of Alstonia scholaris
}

Hao-Fei Yu, ${ }^{\dagger, \$, \S, \Delta}$ Cai-Feng Ding, ${ }^{\dagger, \S, \Delta}$ Lan-Chun Zhang, ${ }^{\S}$ Xin Wei, ${ }^{\dagger}$ Gui-Guang Cheng, ${ }^{\perp}$ Ya-Ping Liu, ${ }^{\dagger, \perp}$ Rong-Ping Zhang, ${ }^{\S, l, *}$ and Xiao-Dong Luo ${ }^{\dagger, \downarrow}, *$

†State Key Laboratory of Phytochemistry and Plant Resources in West China, Kunming Institute of Botany, Chinese Academy of Sciences, Kunming 650201, P. R. China

*Key Laboratory of Medicinal Chemistry for Natural Resources, Ministry of Education and Yunnan Provincial Center for Research \& Development of Natural Products; School of Chemical Science and Technology, Yunnan University, Kunming 650091, P. R. China

${ }^{\S}$ School of Pharmaceutical Sciences, Department of Zoology \& Yunnan Key Laboratory of

Pharmacology for Natural Products, Kunming Medical University, Kunming 650500, P. R. China

'School of Chinese Materia Medica and Yunnan Key Laboratory of Southern Medicinal Resources, Yunnan University of Traditional Chinese Medicine, Kunming 650500, P. R. China

${ }^{\perp}$ Yunnan Institute of Food Safety, Kunming University of Science and Technology, Kunming 650500, P. R. China

*To whom correspondence should be addressed:

Email: xdluo@mail.kib.ac.cn; zhrpkm@163.com.

${ }^{\Delta}$ These authors contributed equally to this work. 


\section{Table of Contents}

\begin{tabular}{|c|c|c|}
\hline No. & Contents & Page \\
\hline \multirow[t]{7}{*}{1} & Detailed experimental procedure & S1 \\
\hline & 1.1 General experimental procedures & S1 \\
\hline & 1.2 Plant material & S1 \\
\hline & 1.3 LC-MS analysis of gall-induced and healthy leaves & S1 \\
\hline & 1.4 Extraction and isolation & S2 \\
\hline & 1.5 Physicochemical properties of alstoscholarisine K (1) & S2 \\
\hline & 1.6 Samples preparation for LC-MS detection & S3 \\
\hline 2 & Relative contents determination of DAO and PAO & S3 \\
\hline \multirow[t]{6}{*}{3} & Antibacterial assays & S4 \\
\hline & 3.1 Micoorganism strains and growth conditions & S4 \\
\hline & 3.2 Determination of minimum inhibitory concentration (MIC) & S4 \\
\hline & 3.3 Determination of properties & S4 \\
\hline & 3.4 Scanning electron microscopy (SEM) & S5 \\
\hline & 3.5 Sytox green assay & S5 \\
\hline \multirow[t]{5}{*}{4} & Quantum chemical ECD and NMR calculations for alstoscholarisine K (1) & S5 \\
\hline & 4.1 Computational methods & S5 \\
\hline & 4.2 Energies and coordinates & S8 \\
\hline & 4.3 Experimental and calculated ECD spectra & S9 \\
\hline & 4.4 Experimental and computed ${ }^{1} \mathrm{H},{ }^{13} \mathrm{C}$ NMR chemical shifts & S11 \\
\hline \multicolumn{2}{|r|}{ Figure S1 TIC method analysis the gall-induced and healthy leaves of $A$. scholaris } & S15 \\
\hline \multicolumn{2}{|r|}{$\begin{array}{l}\text { Figure S2 Peak list views of compared gall-induced with healthy leaves in TIC of } A \text {. } \\
\text { scholaris }\end{array}$} & S16 \\
\hline \multicolumn{2}{|r|}{$\begin{array}{l}\text { Figure S3. SIM method analysis the components of gall-induced and healthy leaves of } A \text {. } \\
\text { scholaris }\end{array}$} & S24 \\
\hline \multicolumn{2}{|r|}{ Figure S4. LC-MS, MS/MS spectrum of standard alstoscholarisine K (1) } & S25 \\
\hline \multicolumn{2}{|r|}{ Figure S5. ${ }^{1} \mathrm{H}$ NMR spectrum of alstoscholarisine $\mathrm{K}(\mathbf{1})$ in DMSO (600 MHz) } & S26 \\
\hline \multicolumn{2}{|r|}{ Figure S6. ${ }^{13} \mathrm{C}$ NMR spectrum of alstoscholarisine K (1) in DMSO $(150 \mathrm{MHz})$} & S27 \\
\hline \multicolumn{2}{|r|}{ Figure S7. The ${ }^{1} \mathrm{H}-{ }^{1} \mathrm{H}$ COSY spectrum of alstoscholarisine $\mathrm{K}(\mathbf{1})$ in DMSO } & S28 \\
\hline \multicolumn{2}{|r|}{ Figure S8. The HSQC spectrum of alstoscholarisine K (1) in DMSO } & S29 \\
\hline \multicolumn{2}{|r|}{ Figure S9. The HMBC spectrum of alstoscholarisine K (1) in DMSO } & S30 \\
\hline \multicolumn{2}{|r|}{ Figure S10. The ROESY spectrum of alstoscholarisine K (1) in DMSO } & S31 \\
\hline \multicolumn{2}{|r|}{ Figure S11. ${ }^{1} \mathrm{H}$ NMR spectrum of alstoscholarisine $\mathrm{K}(\mathbf{1})$ in $\mathrm{CDCl}_{3}(600 \mathrm{MHz})$} & S32 \\
\hline \multicolumn{2}{|r|}{ Figure S12. ${ }^{13} \mathrm{C}$ NMR spectrum of alstoscholarisine $\mathrm{K}(\mathbf{1})$ in $\mathrm{CDCl}_{3}(150 \mathrm{MHz})$} & S33 \\
\hline \multicolumn{2}{|r|}{ Figure S13-S14. DEPT spectrum of alstoscholarisine $\mathrm{K}(\mathbf{1})$ in $\mathrm{CDCl}_{3}(150 \mathrm{MHz})$} & S34-S35 \\
\hline \multicolumn{2}{|r|}{ Figure S15. The HSQC spectrum of alstoscholarisine $\mathrm{K}(\mathbf{1})$ in $\mathrm{CDCl}_{3}$} & S36 \\
\hline \multicolumn{2}{|r|}{ Figure S16. The HMBC spectrum of alstoscholarisine $\mathrm{K}(\mathbf{1})$ in $\mathrm{CDCl}_{3}$} & S37 \\
\hline \multicolumn{2}{|r|}{ Figure S17. CD spectrum of alstoscholarisine K (1) } & S38 \\
\hline \multicolumn{2}{|r|}{ Figure S18. UV spectrum of alstoscholarisine K (1) } & S39 \\
\hline \multicolumn{2}{|r|}{ Figure S19. Optical rotation measurement of alstoscholarisine K (1) } & S40 \\
\hline \multicolumn{2}{|c|}{ Figure S20. IR spectrum of alstoscholarisine K (1) } & S41 \\
\hline \multicolumn{2}{|r|}{ Figure S21. ESIMS spectrum of alstoscholarisine K (1) } & S42 \\
\hline \multicolumn{2}{|r|}{ Figure S22. HR-ESI-MS spetrum of alstoscholarisine K (1) } & S43 \\
\hline \multicolumn{2}{|c|}{ Figure S23. Crystal of alstoscholarisine K (1) } & S44 \\
\hline
\end{tabular}




\section{Detailed experimental procedure}

\subsection{General Experimental Procedures}

ESIMS, HRESIMS, MS/MS were measured on an Agilent G6230 TOF MS or Thermo Ultimate 3000 UHPLC with a Q-Exactive Focus mass spectrometer. UV spectra were detected on a Shimadzu UV-2401 PC spectrophotometer. X-ray diffraction was performed on a Bruker APEX DUO diffractometer using graphite-monochromated $\mathrm{CuK} \alpha$ radiation. Infrared spectra were recorded on a Bruker Tensor-27 instrument using $\mathrm{KBr}$ pellets. Optical rotations were determined on a JASCO P-1020 digital polarimeter. CD spectra were measured on a Chirascan instrument. 1D and 2D NMR spectra were recorded on a Bruker AV-600 MHz (Bruker, Zurich, Switzerland) using TMS as internal standard for chemical shifts. Chemical shifts $(\delta)$ were expressed in ppm with reference to TMS as an internal standard. High performance liquid chromatography (HPLC) was performed using Waters 600 instrument equipped with semi-preparative C18-reverse column $(5 \mu \mathrm{m}, 150 \mathrm{~mm} \times 9.4 \mathrm{~mm})$. Scanning electron microscope was used to evaluate the membrane morphology (Hitachi S-3000N). Laser scanning confocal microscopy was used to evaluate the intracellular nucleic acid content (Japan, FV1000). Relative contents of diamine oxidase (DAO) and polyamine oxidase (PAO) were recorded on Thermo Scientific Multiskan GO microplate spectrophotometer.

TLC was performed on precoated silica plates (200-250 $\mu$ m thickness, F254 Si gel 60, Qingdao Marine Chemical, Inc.) and the compound was visualized by Dragendorff's reagent. Silica gel ((200-300) mesh, Qingdao Marine Chemical, Inc.), RP-18 (40-63 $\mu \mathrm{m}$, Fuji), and Sephadex LH-20 (20-150 $\mu \mathrm{m}$, Pharmacia) were used for column chromatography. Methanol, chloroform, ethyl acetate, acetone, and petroleum ether were purchased from Tianjin Chemical Reagents Co. (Tianjin, China). Deamination enzymes of diamine oxidase (DAO) and polyamine oxidase (PAO) were supplied from Beijing Feimo Bioscience Company. All the other materials were of the highest grade available.

\subsection{Plant material}

Healthy leaves, Pseudophacopteron alstonium induced leaves, and Diaphania angustalis bitten leaves of Alstonia scholaris were collected from different areas in Yunnan Province of China, in may to september 2016, and were identified by Mr. Jun Zhang, Kunming Medical University. A voucher specimen (No. 20160901) has been deposited in the State Key Laboratory of Phytochemistry and Plant Resources in West China, Kunming Institute of Botany, Chinese Academy of Sciences.

\subsection{LC-MS analysis of gall-induced and healthy leaves}

The chemical compositions have compared between gall-induced and healthy leaves using total ion chromatogram (TIC) analysis method by LC-MS $(\mathrm{m} / \mathrm{z}=100.0000$ - 
1000.0000), while the content of some metabolites increase or decrease significantly, and some novel metabolites might generate (Figure S1). Peak list views $(n=837)$ have compared between gall-induced and healthy leaves using MZmine 2.32[1], the differences of relative peak areas and peak height ratios show that the contents of some compounds have changed significantly, as well as novel secondary metabolites have generated (Figure S2, green means yes and red means no). Based on our longestablished monoterpene indole alkaloids (MIAs) library, these peaks $(\mathrm{m} / \mathrm{z} 250.0000$ $500.0000)$ were extracted $(\mathrm{n}=439)$ from TIC and confirmed that some new metabolites $(\mathrm{n}=157)$ might be produced in gall-induced leaves. These new peaks were filtrated by "nitrogen rule" that compounds containing odd number of nitrogen atoms and resulted $\mathrm{n}=77$. These 77 even molecular ion peaks $\mathrm{m} / \mathrm{z}$ were filtrated with secondary mass spectrometry (MS/MS) and resulted $n=16$. Just one compound with characteristic indole fragment $(\mathrm{m} / \mathrm{z}=120.0814,107.0736)$ was screened out from these even molecular ion peaks with MS/MS. Further, we target the separation of the one which containing the common indole ring with $[\mathrm{M}+\mathrm{H}]^{+}$ion at $\mathrm{m} / z 420.1913$ using selective ion monitored (SIM, $m / z$ 418.6920-421.6920) detection method in LC-MS/MS (Figure S3).

\subsection{Extraction and Isolation}

Air-dried and powdered gall-induced leaves $(35 \mathrm{~kg})$ of Alstonia scholaris were collected from Yunnan and extracted with ethanol $(4 \mathrm{~h} \times 3)$ under reflux conditions. The solvent was evaporated in vacuo to give a residue, which was dissolved in $0.5 \%$ hydrochloric acid and then adjusted to $\mathrm{pH}=2-3$. The solution was filtered and adjusted to $\mathrm{pH}=9-10$ with $10 \%$ ammonia, and the basified solution was then partitioned with EtOAc to afford the alkaloidal extract $(90.0 \mathrm{~g})$. The extract was chromatographed on a silica gel column (chloroform-methanol, 100:0 to 0:100 v/v) to afford fractions I-V by HRESIMS-guided isolation. Fraction V (41 g) was eluted on a silica gel column (chloroform-methanol, 9:1 to 0:1 v/v) to yield subfractions V-1 to V-4. Subfraction V4 was further separated on sephadex LH-20, MCI and purified by semi-preparative HPLC (RP-C18, acetonitrile $/ \mathrm{H}_{2} \mathrm{O}=60 / 40$, flow rate $=2.5 \mathrm{~mL} / \mathrm{min}, 1=230,280 \mathrm{~nm}$ ) $\mathrm{tR}=15.6 \mathrm{~min}$ (major), $17.2 \mathrm{~min}$ (minor) to yield compound $\mathbf{1}(1.7 \mathrm{mg}), \mathrm{Rf}=0.52$ (chloroform/ acetone $=2: 1$ ).

\subsection{Physicochemical properties of Compound 1}

Alstoscholarisine K (1): monoclinic crystal, m.p. $165-167{ }^{0} \mathrm{C},[\alpha]_{D}^{21}-137.7$ (c 0.1, $\mathrm{MeOH})$; UV (MeOH) $\lambda_{\max }(\log \varepsilon) \mathrm{nm} 205$ (3.76), and 267 (4.36); IR (KBr) $v_{\max } 3432$, 2926, 1737, 1681, 1630, 1436, 1384, 1194, $1036 \mathrm{~cm}^{-1} ;{ }^{1} \mathrm{H}$ and ${ }^{13} \mathrm{C}$ NMR spectroscopic 
data, see Table 1; ESIMS $m / z 442[\mathrm{M}+\mathrm{Na}]^{+}$; HRMS (ESI) $m / z$ : $[\mathrm{M}+\mathrm{Na}]^{+}$calcd for $\mathrm{C}_{24} \mathrm{H}_{25} \mathrm{~N}_{3} \mathrm{O}_{4} \mathrm{Na} 442.1737$, Found 442.1734 .

Sample preparation for crystal measurement: alstoscholarisine K (1) was successfully obtained from a mixture of methanol $/ \mathrm{H}_{2} \mathrm{O}(1: 0.1)$ as monoclinic crystal. The crystal was used for measurement on a Bruker APEX DUO diffractometer with graphite monochromater $\mathrm{CuK} \alpha$ radiation. Crystal structure was solved by direct methods with SHELXS-2014, expanded using difference Fourier technique, and refined with full-matrix least-squares on F2 using SHELXS-2014. Non-hydrogen atoms were refined anisotropically. Hydrogen atom were placed in idealized positions and refined using a riding model. Crystallographic data for compound $\mathbf{1}$ have been deposited in the Cambridge Crystallographic Data Centre (deposition number: CCDC 2077717).

Crystallographic data for 1: $\mathrm{C}_{24} \mathrm{H}_{25} \mathrm{~N}_{3} \mathrm{O}_{4}, M=419.47, a=6.83220(10) \AA, b=$ 16.0357(3) $\AA, c=9.3673(2) \AA, \alpha=90^{\circ}, \beta=97.9690(10)^{\circ}, \gamma=90^{\circ}, V=1016.36(3) \AA^{3}$, $T=173(2) \mathrm{K}$, space group $P 21, Z=2, \mu(\mathrm{CuK} \alpha)=0.769 \mathrm{~mm}^{-1}, 10869$ reflections collected, 3749 independent reflections $\left(R_{\text {int }}=0.0539\right)$. The final $R_{l}$ values were 0.0418 $(I>2 \sigma(I))$. The final $w R\left(F^{2}\right)$ values were $0.1074(I>2 \sigma(I))$. The final $R_{l}$ values were 0.0462 (all data). The final $w R\left(F^{2}\right)$ values were 0.1126 (all data). The goodness of fit on $F^{2}$ was 1.038. Absolute structure parameter $=0.18(15)$.

FAIR Data is available as Supporting Information for Publication and includes the primary NMR FID files for compound alstoscholarisine K: [1].

\subsection{Samples preparation for LC-MS detection}

Each group of fresh leaves were taken $3.0 \mathrm{~g}$, mashed, added $30 \mathrm{~mL}$ methanol, and ultrasonic extraction performed for 30 minutes, 3 times. The extracting solution was combined, added $10 \mathrm{~mL}$ water and concentrated until it had no alcohol flavor. Then extracted with ethyl acetate for 3 times, concentrated and freeze-dried to obtain the test extraction. $1.0 \mathrm{mg} / \mathrm{mL}$ of test extraction was prepared for LC-MS detection.

\section{Relative contents determination of diamine oxidase (DAO) and polyamine oxidase (PAO)}

Healthy leaves and $P$. alstonium induced leaves were collected from 12 plants of $A$. scholaris on the same twig in the Xishuangbanna, Yunnan province of China. $1.0 \mathrm{~g}$ of each samples were ground with liquid nitrogen, 10\% homogenization buffer of PBS $(\mathrm{pH}=7.2-7.4, \quad 0.01 \mathrm{~mol} / \mathrm{L}) \quad$ was added and kept at $4^{\circ} \mathrm{C}, 5000 \mathrm{rpm}$ for 30 minutes. The 
supernatant was taken for content detection according to the instructions following ELISA method.

\section{Antibacterial assays}

\subsection{Micoorganism strains and growth conditions}

The microorganisms used in antibacterial assays were obtained from the American Type Culture Collection (ATCC) (Staphyloccus aureus ATCC 25922, Escherichia coli ATCC 8739, Bacillus subtilis ATCC 6633, and Candida albicans ATCC2002. The culture media: Lysogeny Broth (LB, Conda) was used for culturing bacteria and Salouraud liquid medium broth for fungus, while Mueller Hinton Broth (MHB, Conda) was used for the determination of minimum inhibitory.

\subsection{Determination of minimum inhibitory concentration (MIC)}

The inocula of bacteria were prepared from $24 \mathrm{~h}$ old agar cultures, and incubated to logarithmic phase. Berberine, which has long been used for infections in clinical, was used as positive reference substances. Meanwhile, we measure the MIC value of compound 1 by the broth microdilution method in 96-well micro-titre plates as described in the literature. ${ }^{[2]}$ The MIC was defined as the lowest concentration without any colony growth and incubating fungus at $28^{\circ} \mathrm{C}$ for $16 \mathrm{~h}$, respectively. All tests were performed in thrice, the values are shown in Table S1.

Table S1. Minimum inhibitory concentrations (MICs, $\mu \mathrm{g} / \mathrm{mL}$ ) of alstoscholarisine K (1) against four microbial strains, with berberine included for comparison.

\begin{tabular}{lll}
\hline Strain & $\mathbf{1}$ & Berberine \\
\hline Escherichia coli & 18.75 & 37.50 \\
Staphylococcus aureus & 75.00 & 37.50 \\
Bacillus subtilis & 37.50 & 18.75 \\
Candida albicans & $>100$ & 37.50 \\
\hline
\end{tabular}

\subsection{Determination of properties}

According to the method of measuring bacterial growth curve, E. coli was grown to exponential-phase, and resuspended in liquid medium until reproduction to $1 \times 10^{6}$ $\mathrm{CFU} / \mathrm{mL}$ as control group. Meanwhile, E. coli was resuspended in liquid medium containing Compound 1 with MIC mass concentration to give a cell density of $1 \times 10^{6}$ $\mathrm{CFU} / \mathrm{mL}$ as treated group. Two samples were incubated at $37^{\circ} \mathrm{C}$ and $130 \mathrm{rpm}$ for $24 \mathrm{~h}$, and measured the $\mathrm{OD}_{600}$ values of each sample every $2 \mathrm{~h}$. Finally, we take the culture time (h) as the abscissa, as well as the value of $\mathrm{OD}_{600}$ as the ordinate, so the bacterial growth curves were drawn. 


\subsection{Scanning Electron Microscopy (SEM)}

According to the previous method, E. coli was grown to the exponential-phase in lysogeny broth medium and centrifuged at $1000 \mathrm{rpm}$ for $5 \mathrm{~min}$. Then the pellet was washed with PBS twice and resuspended in LB medium. Compound $1(10 \times \mathrm{MIC})$ was incubated with E. coli at $37^{\circ} \mathrm{C}$ for $1 \mathrm{~h}$ and centrifuged at $1000 \mathrm{rpm}$ for $10 \mathrm{~min}$, while negative control group just received the same volume of vehicle. The pellet was washed with PBS twice and resuspended in $2.5 \%$ glutaraldehyde solution at $4{ }^{\circ} \mathrm{C}$ for $2 \mathrm{~h}$. Then the E. coli was centrifuged (2000 rpm for $10 \mathrm{~min}$ ) and washed with PBS. The pellet was fixed in $1 \%$ osmium tetroxide in PBS for $1 \mathrm{~h}$. Cells were rinsed with same buffer, dehydrated in a grade series of ethanol, frozen in liquid nitrogen-cooled tert-butyl alcohol, and vacuum-dried overnight. The samples were mounted onto aluminum stubs. After sputter coating with gold, they were analyzed by Hitachi S-3000N Scanning Electron Microscope.

\subsection{Sytox Green Assay}

The method ${ }^{[3-4]}$ was used to determine the membrane integrity of $E$. coli after treatmented with compound 1. Briefly, the exponential-phase E. coli was grown in lysogeny broth medium and centrifuged at $1000 \mathrm{rpm}$ for $10 \mathrm{~min}$. Then the bacterium pellet was washed twice, and resuspended in PBS $(10 \mathrm{mM}, \mathrm{pH}=7.4)$ to give a cell density of $1 \times 10^{5} \mathrm{CFU} / \mathrm{mL}$, and incubated with Sytox green nucleic acid stain at a final concentration of $0.1 \mu \mathrm{M}$ at $37^{\circ} \mathrm{C}$ for $15 \mathrm{~min}$ on a shaking table. Sytox green-treated $E$. coli was loaded into a FlexStation microplate reader (Molecular Devices, Sunnyvale, $\mathrm{CA}$ ), and the samples were added robotically. After $1 \mathrm{~h}$ in the dark, we initiated monitoring the samples, and the fluorescence of each one was recorded every $2 \mathrm{~min}$ using an excitation of $488 \mathrm{~nm}$ and emission of $530 \mathrm{~nm}$. Results were determined as relative fluorescence units (RFU).

\section{Computational studies of ECD and NMR for alstoscholarisine K (1)}

\subsection{Computational methods}

\section{(1) Conformational analysis}

Conformational analysis for compound $\mathbf{1}$ were performed using systematic algorithm by Confab ${ }^{[5]}$ at MMFF94 force field with RMSD threshold of $0.2 \AA$ and energy window of $7 \mathrm{kcal} / \mathrm{mol}$. The energies of all dominative conformers were provided in Table S2. 


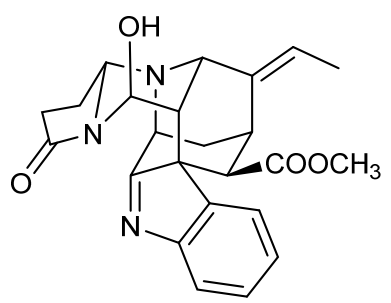

Chemical structure of alstoscholarisine K (1).

Table S2 Energies of configurations 1.

\begin{tabular}{|c|c|c|c|c|}
\hline Configuration & Conformer & Structure & Energy (kcal/mol) & Population (\%) \\
\hline 1 & $1 \mathrm{a}$ & & -77.96 & 73.44 \\
\hline 1 & $1 \mathrm{~b}$ & & -77.33 & 25.36 \\
\hline 1 & $1 \mathrm{c}$ & & -75.41 & 0.99 \\
\hline 1 & $1 d$ & & -74.19 & 0.13 \\
\hline 1 & $1 \mathrm{e}$ & & -73.63 & 0.05 \\
\hline 1 & $1 \mathrm{f}$ & $\begin{array}{c}80 \\
86\end{array}$ & -73.47 & 0.04 \\
\hline
\end{tabular}

\section{(2) ECD calculation}

The theoretical calculations were carried out using Gaussian 09 ${ }^{[6]}$. At first, all conformers were optimized at PM6. Room-temperature equilibrium populations were calculated according to Boltzmann distribution law, based on which dominative conformers of population over $1 \%$ were kept. The chosen conformers were further 
optimized at B3LYP/6-31G(d,p) in gas phase. Vibrational frequency analysis confirmed the stable structures. ECD calculations were conducted at B3LYP/6-311G(d,p) level in methanol with IEFPCM model using Time-dependent Density functional theory (TDDFT). Rotatory strengths for 30 excited state was calculated. The ECD spectrum was simulated using the ECD/UV analysis tool by overlapping Gaussian functions for each transition according to (2).

$$
\frac{N_{i}}{N}=\frac{g_{i} e^{-\frac{E_{i}}{k_{\mathrm{B}} T}}}{\sum g_{i} e^{-\frac{E_{i}}{k_{\mathrm{B}} T}}}
$$

where $N_{i}$ is the number of conformer $\mathrm{i}$ with energy $E_{i}$ and degeneracy $g_{i}$ at temperature $T$, and $k_{\mathrm{B}}$ is Boltzmann constant.

$$
\Delta \varepsilon(E)=\frac{1}{2.297 \times 10^{-39}} \times \frac{1}{\sqrt{2 \pi \sigma}} \sum_{i}^{A} \Delta E_{i} R_{i} e^{-\left(\frac{E-E_{i}}{2 \sigma}\right)^{2}}
$$

where $\sigma$ represents the width of the band at 1/e height, while $\Delta E_{i}$ and $R_{i}$ are the excitation energies and rotatory strengths for transition $i$, respectively.

The $\sigma$ and UV-shift values were set $0.41 \mathrm{eV}$ and $0 \mathrm{~nm}$, respectively. The spectrum of the enantiomers were produced directly by mirror inversion about the horizontal axis.

\section{(3) NMR calculation}

The structure was directly derived from the previous ECD calculations. NMR calculations were carried out following the protocol adapted from Michael et al. ${ }^{[7]}$ (Table S3) using the Gauge-Including Atomic Orbitals (GIAO) method at mPW1PW91/6-311+G(2d,p) level in DMSO simulated by the IEFPCM model. The TMS-corrected NMR chemical shift values were averaged according to Boltzmann distribution and fitted to the experimental values by linear regression. The calculated ${ }^{13} \mathrm{C}$ - and ${ }^{1} \mathrm{H}-\mathrm{NMR}$ chemical shift values of TMS in DMSO were 187.3895 and 31.7337 ppm. 


\subsection{Energies and coordinates}

\section{(1) Energies at B3LYP theory level}

Structures for ECD calculation which further convergence based HF/6-31G(d) and B3LYP/6-31G(d) methods was shown in Table S3.

Table S3 Energies of configurations 1 at B3LYP/6-311G(d,p) in methanol

\begin{tabular}{|c|c|c|c|c|c|}
\hline Configuration & Conformer & Structure & E (Hartree) & $\mathrm{E}(\mathrm{kcal} / \mathrm{mol})$ & Population (\%) \\
\hline 1 & $1 \mathrm{a}$ & & -1394.75669870 & -875223.04 & 94.7 \\
\hline 1 & $1 \mathrm{c}$ & & -1394.75398600 & -875221.33 & 5.3 \\
\hline
\end{tabular}




\subsection{Experimental and calculated ECD spectra}

Table S4 Standard orientations of configurations 1 for ECD calculation

Conformer 1-1a

\begin{tabular}{|c|c|c|c|c|c|}
\hline \multirow{2}{*}{$\begin{array}{c}\text { Center } \\
\text { Number }\end{array}$} & \multirow{2}{*}{$\begin{array}{l}\text { Atomic } \\
\text { Number }\end{array}$} & \multirow{2}{*}{$\begin{array}{c}\text { Atomic } \\
\text { Type }\end{array}$} & \multicolumn{3}{|c|}{ Coordinates (Angstroms) } \\
\hline & & & $\mathrm{X}$ & $\mathrm{Y}$ & $\mathrm{Z}$ \\
\hline 1 & 6 & 0 & 0.707503 & 0.049403 & -1.234698 \\
\hline 2 & 6 & 0 & -0.201601 & 0.573596 & -0.126098 \\
\hline 3 & 6 & 0 & -0.090594 & -0.394003 & 1.095702 \\
\hline 4 & 6 & 0 & -0.467483 & -1.824906 & 0.593702 \\
\hline 5 & 7 & 0 & 0.517321 & -2.273498 & -0.441398 \\
\hline 6 & 6 & 0 & 0.471314 & -1.377499 & -1.630198 \\
\hline 7 & 6 & 0 & -0.952785 & -1.44411 & -2.225598 \\
\hline 8 & 6 & 0 & -1.640001 & 0.516185 & -0.746498 \\
\hline 9 & 6 & 0 & -1.977989 & -0.951118 & -1.177698 \\
\hline 10 & 6 & 0 & -1.869182 & -1.849117 & 0.032002 \\
\hline 11 & 6 & 0 & 1.819722 & -2.390988 & 0.217702 \\
\hline 12 & 6 & 0 & 1.321006 & -0.425492 & 1.722002 \\
\hline 13 & 8 & 0 & 1.172312 & -1.068793 & 2.983702 \\
\hline 14 & 6 & 0 & 3.032125 & -2.772078 & -0.672698 \\
\hline 15 & 7 & 0 & 2.243812 & -1.144085 & 0.863302 \\
\hline 16 & 6 & 0 & 3.960215 & -1.542471 & -0.680798 \\
\hline 17 & 6 & 0 & 3.463808 & -0.648375 & 0.453502 \\
\hline 18 & 6 & 0 & -2.843877 & -2.581125 & 0.584902 \\
\hline 19 & 6 & 0 & -4.282076 & -2.681936 & 0.160702 \\
\hline 20 & 7 & 0 & 1.543696 & 0.89391 & -1.729198 \\
\hline 21 & 6 & 0 & 1.355587 & 2.100108 & -0.992898 \\
\hline 22 & 6 & 0 & 0.353188 & 1.979001 & -0.006298 \\
\hline 23 & 6 & 0 & 2.056877 & 3.286514 & -1.175798 \\
\hline 24 & 6 & 0 & 1.746569 & 4.366211 & -0.342798 \\
\hline 25 & 6 & 0 & 0.76067 & 4.252504 & 0.642402 \\
\hline 26 & 6 & 0 & 0.051679 & 3.055598 & 0.819602 \\
\hline 27 & 8 & 0 & 4.0081 & 0.344829 & 0.903502 \\
\hline 28 & 6 & 0 & -2.730305 & 1.077576 & 0.158102 \\
\hline 29 & 8 & 0 & -2.623308 & 1.389677 & 1.325202 \\
\hline 30 & 8 & 0 & -3.890006 & 1.188267 & -0.528198 \\
\hline 31 & 6 & 0 & -5.00581 & 1.702458 & 0.220002 \\
\hline 32 & 1 & 0 & -0.783396 & -0.077208 & 1.877802 \\
\hline 33 & 1 & 0 & -0.388177 & -2.520505 & 1.434402 \\
\hline 34 & 1 & 0 & 1.206517 & -1.709793 & -2.367298 \\
\hline 35 & 1 & 0 & -1.180677 & -2.478512 & -2.504398 \\
\hline 36 & 1 & 0 & -0.99649 & -0.82401 & -3.129398 \\
\hline 37 & 1 & 0 & -1.641406 & 1.138985 & -1.650598 \\
\hline 38 & 1 & 0 & -2.979289 & -0.961426 & -1.612998 \\
\hline 39 & 1 & 0 & 1.667028 & -3.149089 & 0.994502 \\
\hline 40 & 1 & 0 & 1.730399 & 0.582311 & 1.841102 \\
\hline 41 & 1 & 0 & 2.040011 & -1.041186 & 3.417902 \\
\hline 42 & 1 & 0 & 3.536932 & -3.633874 & -0.226598 \\
\hline 43 & 1 & 0 & 2.707627 & -3.078881 & -1.669498 \\
\hline 44 & 1 & 0 & 3.874711 & -0.953872 & -1.601498 \\
\hline 45 & 1 & 0 & 5.016717 & -1.785563 & -0.541298 \\
\hline 46 & 1 & 0 & -2.579872 & -3.185423 & 1.454302 \\
\hline 47 & 1 & 0 & -4.530281 & -2.024438 & -0.676898 \\
\hline 48 & 1 & 0 & -4.530268 & -3.710938 & -0.132898 \\
\hline 49 & 1 & 0 & -4.948978 & -2.427941 & 0.995402 \\
\hline 50 & 1 & 0 & 2.827277 & 3.35652 & -1.937398 \\
\hline 51 & 1 & 0 & 2.283561 & 5.303916 & -0.458798 \\
\hline 52 & 1 & 0 & 0.540763 & 5.102702 & 1.282502 \\
\hline 53 & 1 & 0 & -0.71652 & 2.973292 & 1.581502 \\
\hline 54 & 1 & 0 & -5.84161 & 1.721552 & -0.479698 \\
\hline
\end{tabular}




\begin{tabular}{llllll}
\hline 55 & 1 & 0 & -5.228705 & 1.053157 & 1.070502 \\
56 & 1 & 0 & -4.787818 & 2.70846 & 0.587302 \\
\hline
\end{tabular}

Conformer 1-1c

\begin{tabular}{|c|c|c|c|c|c|}
\hline \multirow{2}{*}{$\begin{array}{l}\text { Center } \\
\text { Number }\end{array}$} & \multirow{2}{*}{$\begin{array}{l}\text { Atomic } \\
\text { Number }\end{array}$} & \multirow{2}{*}{$\begin{array}{l}\text { Atomic } \\
\text { Type }\end{array}$} & \multicolumn{3}{|c|}{ Coordinates (Angstroms) } \\
\hline & & & $\mathrm{X}$ & $\mathrm{Y}$ & $\mathrm{Z}$ \\
\hline 1 & 6 & 0 & 0.73439 & -0.06792 & -1.259303 \\
\hline 2 & 6 & 0 & -0.219397 & 0.567299 & -0.246203 \\
\hline 3 & 6 & 0 & -0.231015 & -0.332801 & 1.030197 \\
\hline 4 & 6 & 0 & -0.643245 & -1.774192 & 0.585397 \\
\hline 5 & 7 & 0 & 0.386444 & -2.328213 & -0.348403 \\
\hline 6 & 6 & 0 & 0.462561 & -1.505315 & -1.587303 \\
\hline 7 & 6 & 0 & -0.91664 & -1.549187 & -2.279903 \\
\hline 8 & 6 & 0 & -1.613298 & 0.532128 & -0.972303 \\
\hline 9 & 6 & 0 & -1.983228 & -0.943965 & -1.341003 \\
\hline 10 & 6 & 0 & -2.003645 & -1.763064 & -0.071403 \\
\hline 11 & 6 & 0 & 1.635641 & -2.461139 & 0.403097 \\
\hline 12 & 6 & 0 & 1.133883 & -0.387229 & 1.751997 \\
\hline 13 & 8 & 0 & 0.871072 & -0.943823 & 3.037097 \\
\hline 14 & 6 & 0 & 2.884931 & -2.946665 & -0.379203 \\
\hline 15 & 7 & 0 & 2.074867 & -1.195748 & 1.002197 \\
\hline 16 & 6 & 0 & 3.866355 & -1.759385 & -0.399003 \\
\hline 17 & 6 & 0 & 3.338876 & -0.775574 & 0.643097 \\
\hline 18 & 6 & 0 & -3.055958 & -2.396443 & 0.461797 \\
\hline 19 & 6 & 0 & -4.468559 & -2.436014 & -0.050403 \\
\hline 20 & 7 & 0 & 1.639606 & 0.704761 & -1.748803 \\
\hline 21 & 6 & 0 & 1.468532 & 1.961064 & -1.100503 \\
\hline 22 & 6 & 0 & 0.404331 & 1.949686 & -0.172503 \\
\hline 23 & 6 & 0 & 2.244855 & 3.095649 & -1.308403 \\
\hline 24 & 6 & 0 & 1.951278 & 4.238455 & -0.558403 \\
\hline 25 & 6 & 0 & 0.908278 & 4.234776 & 0.372497 \\
\hline 26 & 6 & 0 & 0.124455 & 3.089592 & 0.572297 \\
\hline 27 & 8 & 0 & 3.895696 & 0.222815 & 1.065497 \\
\hline 28 & 6 & 0 & -2.824685 & 1.161753 & -0.286703 \\
\hline 29 & 8 & 0 & -3.901983 & 1.248275 & -0.837503 \\
\hline 30 & 8 & 0 & -2.610276 & 1.588948 & 0.974097 \\
\hline 31 & 6 & 0 & -3.757564 & 2.159872 & 1.632597 \\
\hline 32 & 1 & 0 & -0.955707 & 0.051714 & 1.750497 \\
\hline 33 & 1 & 0 & -0.657658 & -2.419692 & 1.468697 \\
\hline 34 & 1 & 0 & 1.233652 & -1.909231 & -2.247703 \\
\hline 35 & 1 & 0 & -1.173962 & -2.588481 & -2.510703 \\
\hline 36 & 1 & 0 & -0.867629 & -0.987488 & -3.220803 \\
\hline 37 & 1 & 0 & -1.507986 & 1.094626 & -1.909403 \\
\hline 38 & 1 & 0 & -2.953028 & -0.931745 & -1.841403 \\
\hline 39 & 1 & 0 & 1.397927 & -3.163134 & 1.210497 \\
\hline
\end{tabular}




\begin{tabular}{rrrrrr}
\hline 40 & 1 & 0 & 1.582704 & 0.606762 & 1.841397 \\
41 & 1 & 0 & 1.712972 & -0.944641 & 3.520397 \\
42 & 1 & 0 & 3.320713 & -3.798374 & 0.151197 \\
43 & 1 & 0 & 2.612624 & -3.302859 & -1.375103 \\
44 & 1 & 0 & 3.868166 & -1.226985 & -1.357203 \\
45 & 1 & 0 & 4.89945 & -2.036506 & -0.173903 \\
46 & 1 & 0 & -2.883869 & -2.959246 & 1.381097 \\
47 & 1 & 0 & -4.640345 & -1.75541 & -0.888003 \\
48 & 1 & 0 & -4.739579 & -3.451308 & -0.371703 \\
49 & 1 & 0 & -5.172953 & -2.164099 & 0.746397 \\
50 & 1 & 0 & 3.060055 & 3.077132 & -2.024703 \\
51 & 1 & 0 & 2.545997 & 5.137642 & -0.695103 \\
52 & 1 & 0 & 0.701797 & 5.13068 & 0.951797 \\
53 & 1 & 0 & -0.683645 & 3.097609 & 1.295397 \\
54 & 1 & 0 & -3.412959 & 2.436465 & 2.628997 \\
55 & 1 & 0 & -4.111746 & 3.037379 & 1.086597 \\
56 & 1 & 0 & -4.564279 & 1.425588 & 1.691797 \\
\hline
\end{tabular}

(1) Experimental and calculated ECD spectra of compound 1

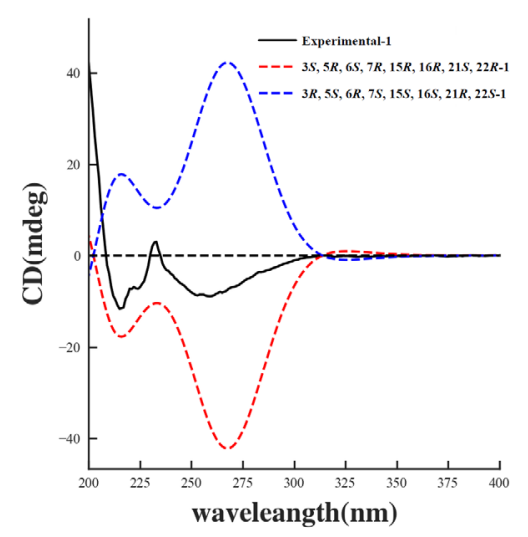

\subsection{Experimental and computed NMR chemical shifts}

\section{(1) ${ }^{13} \mathrm{C}$ - and ${ }^{1} \mathrm{H}$-NMR chemical shifts}

The TMS-corrected computed ${ }^{13} \mathrm{C}$ - and ${ }^{1} \mathrm{H}-\mathrm{NMR}$ chemical shifts of compounds $\mathbf{1 a}$ and 1c were fitted to the experimental values by Ordinary Least Squares (OLS) Linear Regression method in order to remove systematic error that results from the conformational search and random error from experimental conditions (Table S5). 
Table S5 Experimental and computed chemical shifts of 1 .

${ }^{13} \mathrm{C}-\mathrm{NMR}$ :

\begin{tabular}{|c|c|c|}
\hline Position & Experimental & 1 \\
\hline 2 & 186.2 & 188.9 \\
\hline 3 & 50 & 50.7 \\
\hline 5 & 69.6 & 70.0 \\
\hline 6 & 48 & 49.2 \\
\hline 7 & 56.5 & 57.7 \\
\hline 8 & 140.3 & 139.8 \\
\hline 9 & 124.1 & 123.7 \\
\hline 10 & 124.3 & 121.8 \\
\hline 11 & 128.3 & 126.4 \\
\hline 12 & 120.6 & 118.0 \\
\hline 13 & 155.9 & 154.8 \\
\hline 14 & 36.6 & 37.4 \\
\hline 15 & 32.5 & 34.5 \\
\hline 16 & 54.9 & 55.1 \\
\hline 17 & 170.8 & 172.9 \\
\hline 18 & 11.7 & 11.1 \\
\hline 19 & 117.6 & 120.8 \\
\hline 20 & 135.6 & 135.7 \\
\hline 21 & 59 & 59.4 \\
\hline 22 & 72.2 & 70.3 \\
\hline 23 & 19.2 & 19.5 \\
\hline 24 & 28.9 & 28.5 \\
\hline 25 & 171.7 & 170.6 \\
\hline $\mathrm{OCH}_{3}$ & 51.4 & 49.3 \\
\hline
\end{tabular}

\section{${ }^{1} \mathrm{H}-\mathrm{NMR}$ :}

\begin{tabular}{ccc}
\hline Position & Experimental & $\mathbf{1}$ \\
\hline 3 & 4.24 & 3.91 \\
5 & 4.44 & 4.51 \\
6 & 3.32 & 3.62 \\
9 & 7.54 & 7.64 \\
10 & 7.15 & 7.11 \\
11 & 7.32 & 7.31 \\
12 & 7.46 & 7.37 \\
$14 \mathrm{a}$ & 2.18 & 2.23 \\
$14 \mathrm{~b}$ & 1.96 & 1.94 \\
15 & 3.32 & 3.40 \\
16 & 2.21 & 2.13 \\
18 & 1.58 & 1.60 \\
19 & 5.56 & 5.69 \\
21 & 3.88 & 3.77 \\
22 & 4.76 & 4.71
\end{tabular}




\begin{tabular}{cll}
$23 \mathrm{a}$ & 2.05 & 2.16 \\
$23 \mathrm{~b}$ & 2.05 & 1.96 \\
$24 \mathrm{a}$ & 2.05 & 1.97 \\
$24 \mathrm{~b}$ & 2.27 & 2.41 \\
$\mathrm{OCH}_{3}$ & 3.62 & 3.53 \\
\hline
\end{tabular}

Relatively higher $\mathrm{R}^{2}$ and lower CMAD and CLAD values were shown in both ${ }^{13} \mathrm{C}$ and ${ }^{1} \mathrm{H}-\mathrm{NMR}$ Ordinary Least Squares Linear Regression (OLS-LR) for compound 1, which indicated that this configuration was the correct structure (Table S6).

Table S6 Statistics of Ordinary Least Squares Linear Regression (OLS-LR) of experimental and computed ${ }^{13} \mathrm{C},{ }^{1} \mathrm{H}-\mathrm{NMR}$ chemical shifts.

\begin{tabular}{cccccccc}
\hline Type & Compound & CMAD $^{\mathrm{a}}$ & CLAD $^{\mathrm{b}}$ & $R^{2}$ & $R M S D$ & $F$ & $p$ value \\
\hline CNMR & $\mathbf{1}$ & 1.26 & 3.17 & 0.9991 & 1.6266 & 25242.97 & $<0.01$ \\
\hline HNMR & $\mathbf{1}$ & 0.1 & 0.33 & 0.9960 & 0.1339 & 4483.58 & $<0.01$ \\
\hline
\end{tabular}

${ }^{\text {a }} \mathrm{CMAD}=$ corrected mean absolute deviation, computed as $(1 / n) \sum_{i}^{n}\left|\delta_{\text {calc }}-\delta_{\text {exp }}\right|$, where $\delta_{\text {calc }}$ and $\delta_{\text {exp }}$ refer to the calculated and experimental chemical shifts. ${ }^{\text {b }}$ CLAD $=$ corrected largest absolute deviation, computed as $\max \left(\left|\delta_{\text {calc }}-\delta_{\text {exp }}\right|\right)$.

(1) Regression analysis of experimental vs calculated ${ }^{13} \mathrm{C}$ - and ${ }^{1} \mathrm{H}-\mathrm{NMR}$ chemical shifts of 1

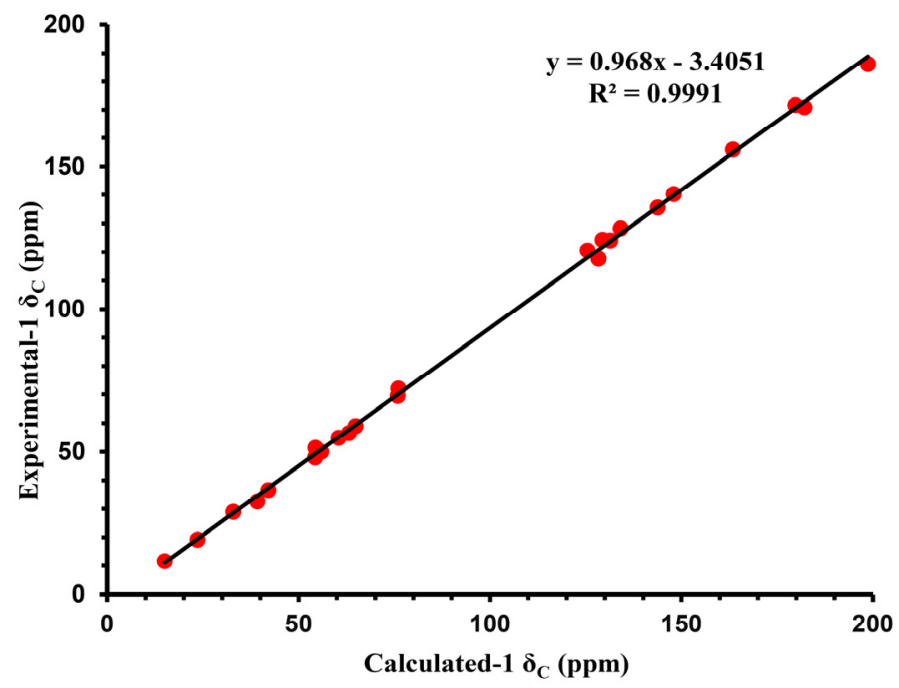




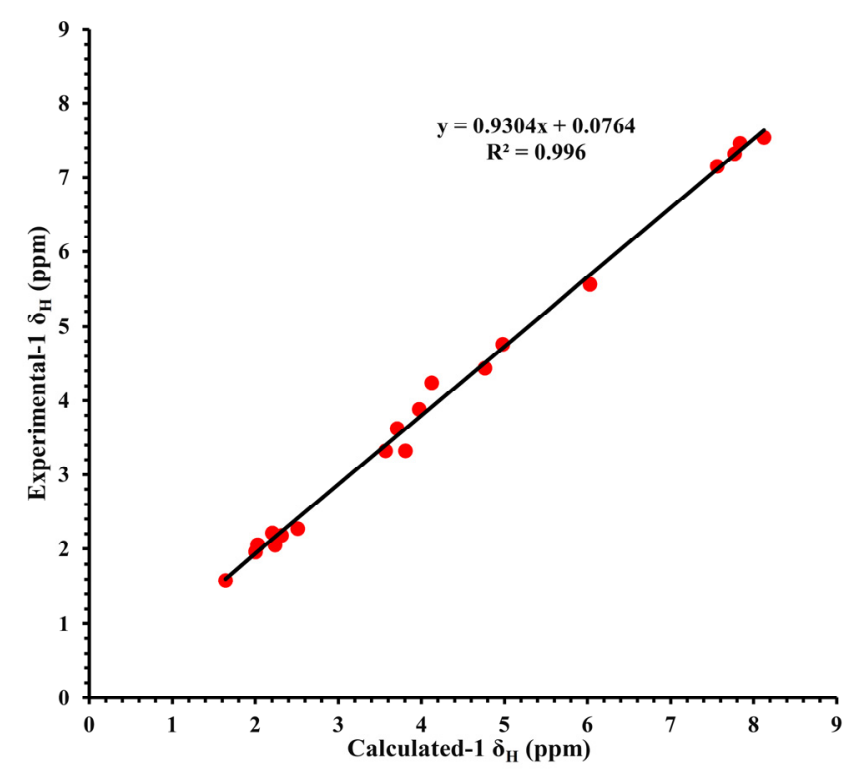

\section{References}

(1) Pluskal T.; Castillo S.; Villar-Briones A.; Orešič M. BMC Bioinformatics, 2010, 11, 395.

(2) Orasch C.; Marchetti O.; Garbino J.; Schrenzel J.; Zimmerli S.; Mühlethaler K.; Pfyffer G.; Ruef C.; Fehr J.; Zbinden R. Clinical Microbiology and Infection, 2014, 20, 698-705.

(3) Ling, L. L.; Schneider, T.; Peoples, A. J.; Spoering, A. L.; Engels, I.; Conlon, B. P.; Mueller, A.; Schäberle, T. F.; Hughes, D. E.; Epstein, S. Nature, 2015, 520, 455-459.

(4) Sochacki, K. A.; Barns, K. J.; Bucki, R.; Weisshaar, J. C. Proceedings of the National Academy of Sciences of the United States of America, 2011, 108, 6347-6348.

(5) OBoyle, N. M.; Ermeersch, T. V.; Christopher, J. F.; Maguire, A. R.; Hutchison, G. R. Journal of Cheminformatics, 2011, 3, 3-8.

(6) Frisch, M. J.; Trucks, G. W.; Schlegel, H. B.; Scuseria, G. E.; Robb, M. A.; Cheeseman, J. R.; Scalmani, G.; Barone, V.; Mennucci, B.; Petersson, G. A.; Nakatsuji, H.; Caricato, M.; Li, X.; Hratchian, H. P.; Izmaylov, A. F.; Bloino, J.; Zheng, G.; Sonnenberg, J. L.; Hada, M.; Ehara, M.; Toyota, K.; Fukuda, R.; Hasegawa, J.; Ishida, M.; Nakajima, T.; Honda, Y.; Kitao, O.; Nakai, H.; Vreven, T.; Montgomery, J. A.; Peralta, J. E.; Ogliaro, F.; Bearpark, M.; Heyd, J. J.; Brothers, E.; Kudin, K. N.; Staroverov, V. N.; Kobayashi, R.; Normand, J.; Raghavachari, K.; Rendell, A.; Burant, J. C.; Iyengar, S. S.; Tomasi, J.; Cossi, M.; Rega, N.; Millam, J. M.; Klene, M.; Knox, J. E.; Cross, J. B.; Bakken,V.; Adamo, C.; Jaramillo, J.; Gomperts, R.; Stratmann, R. E.; Yazyev, O.; Austin, A. J.; Cammi, R.; Pomelli, C.; Ochterski, J. W.; Martin, R. L.; Morokuma, K.; Zakrzewski, V. G.; Voth, G. A.; Salvador, P.; Dannenberg, J. J.; Dapprich, S.; Daniels, A. D.; Farkas, O.; Foresman, J. B.; Ortiz, J. V.; Cioslowski, J.; Fox, D. J. Gaussian 09 Revision D.01. Gaussian Inc. Wallingford CT 2009.

(7) Lodewyk, M. W.; Siebert, M. R.; Tantillo, D. J. Chemical Reviews, 2012, 112, 1839-1862. 
Figure S1 TIC method analysis the gall-induced and healthy leaves of $\boldsymbol{A}$. scholaris $(m / z, 100.0000-1000.0000)$

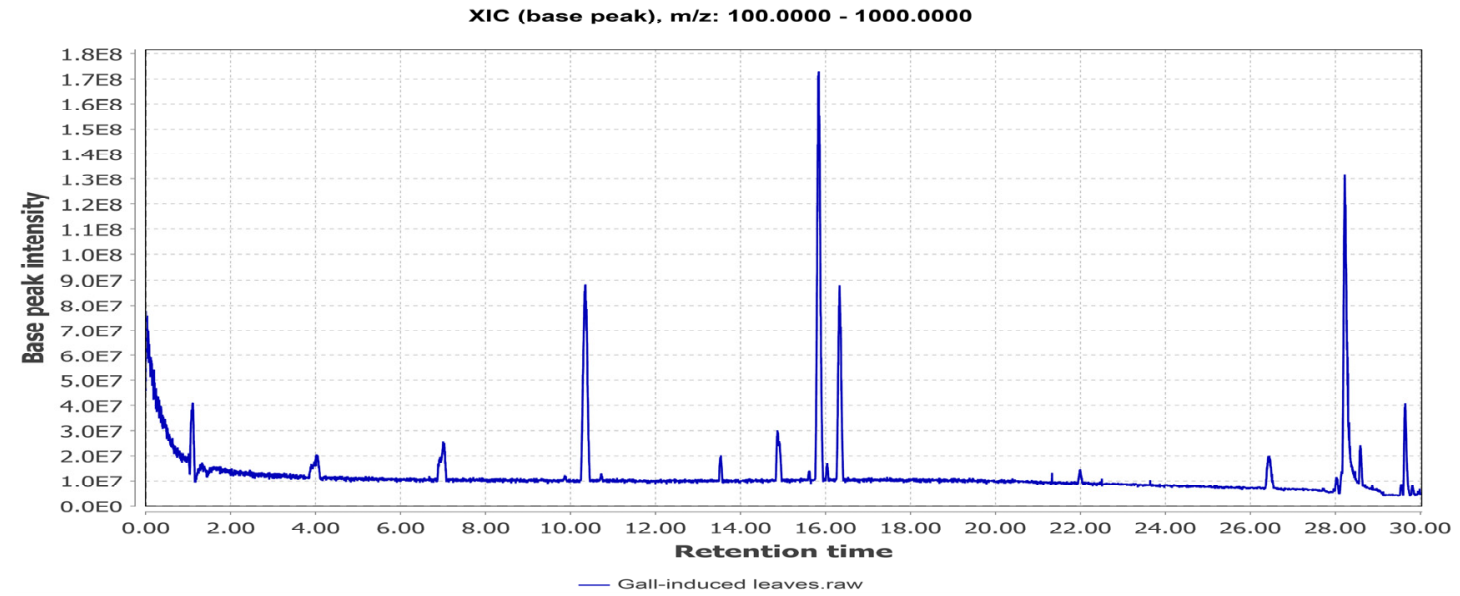

(a) The gall-induced leaves of $A$. scholaris

XIC (base peak), m/z: $100.0000-1000.0000$

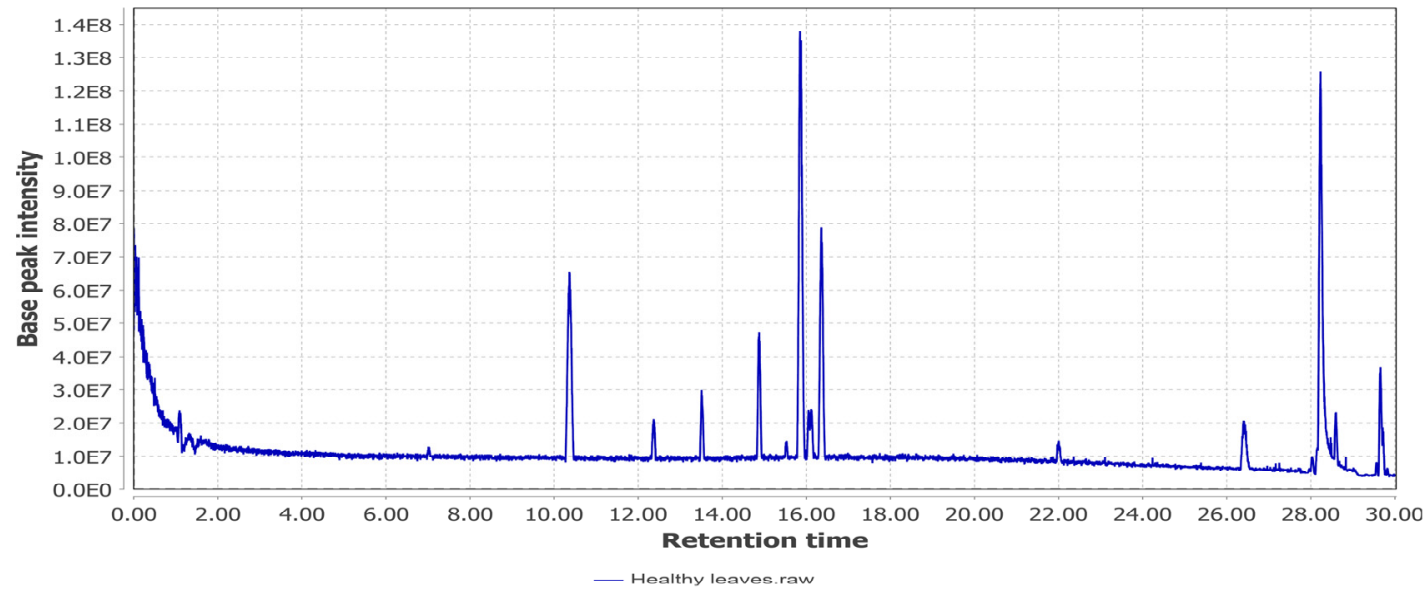

(b) The healthy leaves of $A$. scholaris XIC (base peak), m/z: $100.0000-1000.0000$

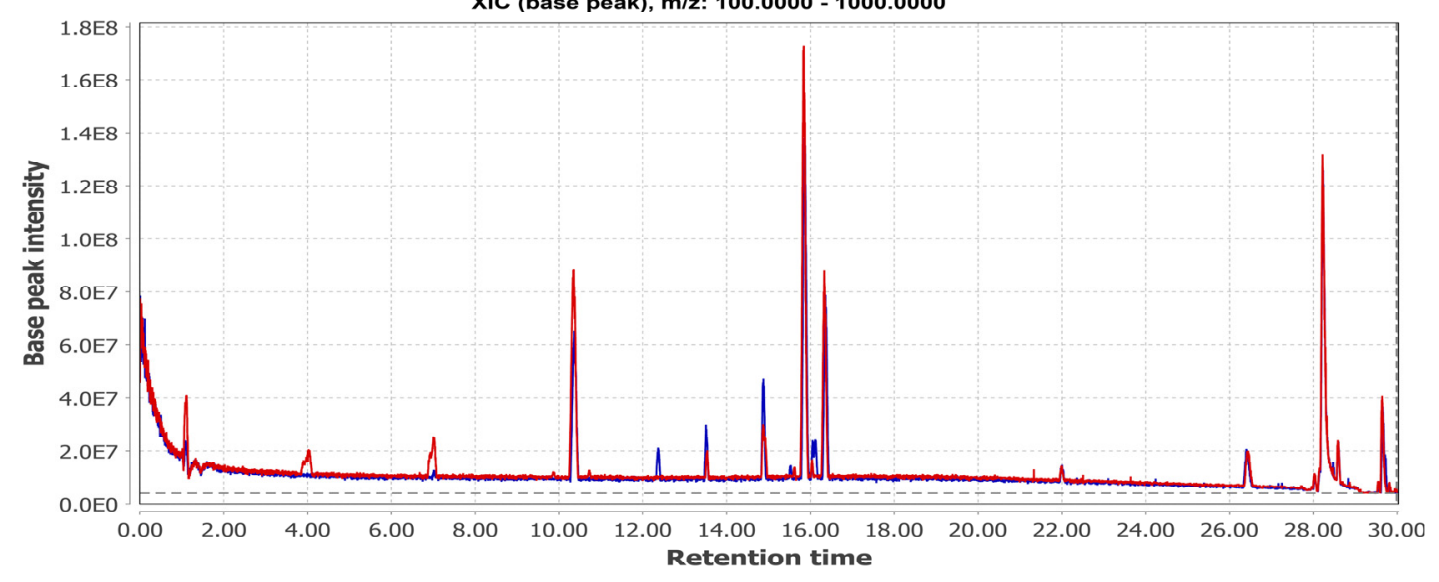

- Healthy leaves.raw — Gall-induced leaves.raw

(c) Comparation between gall-induced and healthy leaves of $A$. scholaris 
Figure S2 Peak list views of compared gall-induced with healthy leaves in TIC of $A$. scholaris (green means yes and red means no, $\mathrm{m} / \mathbf{z}$ 250.0000-500.0000)

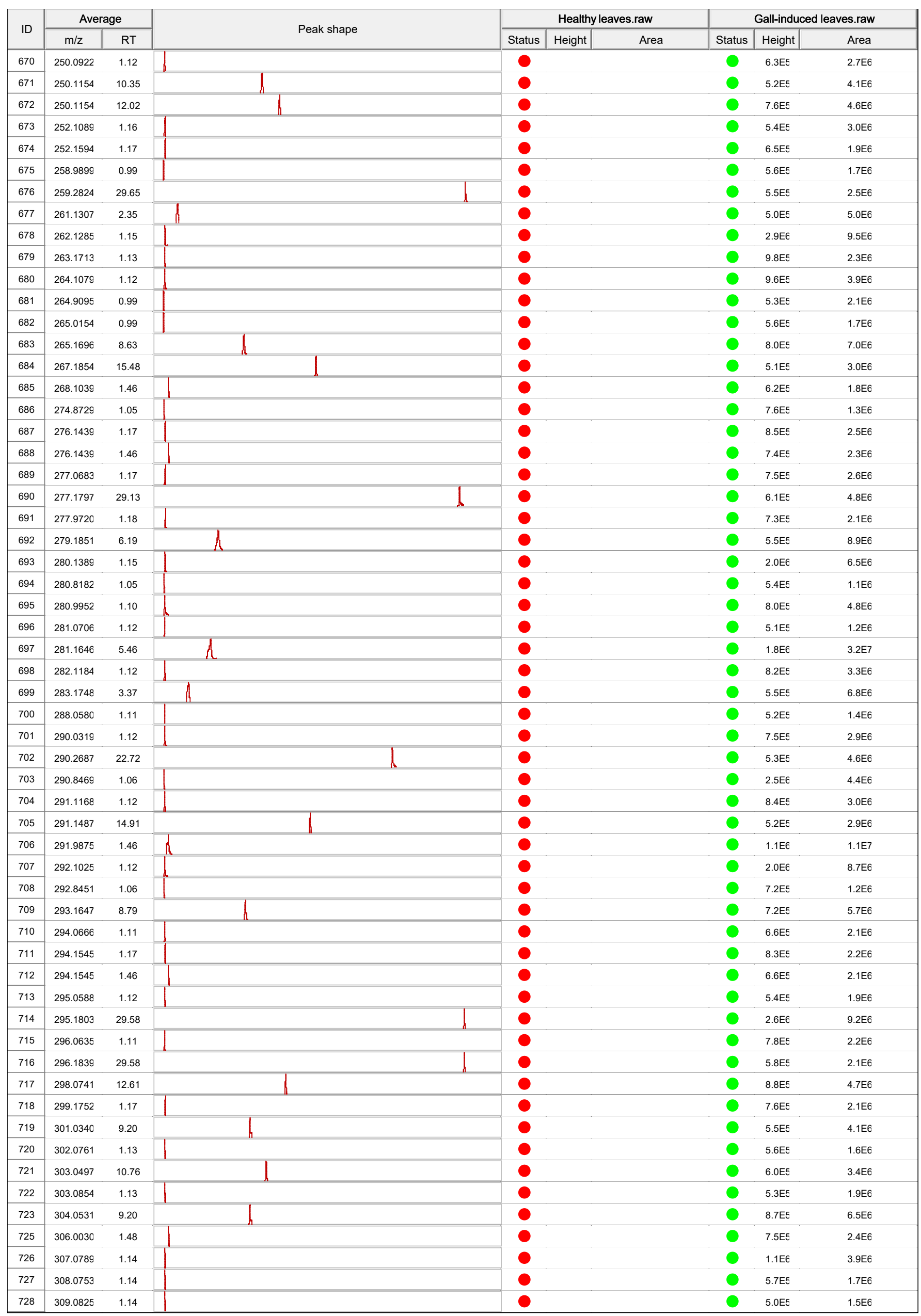


(continued)

\begin{tabular}{|c|c|c|c|c|c|c|c|c|c|}
\hline \multirow{2}{*}{ ID } & \multicolumn{2}{|c|}{ Average } & \multirow{2}{*}{ Peak shape } & \multicolumn{3}{|c|}{ Healthy leaves.raw } & \multicolumn{3}{|c|}{ Gall-induced leaves.raw } \\
\hline & $\mathrm{m} / \mathrm{z}$ & RT & & Status & Height & Area & Status & Height & Area \\
\hline 729 & 309.1290 & 1.12 & & 0 & & & 0 & 3.4E6 & 1.4E7 \\
\hline 730 & 309.1595 & 9.70 & & 0 & & & 0 & $6.1 \mathrm{E5}$ & 4.5E€ \\
\hline 731 & 309.1595 & 10.35 & & 0 & & & 0 & $6.1 \mathrm{E} 5$ & 4.7EG \\
\hline 732 & 310.1130 & 1.12 & & 0 & & & 0 & $2.3 \mathrm{E} 6$ & $1.0 \mathrm{E} 7$ \\
\hline 733 & 318.2999 & 29.69 & & 0 & & & O & $6.9 \mathrm{E} 5$ & 5.4E€ \\
\hline 734 & 320.8661 & 1.05 & & 0 & & & 0 & $5.4 \mathrm{E} 5$ & $9.7 \mathrm{EE}$ \\
\hline 735 & 322.0346 & 1.14 & & 0 & & & 0 & $6.5 \mathrm{E} 5$ & $1.8 \mathrm{EE}$ \\
\hline 736 & 323.1754 & 13.64 & & 0 & & & 0 & $1.3 \mathrm{E} 6$ & $8.8 \mathrm{E} 6$ \\
\hline 737 & 324.0138 & 1.11 & & 0 & & & 0 & $1.2 \mathrm{E} 6$ & $6.2 \mathrm{E} 6$ \\
\hline 738 & 324.1786 & 13.41 & & O & & & 0 & $1.1 \mathrm{E} 6$ & 7.4EG \\
\hline 739 & 325.1908 & 14.91 & & 0 & & & 0 & $6.8 \mathrm{E} 5$ & 4.1E€ \\
\hline 740 & 327.1701 & 19.27 & & 0 & & & 0 & $6.0 \mathrm{E} 5$ & 3.4EG \\
\hline 741 & 327.2011 & 4.97 & II & 0 & & & 0 & $5.9 \mathrm{ES}$ & $8.9 \mathrm{EE}$ \\
\hline 742 & 328.1740 & 15.38 & & 0 & & & 0 & $6.2 \mathrm{E} 5$ & $3.3 \mathrm{E} 6$ \\
\hline 743 & 333.9980 & 1.17 & & 0 & & & 0 & $6.2 \mathrm{E} 5$ & 2.7EG \\
\hline 744 & 334.0217 & 1.15 & & O & & & 0 & $5.3 \mathrm{E} 5$ & 4.2E€ \\
\hline 745 & 335.1751 & 14.72 & & 0 & & & 0 & $1.5 \mathrm{E} 6$ & $9.4 \mathrm{E} 6$ \\
\hline 746 & 337.1715 & 1.03 & & O & & & 0 & $9.5 \mathrm{E} 5$ & $6.6 \mathrm{E} 6$ \\
\hline 747 & 339.1700 & 9.34 & & 0 & & & 0 & $1.9 \mathrm{E} 6$ & 1.6E7 \\
\hline 748 & 339.1700 & 10.92 & & O & & & O & $9.1 \mathrm{E} 6$ & $6.8 \mathrm{E} 7$ \\
\hline 749 & 339.1700 & 16.30 & & 0 & & & 0 & $2.2 \mathrm{E} 6$ & $1.8 \mathrm{E} 7$ \\
\hline 750 & 340.1735 & 10.89 & & 0 & & & 0 & $2.0 \mathrm{E} 6$ & $1.5 \mathrm{E} 7$ \\
\hline 751 & 340.1735 & 11.22 & & 0 & & & 0 & 2.4E 6 & $1.8 \mathrm{E} 7$ \\
\hline 752 & 340.1735 & 15.04 & & 0 & & & 0 & 1.1EG & 7.2E6 \\
\hline 753 & 342.1891 & 10.73 & & 0 & & & 0 & $2.8 \mathrm{E} 6$ & $2.6 \mathrm{E} 7$ \\
\hline 754 & 344.1340 & 1.17 & & 0 & & & 0 & 7.5E5 & 2.1E€ \\
\hline 755 & 349.1544 & 17.03 & & 0 & & & 0 & $1.9 \mathrm{E} 6$ & $1.2 \mathrm{E} 7$ \\
\hline 756 & 350.9998 & 1.47 & & 0 & & & 0 & $9.5 \mathrm{E} 5$ & 2.6E€ \\
\hline 757 & 351.0688 & 1.12 & 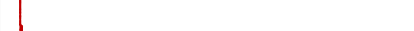 & 0 & & & 0 & 1.1EG & 4.3EG \\
\hline 758 & 351.1701 & 13.05 & & 0 & & & 0 & $8.0 \mathrm{E} 5$ & 5.6E€ \\
\hline 759 & 352.0450 & 1.16 & & O & & & 0 & $5.3 \mathrm{E5}$ & $1.8 \mathrm{E} 6$ \\
\hline 760 & 352.8159 & 1.05 & & 0 & & & 0 & $6.1 \mathrm{E} 5$ & $1.2 \mathrm{E} 6$ \\
\hline 761 & 353.1859 & 12.88 & & 0 & & & 0 & 1.1E6 & $8.5 \mathrm{E} 6$ \\
\hline 762 & 353.1859 & 15.36 & & 0 & & & 0 & $1.8 \mathrm{E} 6$ & $1.2 \mathrm{E} 7$ \\
\hline 765 & 355.1649 & 12.47 & & 0 & & & 0 & 3.7E6 & $2.2 \mathrm{E} 7$ \\
\hline 766 & 355.1649 & 12.72 & & O & & & 0 & $6.8 \mathrm{E} 5$ & 4.4E€ \\
\hline 763 & 355.1650 & 7.08 & & 0 & & & 0 & $2.8 \mathrm{E} 6$ & $3.6 \mathrm{E} 7$ \\
\hline 764 & 355.1650 & 8.14 & & 0 & & & 0 & $3.0 \mathrm{E} 6$ & $2.5 \mathrm{E} 7$ \\
\hline 767 & 356.1056 & 4.03 & & 0 & & & 0 & $1.1 \mathrm{EG}$ & 1.6E7 \\
\hline 768 & 356.1682 & 7.07 & & 0 & & & 0 & $6.6 \mathrm{E5}$ & 8.2E€ \\
\hline 769 & 356.1682 & 8.15 & & 0 & & & 0 & 7.0E5 & 5.4E€ \\
\hline 770 & 356.1682 & 12.47 & & 0 & & & 0 & $8.2 \mathrm{E} 5$ & 4.7EG \\
\hline 771 & 356.2047 & 12.98 & & 0 & & & 0 & 1.7EG & 1.1E7 \\
\hline 772 & 359.1867 & 7.02 & & 0 & & & 0 & 7.4E5 & $7.9 \mathrm{E} 6$ \\
\hline 773 & 363.3295 & 28.47 & & 0 & & & 0 & $5.2 \mathrm{E} 5$ & 3.3E€ \\
\hline 774 & 367.0985 & 1.12 & . & 0 & & & 0 & 8.7E5 & 2.9E€ \\
\hline 775 & 368.2047 & 18.42 & & 0 & & & 0 & $6.1 \mathrm{E} 5$ & 3.4E€ \\
\hline 776 & 369.1807 & 9.52 & & 0 & & & 0 & 7.4E5 & 5.3E€ \\
\hline 777 & 370.1839 & 10.87 & & 0 & & & 0 & 2.0E6 & 1.5E7 \\
\hline 778 & 371.1964 & 9.58 & & 0 & & & 0 & 1.7E6 & 1.1E7 \\
\hline 779 & 371.2273 & 6.80 & & 0 & & & 0 & $7.8 \mathrm{E5}$ & $7.9 \mathrm{E} 6$ \\
\hline 780 & 380.0033 & 1.17 & & 0 & & & 0 & $6.5 \mathrm{E5}$ & $1.8 \mathrm{EG}$ \\
\hline 781 & 381.0117 & 1.17 & & 0 & & & 0 & $1.2 \mathrm{E} 6$ & $3.8 \mathrm{E} 6$ \\
\hline 782 & 382.0184 & 1.16 & & 0 & & & 0 & $5.0 \mathrm{E} 5$ & 1.7EG \\
\hline 783 & 385.2121 & 9.87 & & 0 & & & 0 & $1.2 \mathrm{E} 7$ & $9.7 \mathrm{E} 7$ \\
\hline 784 & 386.2152 & 9.87 & & 0 & & & 0 & $2.9 \mathrm{E} 6$ & $2.3 \mathrm{E} 7$ \\
\hline 785 & 389.1439 & 8.41 & & 0 & & & 0 & $8.1 \mathrm{ES}$ & 5.4E€ \\
\hline 786 & 389.1439 & 8.75 & & 0 & & & 0 & $6.1 \mathrm{E} 5$ & 4.7E€ \\
\hline
\end{tabular}


(continued)

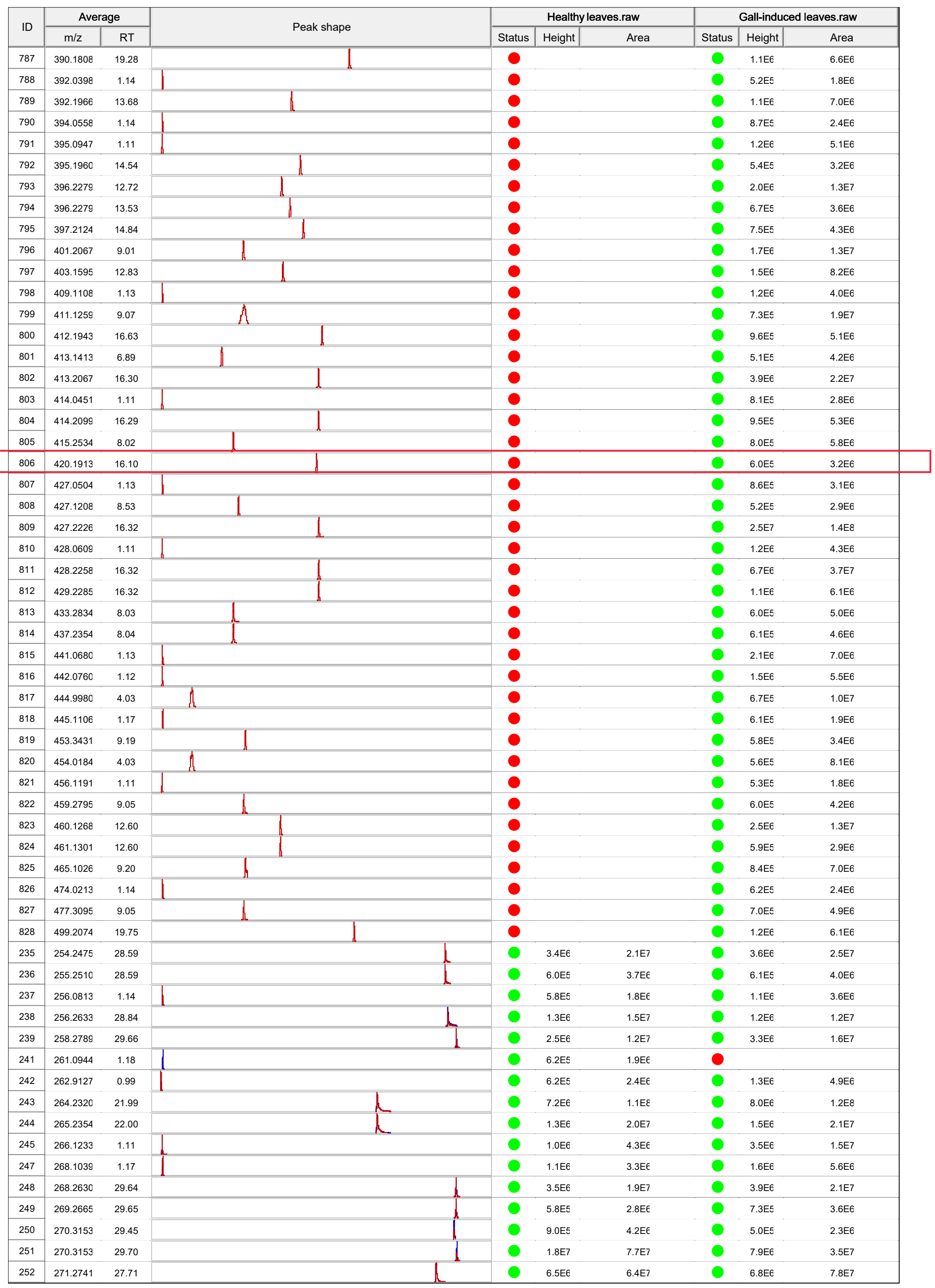


(continued)

\begin{tabular}{|c|c|c|c|c|c|c|c|c|c|}
\hline \multirow{2}{*}{ ID } & \multicolumn{2}{|c|}{ Average } & \multirow{2}{*}{ Peak shape } & \multicolumn{3}{|c|}{ Healthy leaves.raw } & \multicolumn{3}{|c|}{ Gall-induced leaves.raw } \\
\hline & $\mathrm{m} / \mathrm{z}$ & RT & & Status & Height & Area & Status & Height & Area \\
\hline 253 & 271.3186 & 29.70 & & 0 & 3.7E6 & $1.5 \mathrm{E} 7$ & 0 & 1.6EG & $6.9 \mathrm{E} 6$ \\
\hline 254 & 272.2582 & 28.59 & & 0 & 2.3E7 & $1.8 \mathrm{E} \varepsilon$ & 0 & 2.3E7 & $1.8 \mathrm{E} \varepsilon$ \\
\hline 255 & 272.2776 & 27.71 & & 0 & $1.2 \mathrm{E} 6$ & 1.1E7 & 0 & $1.2 \mathrm{E} 6$ & $1.2 \mathrm{E} 7$ \\
\hline 256 & 273.2615 & 28.59 & & 0 & $3.8 \mathrm{E} 6$ & $2.9 \mathrm{E} 7$ & 0 & 4.1E6 & $2.8 \mathrm{E} 7$ \\
\hline 257 & 274.2739 & 28.03 & & O & $9.8 \mathrm{E} 6$ & $6.6 \mathrm{E} 7$ & 0 & 1.1E7 & 7.4E7 \\
\hline 258 & 274.2739 & 28.40 & & ? & $1.8 \mathrm{E} 6$ & $1.5 \mathrm{E} 7$ & 0 & $2.2 \mathrm{E} 6$ & 1.7E7 \\
\hline 259 & 275.0084 & 1.09 & & 0 & $7.5 \mathrm{E} 5$ & $3.1 \mathrm{E} \epsilon$ & 0 & 1.1E6 & 4.3E€ \\
\hline 260 & 275.2773 & 28.03 & & 0 & $1.7 \mathrm{E} 6$ & 1.1E7 & 0 & $1.9 \mathrm{E} 6$ & $1.2 \mathrm{E} 7$ \\
\hline 262 & 275.9926 & 1.11 & & 0 & 2.4E6 & $1.2 \mathrm{E} 7$ & 0 & 2.0E6 & 8.6E€ \\
\hline 264 & 276.8964 & 1.44 & & 0 & $5.7 \mathrm{E} 5$ & 4.7E€ & 0 & & \\
\hline 265 & 277.0000 & 1.12 & & 0 & $6.3 \mathrm{E} 5$ & $3.0 \mathrm{EE}$ & 0 & 6.7E5 & 2.9EG \\
\hline 266 & 277.0893 & 1.13 & & 0 & $9.4 \mathrm{E} 5$ & 3.7E€ & 0 & $1.1 \mathrm{EG}$ & 4.1E€ \\
\hline 267 & 279.0931 & 26.42 & & 0 & $2.0 \mathrm{E} 7$ & 3.0Eع & 0 & 2.0E7 & 3.1Eع \\
\hline 269 & 279.2316 & 29.81 & & 0 & 7.7E5 & $5.3 \mathrm{E} €$ & 0 & & \\
\hline 268 & 279.2316 & 29.57 & & O & 2.5E6 & 1.4E7 & 0 & $1.3 \mathrm{E} 6$ & 7.6E€ \\
\hline 270 & 280.0964 & 26.42 & & 0 & $3.9 \mathrm{E} 6$ & $5.8 \mathrm{E} 7$ & 0 & 3.7E6 & 5.4E7 \\
\hline 271 & 282.1484 & 10.36 & & 0 & 2.7E6 & $2.1 \mathrm{E} 7$ & 0 & 4.1E6 & $3.1 \mathrm{E} 7$ \\
\hline 272 & 282.2788 & 29.81 & & 0 & $7.2 \mathrm{ES}$ & $5.8 \mathrm{E} €$ & 0 & $8.0 \mathrm{E} 5$ & $6.2 \mathrm{E} 6$ \\
\hline 274 & 282.9663 & 1.15 & & 0 & $8.2 \mathrm{E} 5$ & 5.2E€ & 0 & $7.9 \mathrm{E} 5$ & $7.9 \mathrm{E} 6$ \\
\hline 276 & 283.1436 & 12.36 & & 0 & $6.6 \mathrm{E} 5$ & $4.0 \mathrm{E} €$ & 0 & & \\
\hline 275 & 283.1477 & 10.36 & & 0 & $6.2 \mathrm{EF}$ & $5.1 \mathrm{E} \epsilon$ & 0 & $7.9 \mathrm{E} 5$ & $6.9 \mathrm{E} 6$ \\
\hline 277 & 283.7172 & 11.58 & & 0 & $1.8 \mathrm{E} 6$ & $9.7 \mathrm{E} \epsilon$ & 0 & 1.4E6 & $8.1 \mathrm{E} 6$ \\
\hline 278 & 284.2189 & 11.58 & & 0 & $6.4 \mathrm{E} 5$ & 3.3E€ & 0 & $5.0 \mathrm{E5}$ & 2.6E€ \\
\hline 279 & 284.2945 & 29.96 & & 0 & $7.0 \mathrm{E} 5$ & $2.5 \mathrm{E} €$ & 0 & 7.0E5 & $2.8 \mathrm{E} \epsilon$ \\
\hline 281 & 284.9819 & 1.11 & & 0 & $5.9 \mathrm{E} 5$ & $3.2 \mathrm{E} €$ & 0 & $1.4 \mathrm{E} 6$ & $8.2 \mathrm{E} 6$ \\
\hline 282 & 285.2899 & 27.97 & & 0 & $6.4 \mathrm{E} 6$ & 7.0E7 & 0 & $6.5 \mathrm{E} 6$ & 7.1E7 \\
\hline 283 & 286.2932 & 27.97 & & 0 & $1.2 \mathrm{E} 6$ & 1.4E7 & 0 & $1.2 \mathrm{E} 6$ & 1.4E7 \\
\hline 284 & 286.3102 & 29.56 & & 0 & $5.8 \mathrm{E} 5$ & 3.3E€ & 0 & $6.9 \mathrm{E} 5$ & 3.5E€ \\
\hline 286 & 287.0547 & 10.88 & & 0 & $6.0 \mathrm{E} 6$ & $3.1 \mathrm{E} 7$ & 0 & $4.8 \mathrm{E} 6$ & $2.5 \mathrm{E} 7$ \\
\hline 287 & 287.0547 & 11.04 & & 0 & 1.1E6 & $5.9 \mathrm{E} €$ & 0 & $1.0 \mathrm{E} 6$ & 5.7EG \\
\hline 288 & 288.0164 & 1.14 & & 0 & $7.0 \mathrm{ES}$ & $4.0 \mathrm{E} €$ & 0 & $1.1 \mathrm{E} 6$ & $8.0 \mathrm{E} 6$ \\
\hline 289 & 288.0580 & 10.88 & | & 0 & $1.0 \mathrm{E} 6$ & 5.0E€ & 0 & $7.9 \mathrm{E} 5$ & 4.1EG \\
\hline 291 & 288.2530 & 28.88 & & 0 & $1.0 \mathrm{E} 6$ & 1.1E7 & 0 & & \\
\hline 290 & 288.2530 & 28.73 & & O & $1.5 \mathrm{E} 6$ & 1.4E7 & 0 & $1.5 \mathrm{E} 6$ & $2.5 \mathrm{E} 7$ \\
\hline 292 & 288.2894 & 28.80 & & O & 1.1E6 & $6.8 \mathrm{E} €$ & 0 & 1.1E6 & 5.0E€ \\
\hline 293 & 288.2894 & 29.08 & & 0 & $1.2 \mathrm{E} 6$ & 7.3E€ & 0 & $9.3 \mathrm{E} 5$ & $5.6 \mathrm{E} €$ \\
\hline 294 & 289.0241 & 1.11 & & 0 & $5.8 \mathrm{E} 5$ & $2.2 \mathrm{E} €$ & 0 & $9.9 \mathrm{E} 5$ & 4.3E€ \\
\hline 296 & 290.2686 & 28.42 & & 0 & $1.2 \mathrm{E} 6$ & $6.7 \mathrm{E} €$ & 0 & $1.9 \mathrm{E} 6$ & 1.1E7 \\
\hline 297 & 291.9874 & 1.15 & & 0 & $3.1 \mathrm{E} 6$ & $2.1 \mathrm{E} 7$ & 0 & $3.0 \mathrm{E} 6$ & $1.8 \mathrm{E} 7$ \\
\hline 298 & 292.9952 & 1.14 & & 0 & $2.5 \mathrm{E} 6$ & 1.6E7 & 0 & 3.6E6 & $2.9 \mathrm{E} 7$ \\
\hline 299 & 293.0630 & 1.12 & & 0 & 2.4E6 & 8.4E€ & 0 & $6.8 \mathrm{E} 6$ & 2.2E7 \\
\hline 300 & 293.1086 & 27.06 & & O & $7.6 \mathrm{E} 5$ & 9.7E€ & 0 & 8.3E5 & 1.1E7 \\
\hline 302 & 294.0030 & 1.11 & & 0 & $2.6 \mathrm{E} 6$ & $1.3 \mathrm{E} 7$ & 0 & $6.5 \mathrm{E} 6$ & $3.1 \mathrm{E} 7$ \\
\hline 304 & 295.0106 & 1.11 & & 0 & $7.3 \mathrm{ES}$ & $3.5 \mathrm{E} €$ & 0 & $1.9 \mathrm{E} 6$ & $9.8 \mathrm{E} 6$ \\
\hline 307 & 298.9977 & 1.16 & & 0 & $9.3 \mathrm{ES}$ & 4.7E€ & 0 & $8.0 \mathrm{E} 5$ & 4.7E€ \\
\hline 308 & 299.3055 & 29.56 & & 0 & $8.2 \mathrm{E} 6$ & $4.2 \mathrm{E} 7$ & 0 & $8.5 \mathrm{E} 6$ & $4.5 \mathrm{E} 7$ \\
\hline 310 & 300.2894 & 29.81 & & 0 & $6.5 \mathrm{E} 6$ & $3.3 \mathrm{E} 7$ & 0 & $8.0 \mathrm{E} 6$ & $4.0 \mathrm{E} 7$ \\
\hline 311 & 300.3089 & 29.55 & & 0 & 1.6EG & 7.9E€ & 0 & 1.6E6 & 8.0E€ \\
\hline 312 & 301.2846 & 28.22 & & 0 & $1.2 \mathrm{E} 8$ & $9.8 \mathrm{E} \varepsilon$ & 0 & $1.3 \mathrm{E} 8$ & $1.0 \mathrm{EC}$ \\
\hline 313 & 302.2689 & 28.79 & & 0 & $9.0 \mathrm{ES}$ & $4.0 \mathrm{E} €$ & 0 & $9.2 \mathrm{E} 5$ & 4.5E€ \\
\hline 314 & 302.2881 & 28.22 & & 0 & $2.4 \mathrm{E} 7$ & $1.9 \mathrm{E} \varepsilon$ & 0 & $2.3 \mathrm{E} 7$ & $2.1 \mathrm{E} \varepsilon$ \\
\hline 315 & 302.3049 & 29.62 & & 0 & $3.1 \mathrm{E} 6$ & 1.3E7 & 0 & $3.6 \mathrm{E} 6$ & 1.6E7 \\
\hline 316 & 302.5642 & 15.90 & & O & $1.5 \mathrm{E} 6$ & 6.4E€ & 0 & $7.0 \mathrm{E} 5$ & $3.4 \mathrm{E} 6$ \\
\hline 317 & 302.8989 & 15.90 & & 0 & $7.8 \mathrm{E} 5$ & $3.5 \mathrm{E} \epsilon$ & 0 & & \\
\hline 318 & 303.0497 & 9.20 & & 0 & 2.3E6 & $1.9 \mathrm{E} 7$ & 0 & $5.3 \mathrm{E} 6$ & 4.1E7 \\
\hline 319 & 303.2909 & 28.22 & & 0 & 2.4E6 & $1.9 \mathrm{E} 7$ & 0 & $2.5 \mathrm{E} 6$ & $1.8 \mathrm{E} 7$ \\
\hline 320 & 303.3081 & 29.61 & & 0 & $5.7 \mathrm{ES}$ & $2.5 \mathrm{E} €$ & 0 & 7.4E5 & $3.1 \mathrm{EE}$ \\
\hline 323 & 306.0030 & 1.14 & & 0 & $1.8 \mathrm{E} 6$ & $7.2 \mathrm{E} €$ & 0 & $3.7 \mathrm{E} 6$ & 1.7E7 \\
\hline
\end{tabular}


(continued)

\begin{tabular}{|c|c|c|c|c|c|c|c|c|c|}
\hline \multirow{2}{*}{ ID } & \multicolumn{2}{|c|}{ Average } & \multirow{2}{*}{ Peak shape } & \multicolumn{3}{|c|}{ Healthy leaves.raw } & \multicolumn{3}{|c|}{ Gall-induced leaves.raw } \\
\hline & $\mathrm{m} / \mathrm{z}$ & RT & & Status & Height & Area & Status & Height & Area \\
\hline 324 & 307.0100 & 1.13 & & 0 & $5.6 \mathrm{E} 5$ & $1.9 \mathrm{EE}$ & 0 & $1.2 \mathrm{E} 6$ & 4.4EG \\
\hline 325 & 307.1002 & 1.12 & & 0 & $5.8 \mathrm{E} 5$ & $2.4 \mathrm{E} €$ & O & $5.0 \mathrm{E} 5$ & $2.0 \mathrm{E} \epsilon$ \\
\hline 326 & 308.0187 & 1.13 & & 0 & 1.7EG & 8.3E€ & 0 & $3.6 \mathrm{E} 6$ & 1.6E7 \\
\hline 328 & 309.0264 & 1.13 & & 0 & $8.0 \mathrm{E5}$ & 4.0E€ & 0 & $1.3 \mathrm{E} 6$ & 7.1E€ \\
\hline 329 & 309.1594 & 12.37 & & ○ & $5.0 \mathrm{E} 5$ & $3.0 \mathrm{E} €$ & 0 & & \\
\hline 330 & 311.1750 & 10.36 & & ? & $2.3 \mathrm{E} 7$ & $1.8 \mathrm{E} \varepsilon$ & 0 & $3.5 \mathrm{E} 7$ & 2.7EE \\
\hline 331 & 312.1783 & 10.36 & & 0 & $4.9 \mathrm{E} 6$ & 3.7E7 & 0 & $6.9 \mathrm{E} 6$ & $5.3 \mathrm{E} 7$ \\
\hline 332 & 313.1544 & 12.37 & & 0 & $1.0 \mathrm{E} 6$ & $6.0 \mathrm{E} 6$ & 0 & & \\
\hline 333 & 313.1813 & 10.35 & & O & $5.4 \mathrm{E} 5$ & $3.9 \mathrm{EE}$ & 0 & $8.4 \mathrm{E} 5$ & $6.3 \mathrm{EE}$ \\
\hline 334 & 313.2158 & 29.11 & & O & $1.2 \mathrm{E} 6$ & $5.3 \mathrm{E} €$ & 0 & & \\
\hline 335 & 313.3210 & 29.63 & & 0 & $6.4 \mathrm{E} 6$ & $3.5 \mathrm{E} 7$ & 0 & $6.3 \mathrm{E} 6$ & $3.3 \mathrm{E7}$ \\
\hline 336 & 314.0916 & 1.16 & & 0 & $9.6 \mathrm{E} 5$ & 2.7E€ & 0 & & \\
\hline 337 & 314.3244 & 29.63 & & 0 & $1.3 \mathrm{E} 6$ & $6.9 \mathrm{E} €$ & 0 & $1.2 \mathrm{E} 6$ & $6.5 \mathrm{E} 6$ \\
\hline 338 & 316.3209 & 29.88 & & 0 & $7.4 \mathrm{E} 5$ & $3.0 \mathrm{E} €$ & 0 & $6.1 \mathrm{E} 5$ & 2.4EG \\
\hline 339 & 318.2789 & 28.15 & & O & $1.5 \mathrm{E} 6$ & 8.6E€ & 0 & 1.7E6 & $9.0 \mathrm{E} 6$ \\
\hline 340 & 318.2999 & 28.29 & & O & $6.6 \mathrm{E} 6$ & $4.5 \mathrm{E} 7$ & 0 & 7.7E6 & $5.0 \mathrm{E} 7$ \\
\hline 342 & 319.0998 & 1.16 & & 0 & $5.6 \mathrm{E} 5$ & 1.7E€ & 0 & & \\
\hline 343 & 319.3032 & 28.29 & & 0 & 1.4E6 & 8.4E€ & 0 & $1.6 \mathrm{E} 6$ & $8.0 \mathrm{E} 6$ \\
\hline 344 & 321.1155 & 1.14 & & 0 & $9.4 \mathrm{E} 5$ & $3.1 \mathrm{E} \epsilon$ & 0 & $7.8 \mathrm{E} 5$ & $2.8 \mathrm{E} 6$ \\
\hline 345 & 321.1594 & 12.35 & & 0 & $6.8 \mathrm{E} 5$ & $4.2 \mathrm{E} €$ & 0 & $6.0 \mathrm{E5}$ & 4.5E€ \\
\hline 346 & 321.1594 & 15.84 & & 0 & $1.4 \mathrm{E} 6$ & $1.2 \mathrm{E} 7$ & 0 & $1.4 \mathrm{E} 6$ & $1.2 \mathrm{E} 7$ \\
\hline 347 & 323.0737 & 1.11 & & 0 & $9.2 \mathrm{E} 5$ & $3.6 \mathrm{E} €$ & 0 & 2.2E6 & 7.8E€ \\
\hline 348 & 323.1463 & 29.65 & & 0 & $5.2 \mathrm{ES}$ & $9.2 \mathrm{E} \epsilon$ & 0 & $6.3 \mathrm{E5}$ & $7.8 \mathrm{E} 6$ \\
\hline 349 & 323.1752 & 10.36 & & 0 & 3.1E6 & $2.4 \mathrm{E} 7$ & 0 & $4.8 \mathrm{E} 6$ & 3.6E7 \\
\hline 350 & 323.1752 & 13.42 & & 0 & $8.8 \mathrm{E5}$ & $6.4 \mathrm{E} €$ & 0 & $5.0 \mathrm{E} 6$ & $3.6 \mathrm{E} 7$ \\
\hline 351 & 323.1752 & 14.92 & & 0 & $3.6 \mathrm{E} 6$ & $2.3 \mathrm{E} 7$ & 0 & 2.5E7 & 1.6Eع \\
\hline 352 & 323.1752 & 15.43 & & 0 & $5.3 \mathrm{E} 5$ & $2.8 \mathrm{E} €$ & 0 & $1.8 \mathrm{E} 6$ & $1.0 \mathrm{E} 7$ \\
\hline 353 & 323.1752 & 15.63 & & O & $3.3 \mathrm{E} 6$ & $2.0 \mathrm{E} 7$ & 0 & $6.6 \mathrm{E} 6$ & 4.0E7 \\
\hline 354 & 323.1752 & 16.03 & & 0 & 2.7EG & $2.0 \mathrm{E} 7$ & 0 & $4.2 \mathrm{E} 6$ & 3.7E7 \\
\hline 355 & 324.1785 & 10.35 & & 0 & 7.1E5 & 5.1E€ & 0 & $9.6 \mathrm{E} 5$ & 7.4E€ \\
\hline 356 & 324.1785 & 14.92 & & 0 & $7.9 \mathrm{ES}$ & 4.7E€ & 0 & $5.4 \mathrm{E} 6$ & $3.4 \mathrm{E} 7$ \\
\hline 357 & 324.1785 & 15.63 & & 0 & 7.4E5 & $4.3 \mathrm{E} \epsilon$ & 0 & $1.4 \mathrm{E} 6$ & $8.3 \mathrm{E} 6$ \\
\hline 358 & 324.1785 & 16.02 & 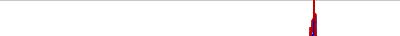 & 0 & $5.7 \mathrm{E} 5$ & $4.0 \mathrm{E} €$ & 0 & $9.0 \mathrm{E} 5$ & 7.7E€ \\
\hline 359 & 325.1127 & 1.12 & & 0 & 1.0E6 & 4.7E€ & 0 & $9.0 \mathrm{E} 5$ & 4.2E€ \\
\hline 360 & 325.1907 & 15.89 & & O & $7.9 \mathrm{E} 6$ & $4.6 \mathrm{E} 7$ & 0 & $1.2 \mathrm{E} 7$ & 7.5E7 \\
\hline 361 & 326.1941 & 15.89 & & 0 & $1.8 \mathrm{E} 6$ & $9.9 \mathrm{E} \epsilon$ & 0 & $2.8 \mathrm{E} 6$ & 1.6E7 \\
\hline 362 & 327.0079 & 29.50 & & 0 & $5.7 \mathrm{E} 5$ & $7.2 \mathrm{E} €$ & 0 & 5.7E5 & 7.3E€ \\
\hline 363 & 327.1700 & 12.37 & & 0 & $7.9 \mathrm{E} 5$ & $4.9 \mathrm{E} €$ & 0 & & \\
\hline 364 & 327.1700 & 15.38 & & 0 & $8.0 \mathrm{ES}$ & 4.4E€ & 0 & 3.1E6 & $1.8 \mathrm{E} 7$ \\
\hline 365 & 329.0049 & 29.51 & & 0 & $5.1 \mathrm{E} 5$ & 7.3E€ & 0 & $5.2 \mathrm{E} 5$ & $6.9 \mathrm{E} 6$ \\
\hline 366 & 329.1857 & 9.29 & & - & 3.6E6 & $2.6 \mathrm{E} 7$ & 0 & $5.8 \mathrm{E} 6$ & 4.6E7 \\
\hline 367 & 329.3159 & 29.65 & & O & $3.6 \mathrm{E} 7$ & 1.7E\& & 0 & $4.0 \mathrm{E} 7$ & $1.9 \mathrm{E} \varepsilon$ \\
\hline 368 & 330.0596 & 1.15 & & 0 & 7.1E5 & 2.1E€ & 0 & 8.1E5 & 2.9E€ \\
\hline 369 & 330.1890 & 9.29 & & 0 & $7.3 \mathrm{ES}$ & 5.4E€ & 0 & $1.3 \mathrm{E} 6$ & $9.8 \mathrm{E} 6$ \\
\hline 370 & 330.2634 & 29.40 & & 0 & $5.2 \mathrm{ES}$ & 2.5E€ & 0 & & \\
\hline 371 & 330.3192 & 29.65 & & O & 7.3E6 & $3.5 \mathrm{E} 7$ & 0 & 8.5E6 & $4.2 \mathrm{E} 7$ \\
\hline 372 & 331.3224 & 29.64 & & 0 & $9.2 \mathrm{EF}$ & $4.0 \mathrm{E} €$ & 0 & $9.9 \mathrm{E} 5$ & 4.5E€ \\
\hline 373 & 332.1337 & 1.13 & & 0 & $6.6 \mathrm{E} 5$ & $2.0 \mathrm{E} \epsilon$ & 0 & $9.6 \mathrm{E} 5$ & 2.7E€ \\
\hline 374 & 334.1129 & 2.05 & & 0 & $6.6 \mathrm{E} 5$ & $6.7 \mathrm{E} \epsilon$ & 0 & $8.8 \mathrm{E} 5$ & 7.6E€ \\
\hline 375 & 334.2948 & 28.42 & & 0 & 1.1E6 & $6.2 \mathrm{E} €$ & 0 & $1.5 \mathrm{E} 6$ & $6.8 \mathrm{E} 6$ \\
\hline 376 & 335.0740 & 1.16 & & 0 & $8.0 \mathrm{E5}$ & $2.6 \mathrm{E} €$ & 0 & $1.4 \mathrm{E} 6$ & $5.3 \mathrm{E} 6$ \\
\hline 377 & 336.0136 & 1.17 & & 0 & $5.8 \mathrm{ES}$ & 2.4E€ & 0 & 1.6E6 & 7.1E€ \\
\hline 378 & 337.0895 & 1.14 & & 0 & $1.3 \mathrm{EE}$ & $4.2 \mathrm{E} €$ & 0 & $2.6 \mathrm{E} 6$ & $9.2 \mathrm{E} 6$ \\
\hline 379 & 337.1107 & 1.12 & & 0 & $6.2 \mathrm{E} 5$ & 2.5E€ & 0 & $7.8 \mathrm{E} 5$ & 3.0E€ \\
\hline 380 & 337.1907 & 10.00 & & 0 & $7.8 \mathrm{E} 5$ & $6.0 \mathrm{E} €$ & 0 & 7.4E5 & $5.6 \mathrm{E} 6$ \\
\hline 381 & 337.1907 & 12.39 & & 0 & $8.0 \mathrm{E} 6$ & $5.5 \mathrm{E} 7$ & 0 & 8.4E6 & $5.7 \mathrm{E} 7$ \\
\hline 382 & 337.1907 & 14.09 & 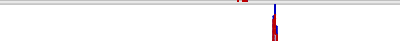 & 0 & $7.0 \mathrm{ES}$ & 4.3E€ & 0 & $5.3 \mathrm{E5}$ & $3.1 \mathrm{EE}$ \\
\hline 383 & 337.1907 & 19.77 & & 0 & $9.0 \mathrm{E} 5$ & $1.5 \mathrm{E} 7$ & 0 & $9.4 \mathrm{E} 5$ & 1.6E7 \\
\hline
\end{tabular}


(continued)

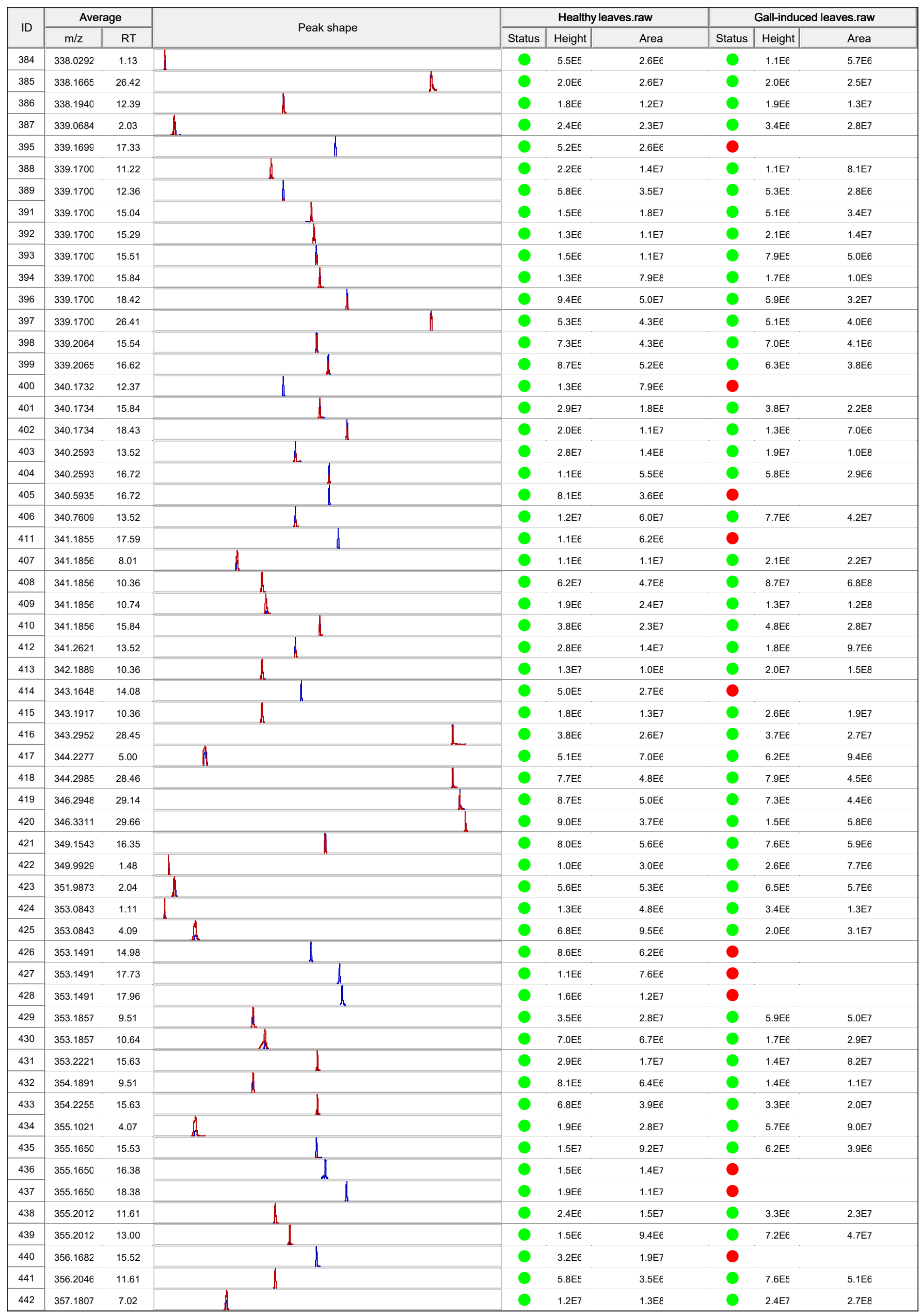


(continued)

\begin{tabular}{|c|c|c|c|c|c|c|c|c|c|}
\hline \multirow{2}{*}{ ID } & \multicolumn{2}{|c|}{ Average } & \multirow{2}{*}{ Peak shape } & \multicolumn{3}{|c|}{ Healthy leaves.raw } & \multicolumn{3}{|c|}{ Gall-induced leaves.raw } \\
\hline & $\mathrm{m} / \mathrm{z}$ & RT & & Status & Height & Area & Status & Height & Area \\
\hline 443 & 357.1807 & 7.38 & & 0 & $4.3 \mathrm{E} 6$ & 4.1E7 & 0 & 8.4E6 & $8.3 \mathrm{E} 7$ \\
\hline 444 & 357.1807 & 7.86 & & 0 & $9.0 \mathrm{E} 5$ & $9.1 \mathrm{E} \epsilon$ & 0 & $1.5 \mathrm{E} 6$ & $1.5 \mathrm{E} 7$ \\
\hline 445 & 357.1807 & 12.36 & & 0 & $2.1 \mathrm{E} 7$ & 1.3Eع & 0 & $1.8 \mathrm{E} 6$ & $1.1 \mathrm{E} 7$ \\
\hline 448 & 358.1839 & 12.37 & & 0 & $4.8 \mathrm{E} 6$ & $2.9 \mathrm{E} 7$ & 0 & & \\
\hline 446 & 358.1839 & 7.02 & $d$ & 0 & $2.8 \mathrm{E} 6$ & $3.0 \mathrm{E} 7$ & 0 & 5.3E6 & $5.8 \mathrm{E} 7$ \\
\hline 447 & 358.1839 & 7.38 & & 0 & $1.0 \mathrm{E} 6$ & $9.5 \mathrm{EE}$ & 0 & $1.8 \mathrm{E} 6$ & 1.8E7 \\
\hline 449 & 359.1866 & 12.37 & & 0 & $6.6 \mathrm{E} 5$ & $3.8 \mathrm{E} 6$ & 0 & & \\
\hline 450 & 360.1497 & 1.12 & & 0 & $1.6 \mathrm{E} 6$ & 7.6EE & 0 & 1.4E6 & 7.1EG \\
\hline 451 & 362.3260 & 28.47 & & 0 & $2.0 \mathrm{E} 6$ & 1.4E7 & ( & 2.3E6 & 1.7E7 \\
\hline 452 & 365.1053 & 1.13 & & 0 & $1.2 \mathrm{E} 7$ & $5.9 \mathrm{E} 7$ & 0 & $9.9 \mathrm{E} 6$ & $5.2 \mathrm{E} 7$ \\
\hline 453 & 366.1087 & 1.13 & & 0 & 1.7E6 & 8.1E€ & 0 & 1.4E 6 & 7.1E€ \\
\hline 455 & 367.1648 & 16.11 & & 0 & 7.4E5 & $5.0 \mathrm{E} €$ & 0 & & \\
\hline 457 & 367.1648 & 17.96 & & 0 & 1.1E6 & 7.1E€ & 0 & & \\
\hline 454 & 367.1649 & 8.82 & & 0 & 1.7E6 & $1.5 \mathrm{E} 7$ & 0 & 1.6E 6 & 1.4E7 \\
\hline 456 & 367.1649 & 16.34 & & 0 & $7.6 \mathrm{E} 7$ & 4.4E\& & 0 & 8.4E7 & $5.0 \mathrm{E} \varepsilon$ \\
\hline 458 & 367.2014 & 15.37 & $d$ & 0 & $5.9 \mathrm{E} 5$ & 3.6E€ & 0 & $1.5 \mathrm{E} 6$ & $1.2 \mathrm{E} 7$ \\
\hline 459 & 367.2014 & 18.43 & & 0 & 7.7E5 & 4.5E€ & 0 & $2.5 \mathrm{E} 6$ & $1.5 \mathrm{E} 7$ \\
\hline 460 & 367.2187 & 13.52 & & 0 & $1.6 \mathrm{E} 6$ & $8.2 \mathrm{E} \epsilon$ & 0 & $1.0 \mathrm{E} 6$ & 5.3E€ \\
\hline 461 & 367.7202 & 13.51 & & 0 & $6.7 \mathrm{E} 5$ & 3.3EE & 0 & & \\
\hline 462 & 368.1683 & 16.34 & & 0 & $1.8 \mathrm{E} 7$ & 1.0Eع & 0 & $1.9 \mathrm{E} 7$ & $1.1 \mathrm{E} \varepsilon$ \\
\hline 464 & 369.1709 & 16.34 & & 0 & $2.4 \mathrm{E} 6$ & 1.4E7 & 0 & $3.0 \mathrm{E} 6$ & 1.7E7 \\
\hline 463 & 369.1757 & 10.88 & & O & $6.6 \mathrm{E} 5$ & $5.5 \mathrm{EE}$ & 0 & $8.9 \mathrm{E} 6$ & $6.9 \mathrm{E} 7$ \\
\hline 465 & 369.9979 & 2.04 & & 0 & $2.6 \mathrm{E} 6$ & $3.2 \mathrm{E} 7$ & 0 & 2.9E 6 & $3.2 \mathrm{E} 7$ \\
\hline 466 & 371.0051 & 2.04 & & 0 & 1.6E6 & $1.8 \mathrm{E} 7$ & 0 & $1.9 \mathrm{E} 6$ & $2.0 \mathrm{E} 7$ \\
\hline 467 & 371.1963 & 6.63 & d & 0 & 6.7E5 & 8.7EE & 0 & & \\
\hline 468 & 371.1963 & 16.05 & & 0 & $2.3 \mathrm{E} 7$ & $1.3 \mathrm{E} \varepsilon$ & 0 & 1.6E7 & $8.9 \mathrm{E} 7$ \\
\hline 469 & 371.1963 & 18.43 & & 0 & $1.0 \mathrm{E} 6$ & $5.4 \mathrm{EE}$ & O & $6.5 \mathrm{E} 5$ & 3.4EG \\
\hline 470 & 372.1996 & 16.05 & & 0 & $5.4 \mathrm{E} 6$ & $3.0 \mathrm{E} 7$ & 0 & $3.9 \mathrm{E} 6$ & $2.0 \mathrm{E} 7$ \\
\hline 471 & 373.1278 & 29.57 & & 0 & $2.3 \mathrm{E} 6$ & $2.0 \mathrm{E} 7$ & 0 & 2.2E6 & $1.8 \mathrm{E} 7$ \\
\hline 472 & 373.1753 & 9.06 & & 0 & $1.2 \mathrm{E} 6$ & $6.9 \mathrm{EE}$ & 0 & & \\
\hline 473 & 373.2023 & 16.05 & & 0 & $7.9 \mathrm{E} 5$ & 4.2E€ & 0 & 5.4E5 & 2.9E€ \\
\hline 474 & 374.2898 & 29.47 & & 0 & 1.2E6 & 4.8E€ & 0 & $6.4 \mathrm{ES}$ & 2.8E€ \\
\hline 475 & 377.0840 & 4.09 & d & 0 & 7.1E5 & $1.0 \mathrm{E} 7$ & 0 & 2.2E 6 & $3.4 \mathrm{E} 7$ \\
\hline 476 & 381.0792 & 1.11 & & 0 & $2.2 \mathrm{E} 7$ & $9.1 \mathrm{E} 7$ & 0 & $4.1 \mathrm{E} 7$ & 1.7Eع \\
\hline 477 & 382.0824 & 1.11 & & 0 & $3.1 \mathrm{E} 6$ & 1.2E7 & 0 & $5.8 \mathrm{E} 6$ & 2.4E7 \\
\hline 478 & 383.0776 & 1.11 & & 0 & $1.8 \mathrm{E} 6$ & 7.2E€ & 0 & 3.5E 6 & 1.4E7 \\
\hline 479 & 383.1598 & 16.11 & & 0 & $2.4 \mathrm{E} 7$ & 1.4Eع & 0 & 1.3E6 & 7.5E€ \\
\hline 480 & 383.1962 & 18.63 & & 0 & $7.3 \mathrm{E} 5$ & 4.0EE & 0 & & \\
\hline 481 & 384.1629 & 16.12 & & 0 & $5.9 \mathrm{E} 6$ & 3.4E7 & 0 & & \\
\hline 482 & 385.1754 & 16.12 & & 0 & $8.8 \mathrm{E} 5$ & $4.9 \mathrm{EE}$ & 0 & & \\
\hline 483 & 385.1754 & 17.96 & & 0 & $1.9 \mathrm{E} 6$ & $1.8 \mathrm{E} 7$ & 0 & & \\
\hline 484 & 385.2119 & 16.58 & & 0 & 4.4E6 & $2.5 \mathrm{E} 7$ & 0 & 3.7E6 & $2.2 \mathrm{E} 7$ \\
\hline 485 & 386.2153 & 16.57 & & 0 & $1.0 \mathrm{E} 6$ & 5.9E€ & 0 & $9.0 \mathrm{E} 5$ & $5.2 \mathrm{E} G$ \\
\hline 486 & 387.1919 & 18.38 & & 0 & $6.5 \mathrm{E} 6$ & $3.7 \mathrm{E} 7$ & 0 & $6.5 \mathrm{E} 5$ & 3.6EE \\
\hline 487 & 388.1944 & 18.38 & & 0 & $1.5 \mathrm{E} 6$ & 8.6E€ & 0 & & \\
\hline 488 & 388.2537 & 6.79 & & 0 & 1.1E6 & 1.2E7 & 0 & $1.9 \mathrm{E} 6$ & $1.9 \mathrm{E} 7$ \\
\hline 489 & 396.0345 & 1.11 & 1 & 0 & $9.6 \mathrm{E} 5$ & 4.5E€ & 0 & 8.3E5 & 4.1EG \\
\hline 490 & 396.8013 & 14.87 & & 0 & $4.6 \mathrm{E} 7$ & 2.3EE & 0 & $2.9 \mathrm{E} 7$ & $1.5 \mathrm{E} \varepsilon$ \\
\hline 491 & 397.0421 & 1.11 & & 0 & 1.3E6 & 7.2E€ & 0 & 1.3E6 & 7.8EG \\
\hline 492 & 397.3027 & 14.87 & & 0 & $2.2 \mathrm{E} 7$ & 1.1Eع & 0 & 1.5E7 & 7.3E7 \\
\hline 493 & 397.8041 & 14.87 & & 0 & $6.0 \mathrm{E} 6$ & $3.0 \mathrm{E} 7$ & 0 & 3.7E6 & 1.8E7 \\
\hline 494 & 398.3055 & 14.87 & & 0 & 1.1E6 & $5.5 \mathrm{E} €$ & 0 & 7.1E5 & 3.4E€ \\
\hline 495 & 399.1911 & 12.95 & & ○ & $8.6 \mathrm{E} 5$ & $6.2 \mathrm{E} €$ & 0 & $2.0 \mathrm{E} 6$ & 1.3E7 \\
\hline 496 & 399.1911 & 15.25 & & 0 & $2.2 \mathrm{E} 6$ & $1.2 \mathrm{E} 7$ & 0 & 9.3E5 & $5.2 \mathrm{E} G$ \\
\hline 497 & 400.1945 & 15.26 & & 0 & $5.3 \mathrm{E} 5$ & $2.9 \mathrm{E} \epsilon$ & 0 & & \\
\hline 498 & 403.1383 & 28.39 & & 0 & 1.5E 6 & 1.6E7 & 0 & 2.1E6 & $1.8 \mathrm{E} 7$ \\
\hline 499 & 406.9822 & 2.03 & & 0 & $5.8 \mathrm{E} 5$ & $6.0 \mathrm{E} €$ & 0 & 7.2E5 & $6.5 \mathrm{E} 6$ \\
\hline 500 & 407.7917 & 14.87 & & 0 & 1.1E6 & $4.9 \mathrm{EE}$ & 0 & $6.5 \mathrm{E} 5$ & 3.2EG \\
\hline
\end{tabular}


(continued)

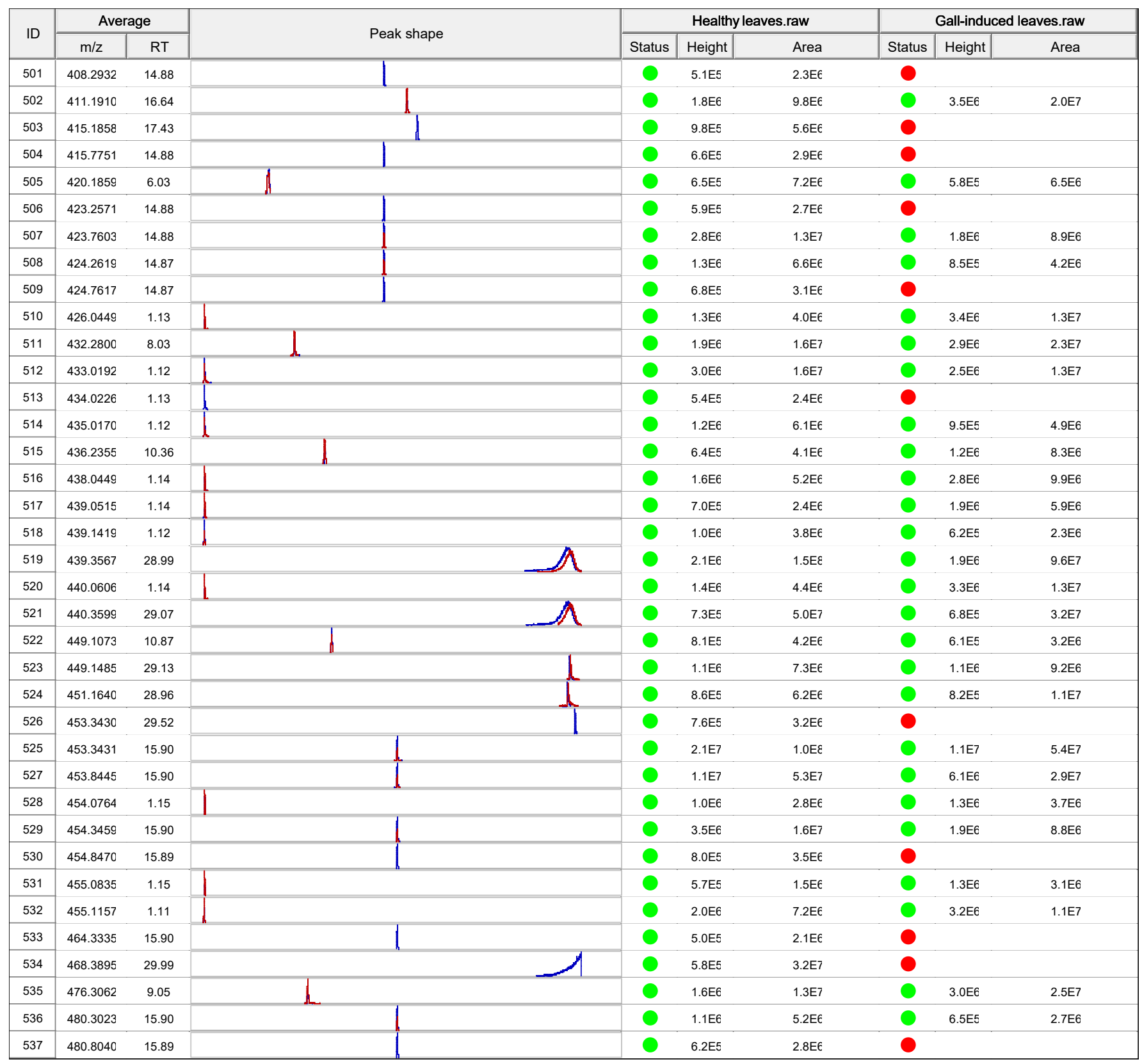


Figure S3. SIM method analysis the components of gall-induced and healthy leaves of $A$. scholaris $(m / z$ 418.6920-421.6920)

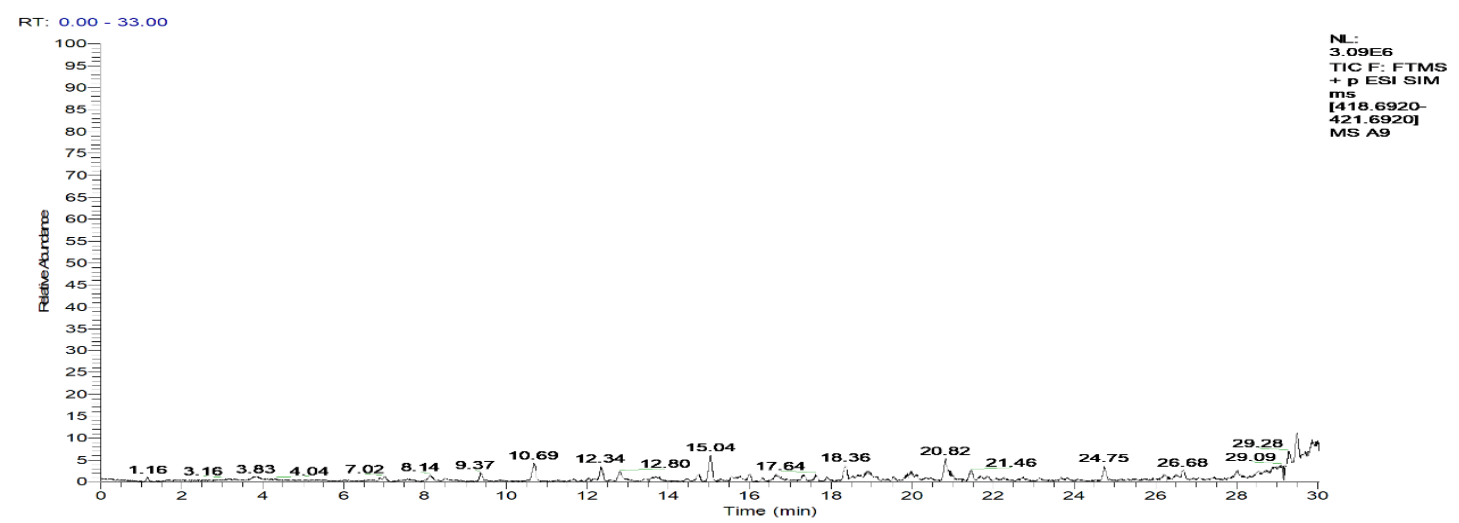

(a) The healthy leaves of $A$. scholaris

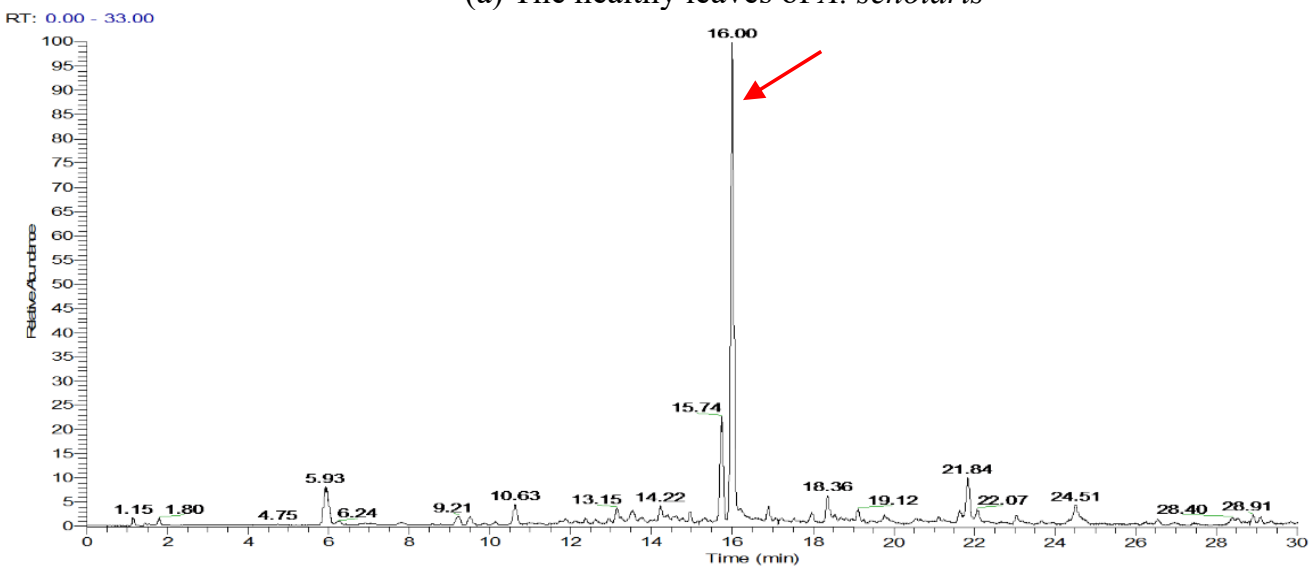

Nit:

TIEFERM

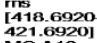

(b) The gall-induced leaves of $A$. scholaris

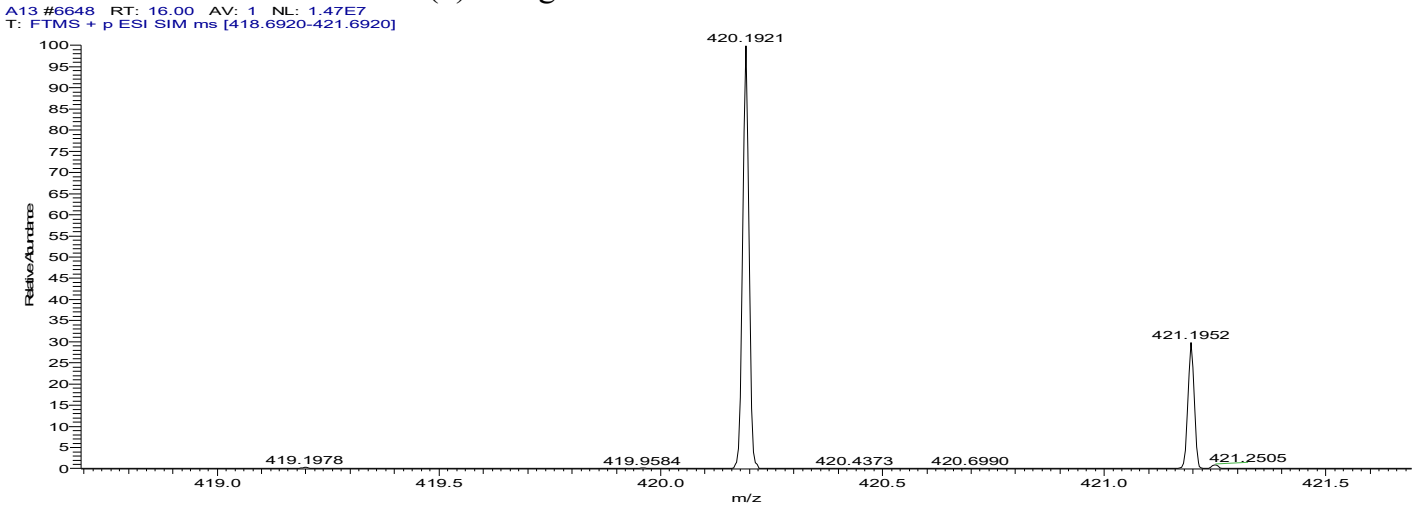

(c) ESI-MS data of compound 1

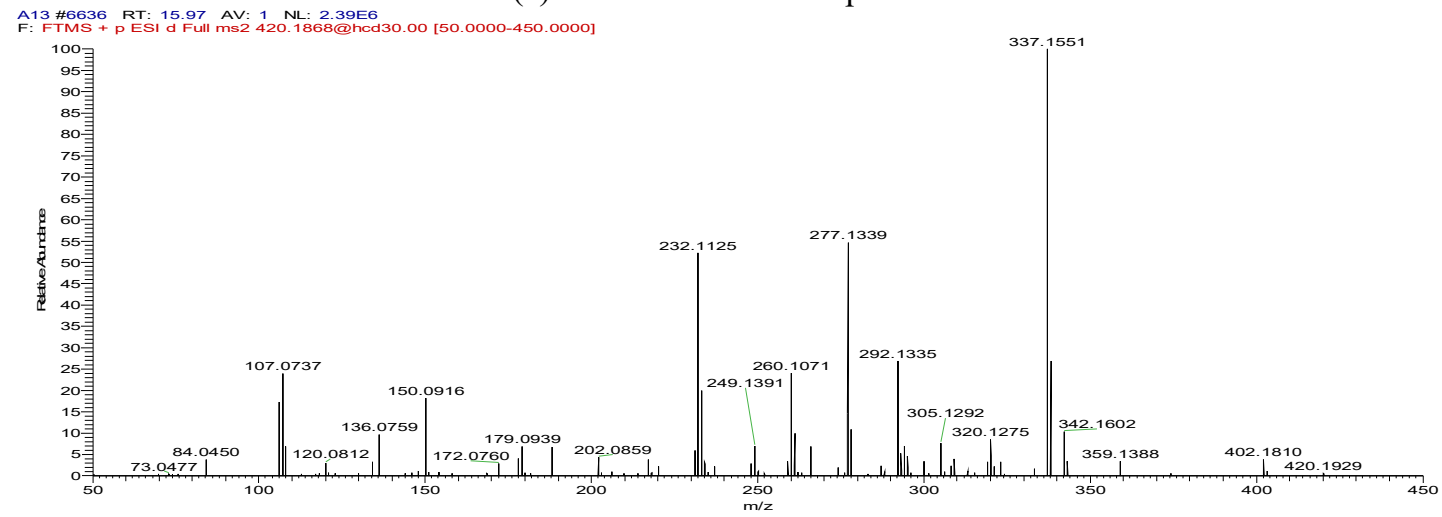

(d) $\mathrm{MS}^{2}$ fragmentation of compound $\mathbf{1}$ 
Figure S4. LC-MS, MS/MS spectrum of standard alstoscholarisine K (1)

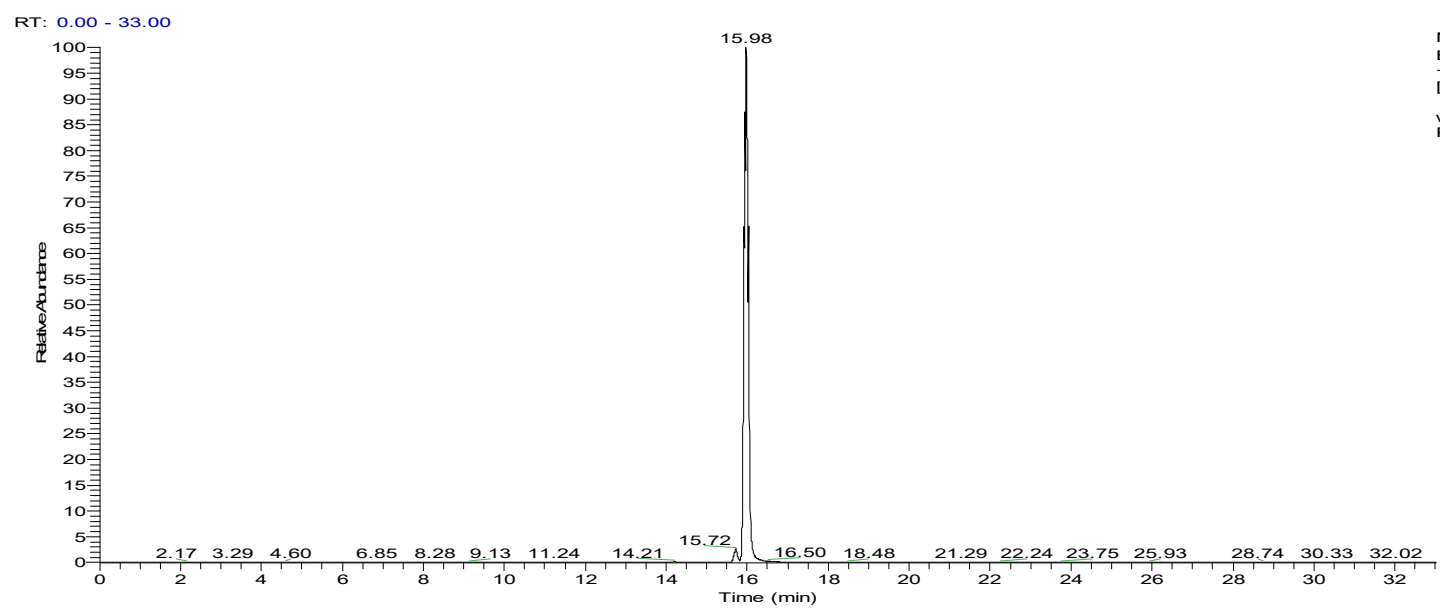

NL: $1.64 E 9$ + PESI SIM ms
$+418.6920-421.6920$ wyas51c-

wyas51c-P_180104204953 \#6633 RT: 16.00 AV: 1 NL: $1.37 E 9$
T: FTMS + p ESI SIM ms [418.6920-421.6920]

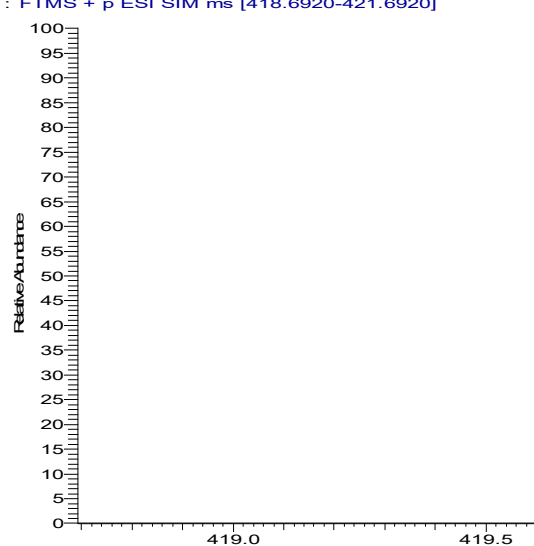

420.1923

wyas51c-P_180104204953 \#6595 RT: 15.89 AV: 1 NL: 9.07E7
F: FTMS + P ESI d Full ms2 420.1847@hcd30.00 [50.0000-450.00oo]

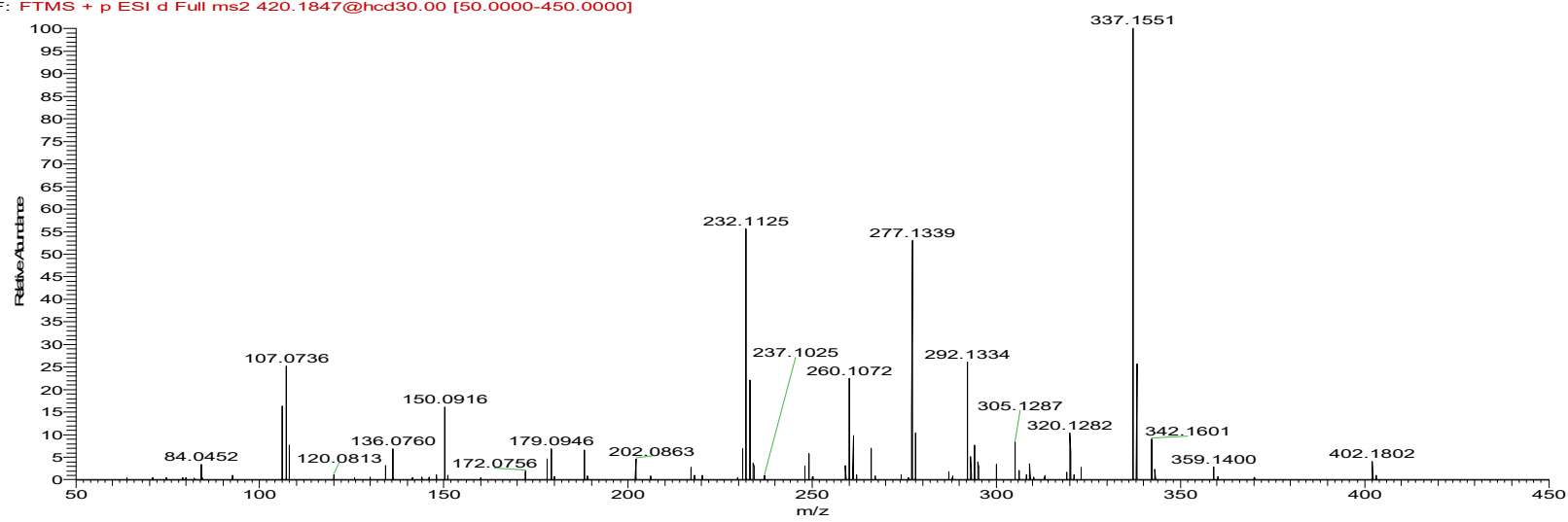




\section{Figure S5. ${ }^{1} \mathrm{H}$ NMR spectrum of alstoscholarisine $\mathrm{K}(1)$ in DMSO (600 MHz)}

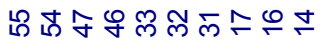

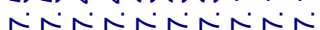

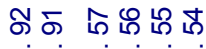
ம் ம் ம்

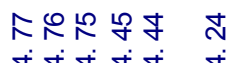
$\begin{array}{lll}\infty & 0 & \widetilde{m} \\ \infty & \infty & m\end{array}$

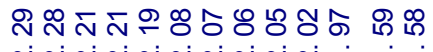

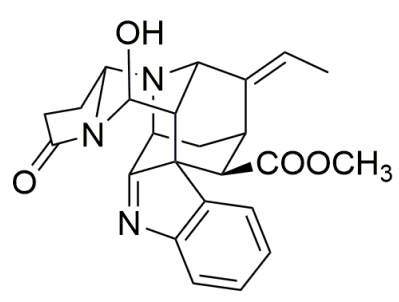

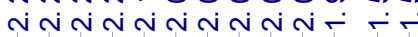

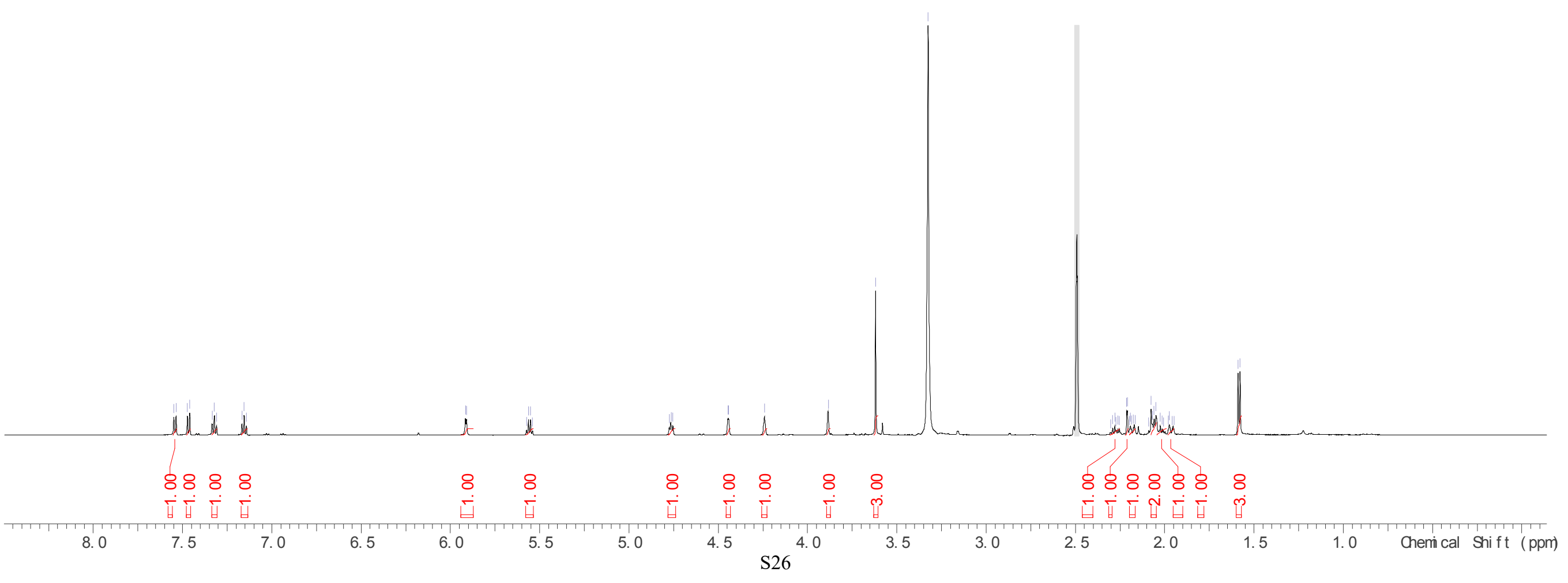


Figure S6. ${ }^{13} \mathrm{C}$ NMR spectrum of alstoscholarisine K (1) in DMSO (150 MHz)

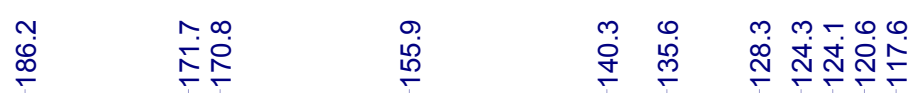

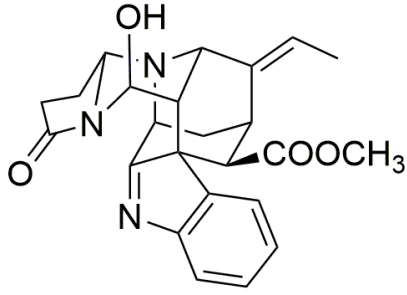


Figure S7. The ${ }^{1} \mathrm{H}-{ }^{1} \mathrm{H}$ COSY spectrum of alstoscholarisine K (1) in DMSO
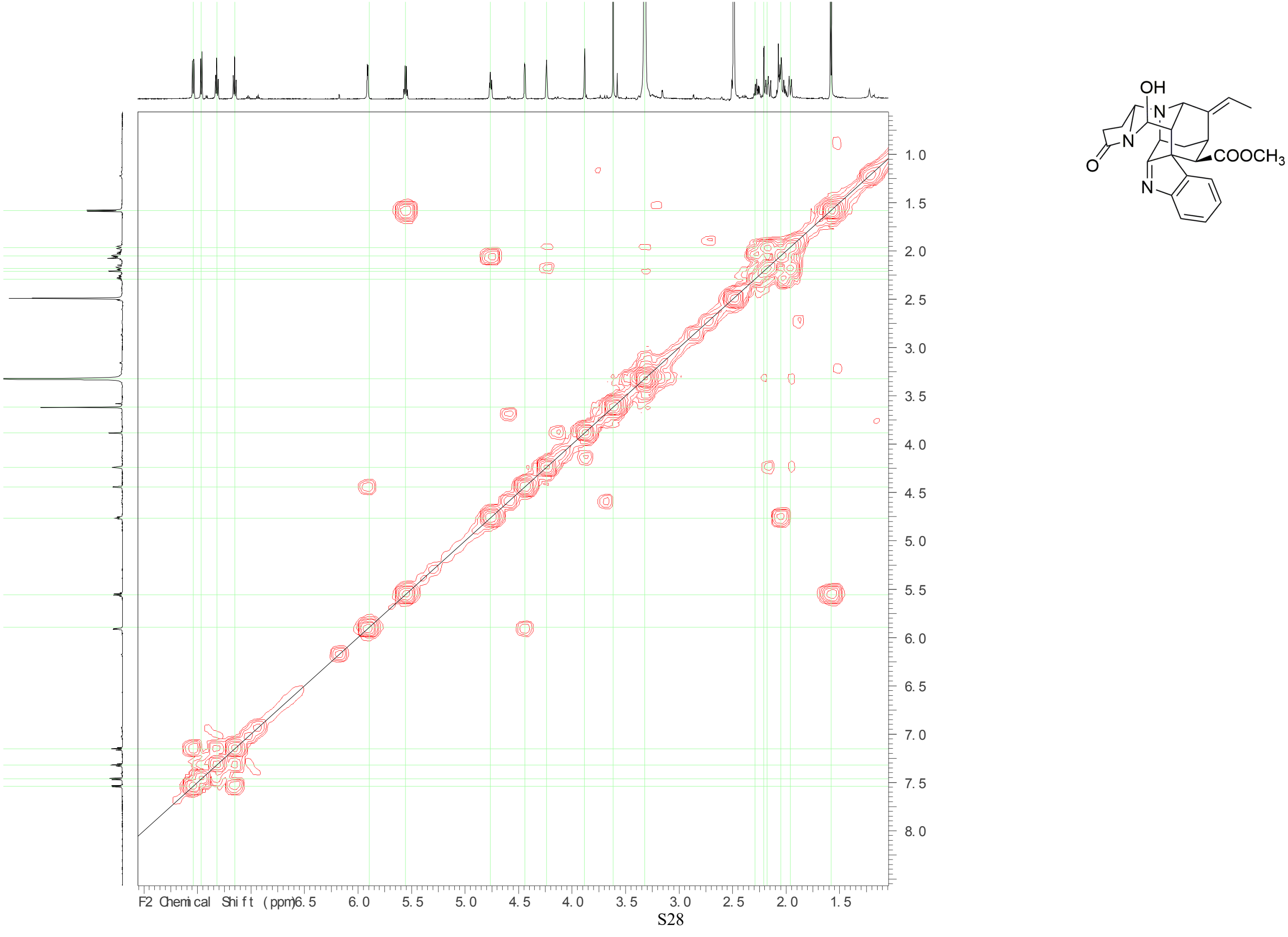
Figure S8. The HSQC spectrum of alstoscholarisine K (1) in DMSO
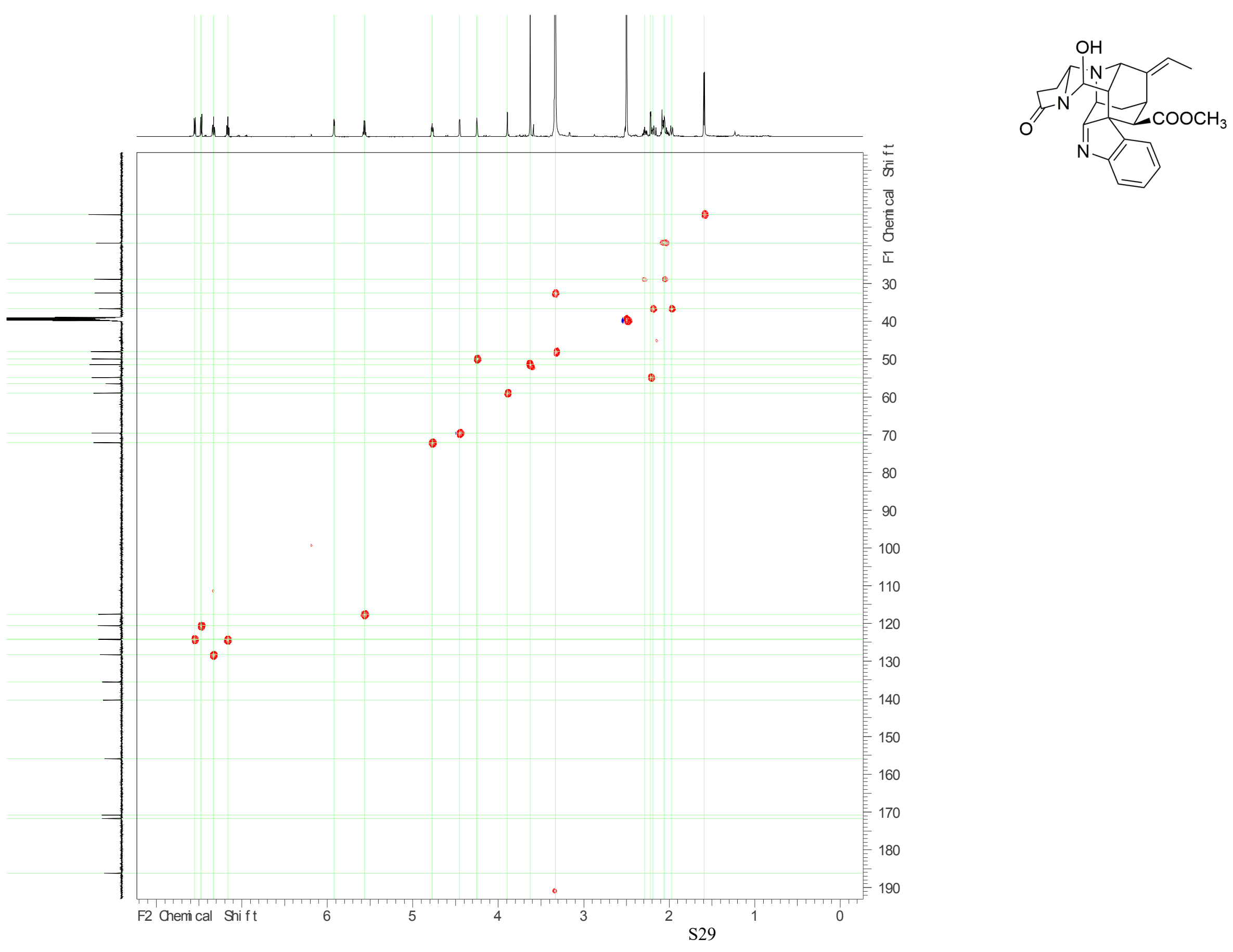
Figure S9. The HMBC spectrum of alstoscholarisine K (1) in DMSO
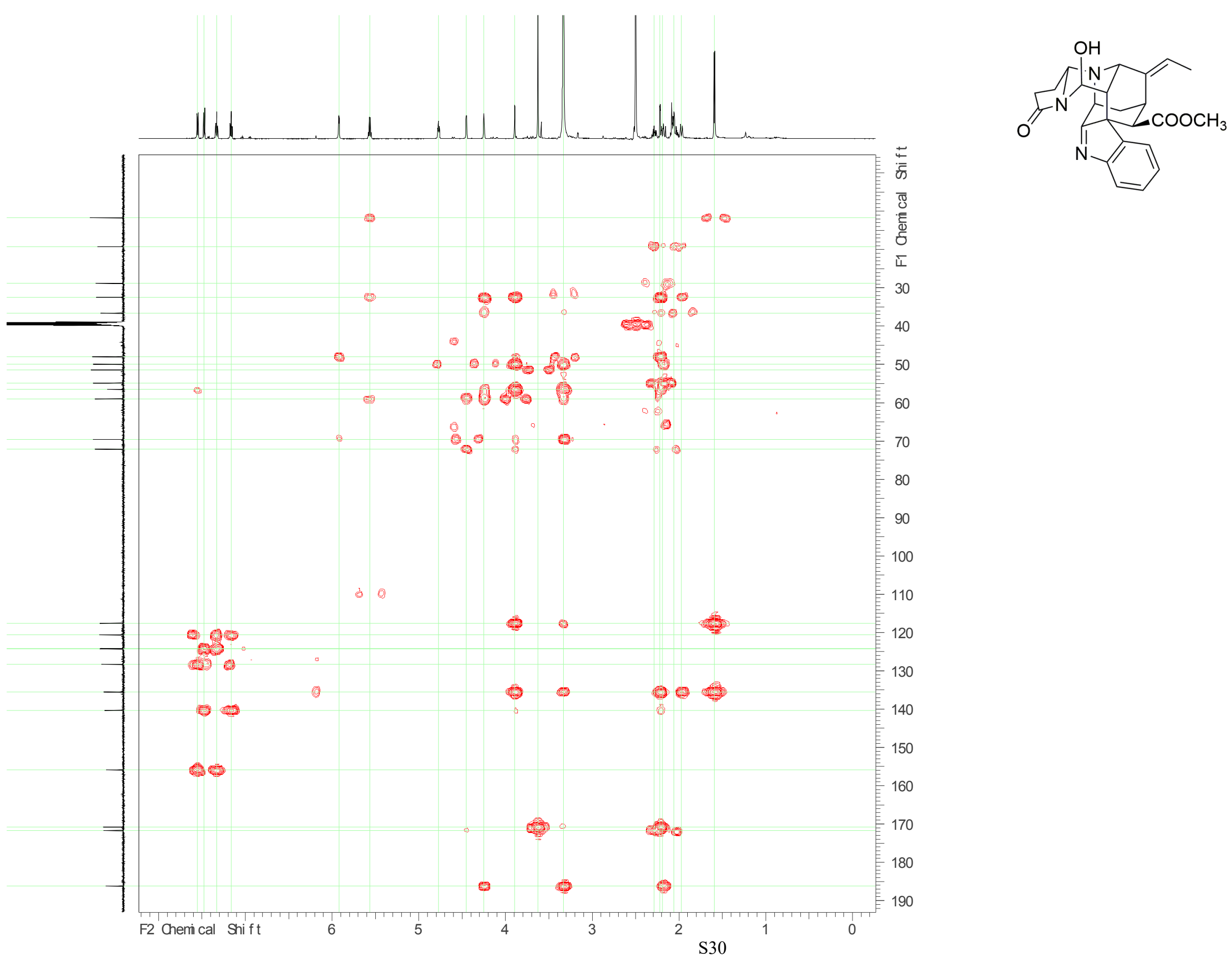
Figure S10. The ROESY spectrum of alstoscholarisine K (1) in DMSO
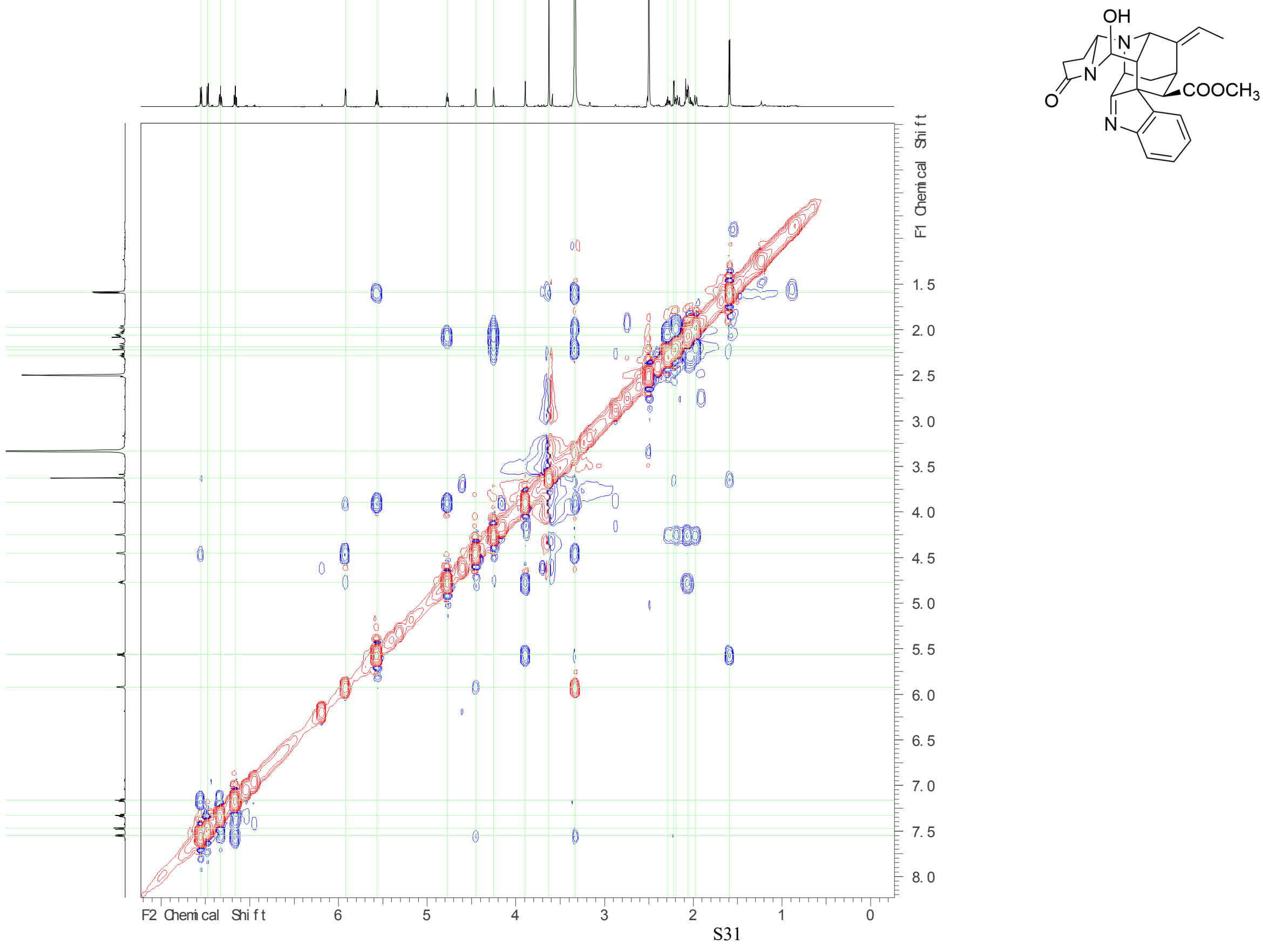
Figure S11. ${ }^{1} \mathrm{H}$ NMR spectrum of alstoscholarisine $\mathrm{K}(1)$ in $\mathrm{CDCl}_{3}(600 \mathrm{MHz})$

sN8

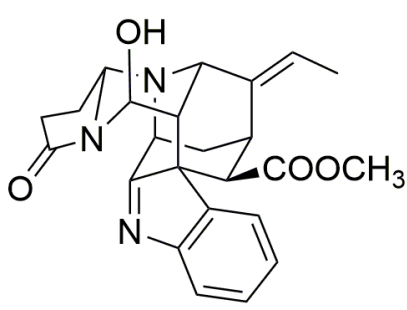

tovis ก่ เก เก

88 के 8 $\dot{+} \dot{+} \dot{+}$

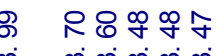
लें लं लं

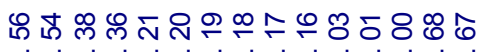

ง่ง

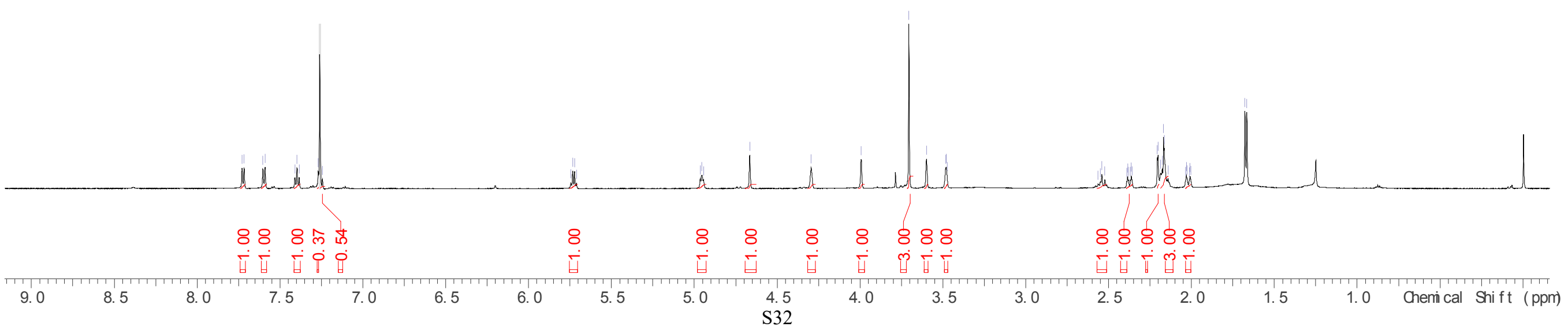


Figure S12. ${ }^{13} \mathrm{C}$ NMR spectrum of alstoscholarisine $\mathrm{K}(1)$ in $\mathrm{CDCl}_{3}(150 \mathrm{MHz})$

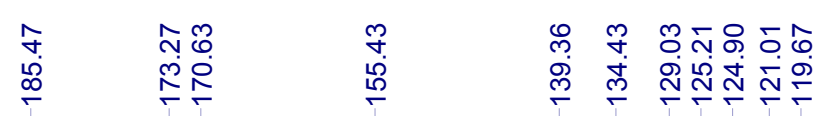

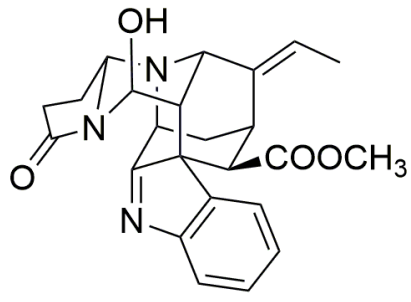


Figure S13. DEPT 90 spectrum of alstoscholarisine $\mathrm{K}(1)$ in $\mathrm{CDCl}_{3}(150 \mathrm{MHz})$

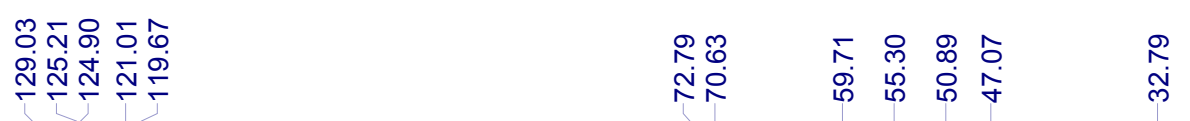

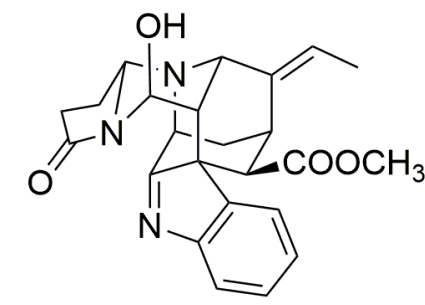

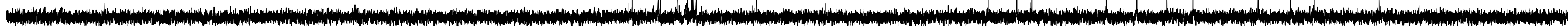

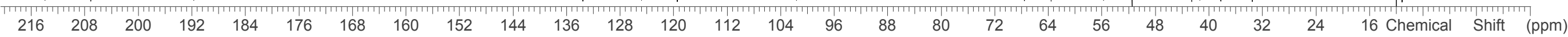
S34 
Figure S14. DEPT 135 spectrum of alstoscholarisine $\mathrm{K}(1)$ in $\mathrm{CDCl}_{3}(150 \mathrm{MHz})$

\begin{tabular}{|c|c|c|c|c|}
\hline 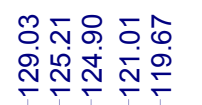 & $\begin{array}{l}\mathbb{0} \\
\text { N̦ } \\
\end{array}$ & 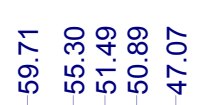 & 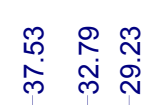 & 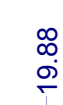 \\
\hline
\end{tabular}

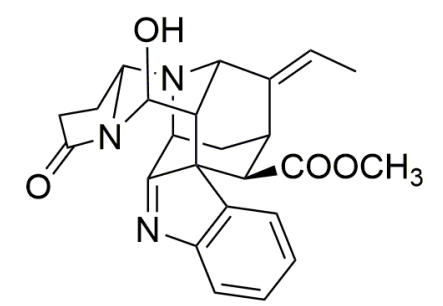

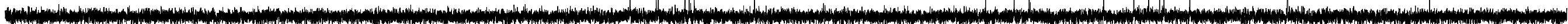


Figure S15. The HSQC spectrum of alstoscholarisine $\mathrm{K}(1)$ in $\mathrm{CDCl}_{33}$
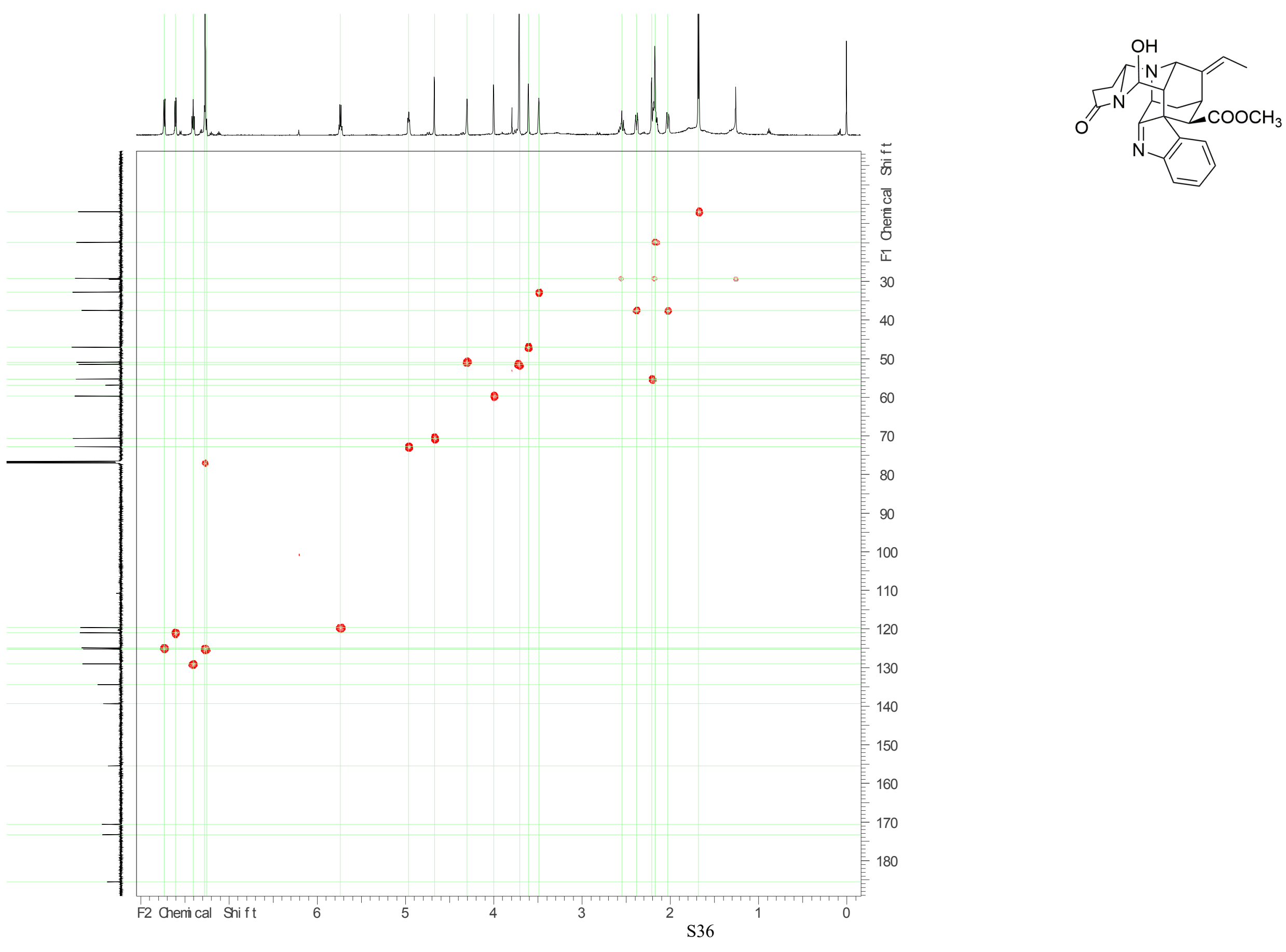
Figure S16. The HMBC spectrum of alstoscholarisine $\mathrm{K}(1)$ in $\mathrm{CDCl}_{33}$
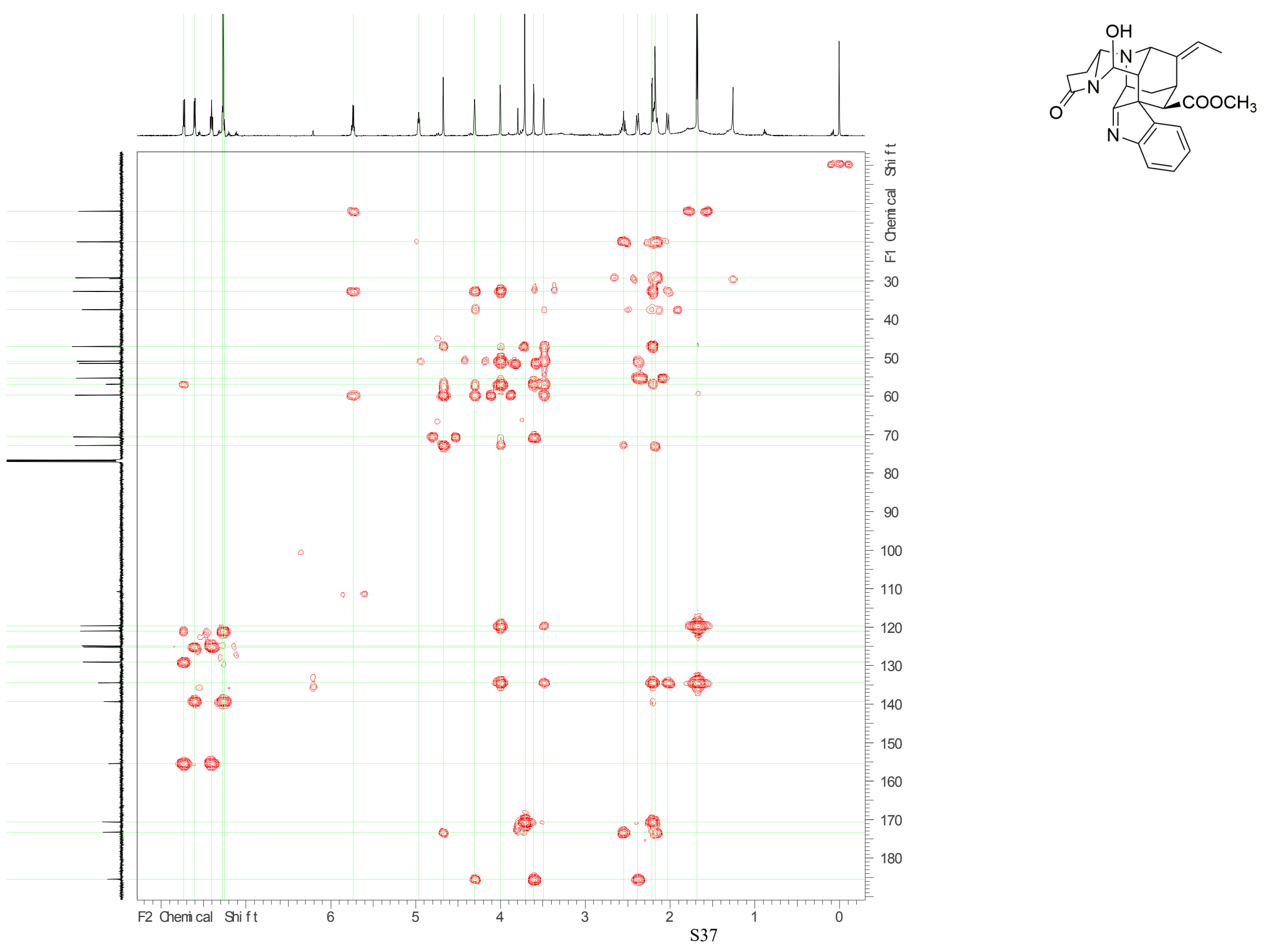
Figure S17. CD spectrum of alstoscholarisine K (1)

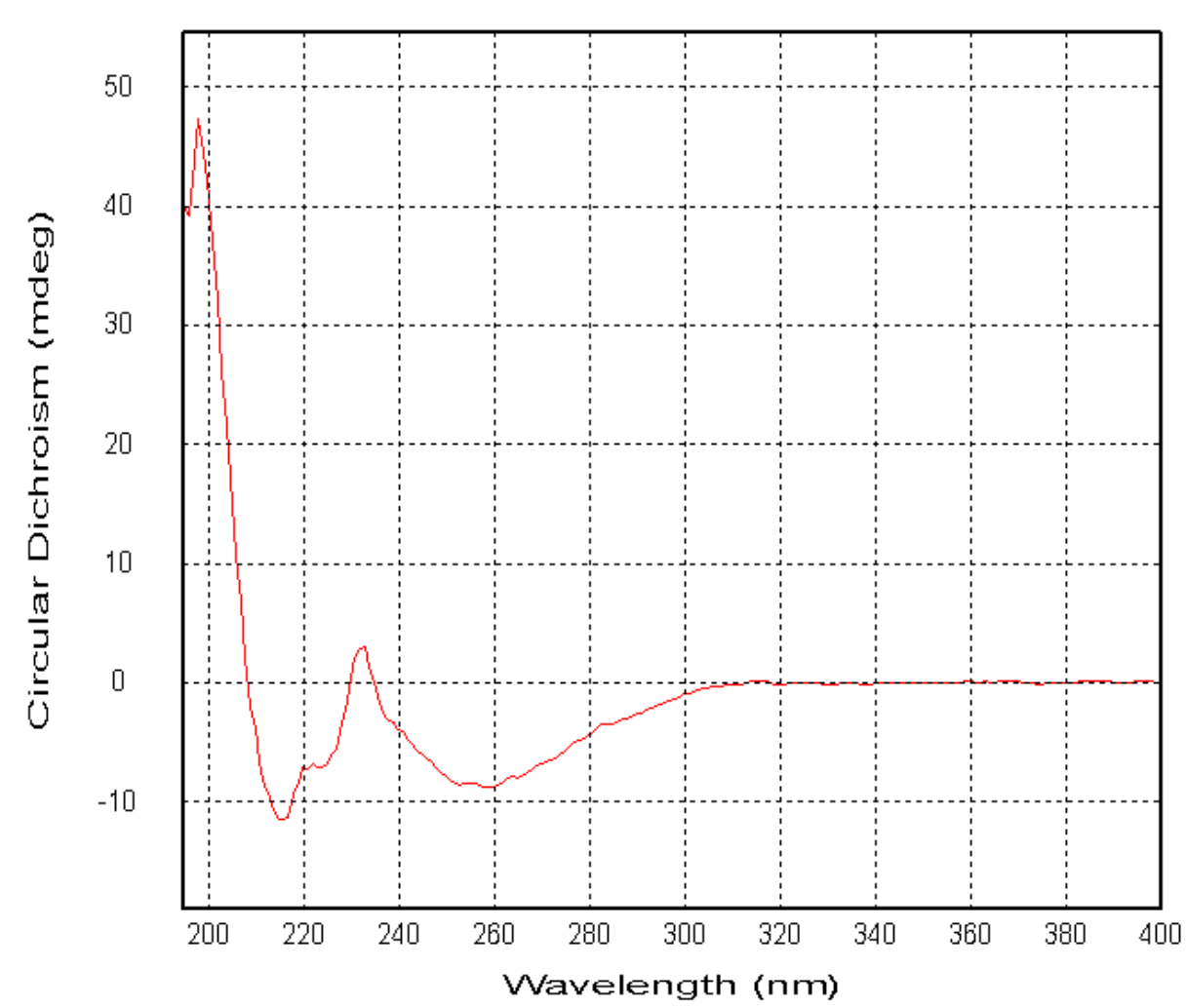

Smooth (s):0

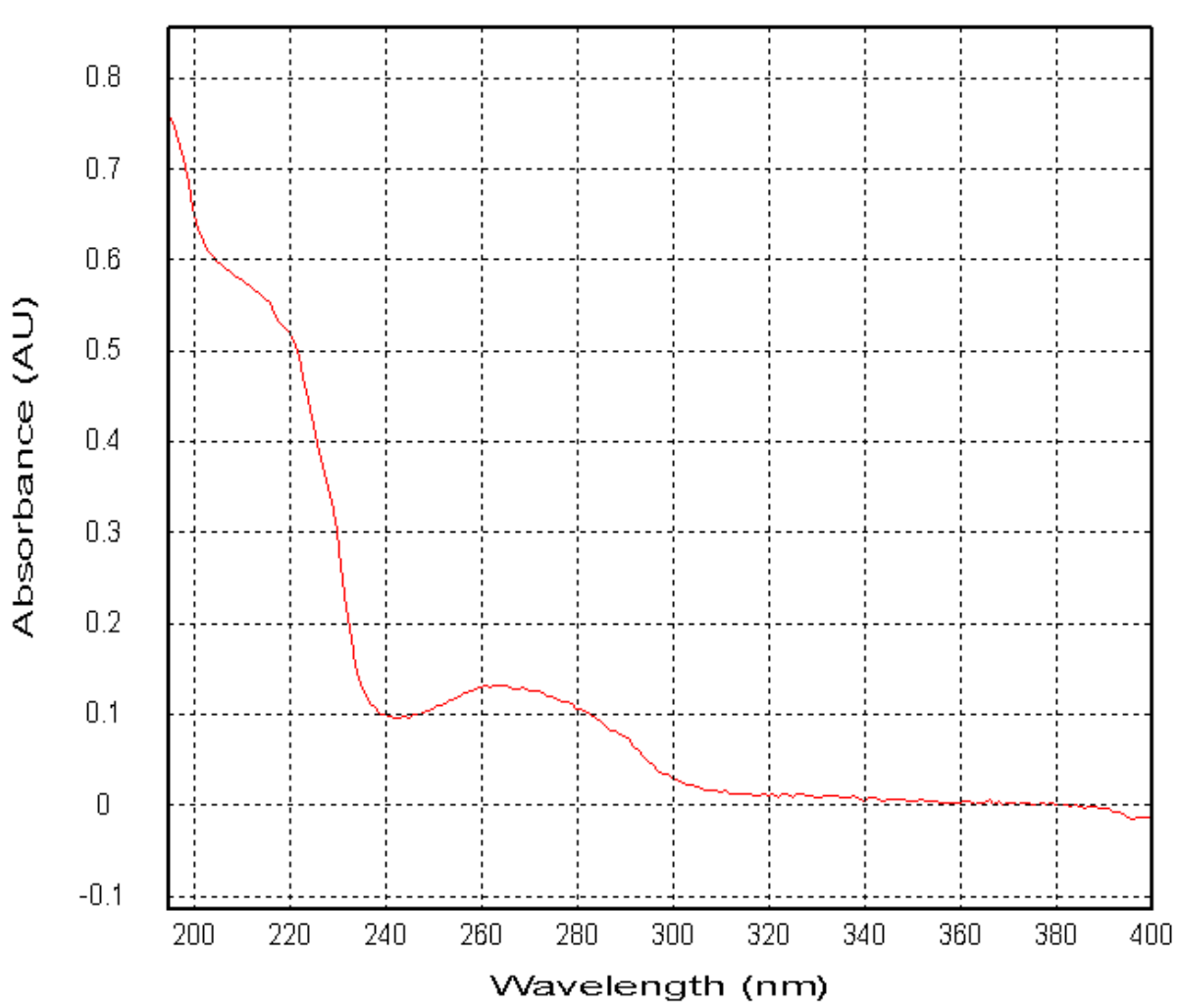

$\overline{\text { Subtracted:0 }}$ 

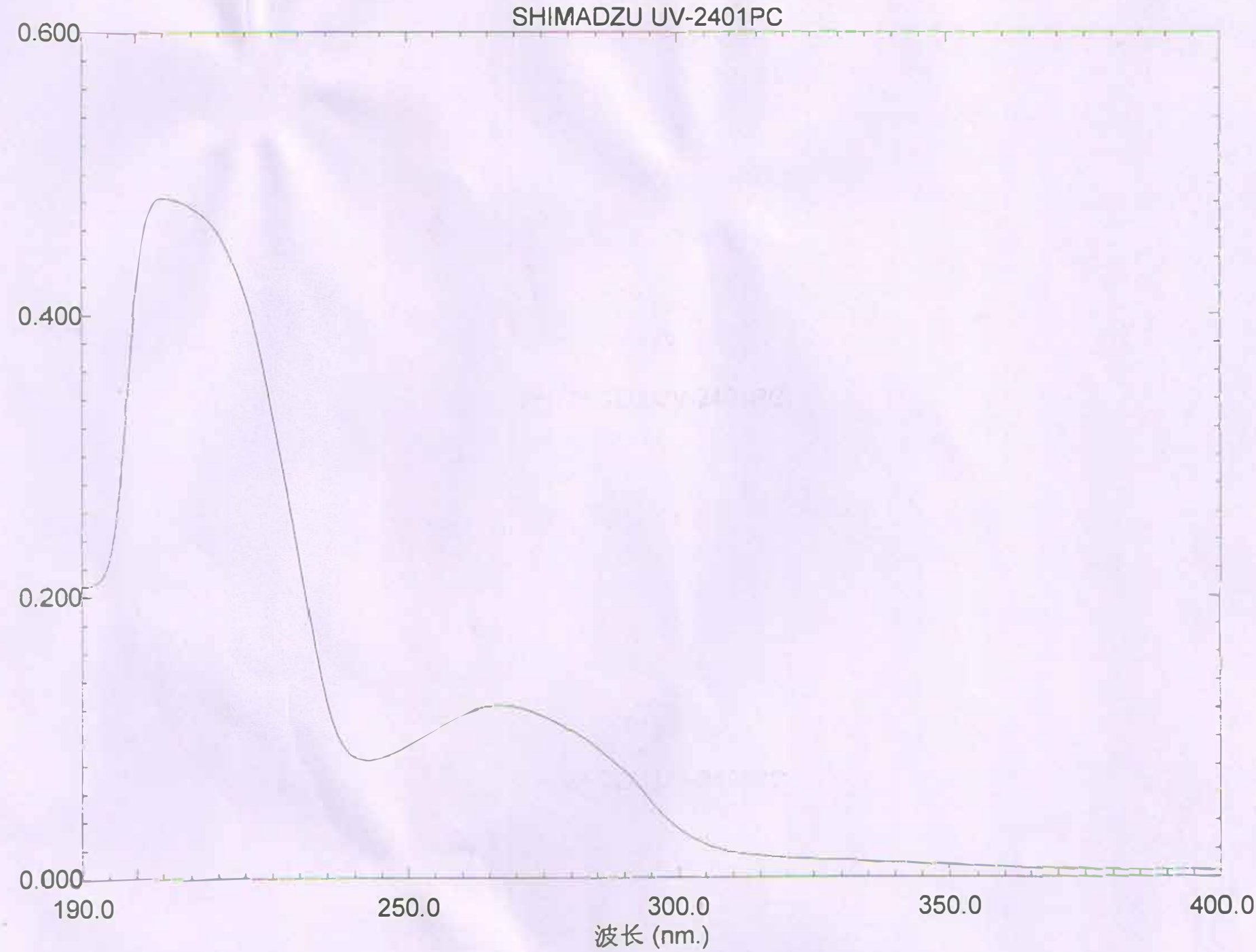

文件名：WYAS51C WYAS516

创建于： $13: 42 \quad 17-12-02$

样品浓度: 0.0088 毫克/ 毫升 溶剂: 甲醇

数据: 原始
量模式: Abs.
扫描速度: 中速
狭缝: $\quad 5.0$

采样间隔： 0.5

否. 波长 $(\mathrm{nm}$.) Abs.

$1 \quad 267.50 \quad 0.1225$

$2 \quad 205.00 \quad 0.4826$

Figure S18. UV spectrum of alstoscholarisine K (1) 
Figure S19. Optical rotation measurement of Alstoscholarisine K (1)

Optical rotation measurement

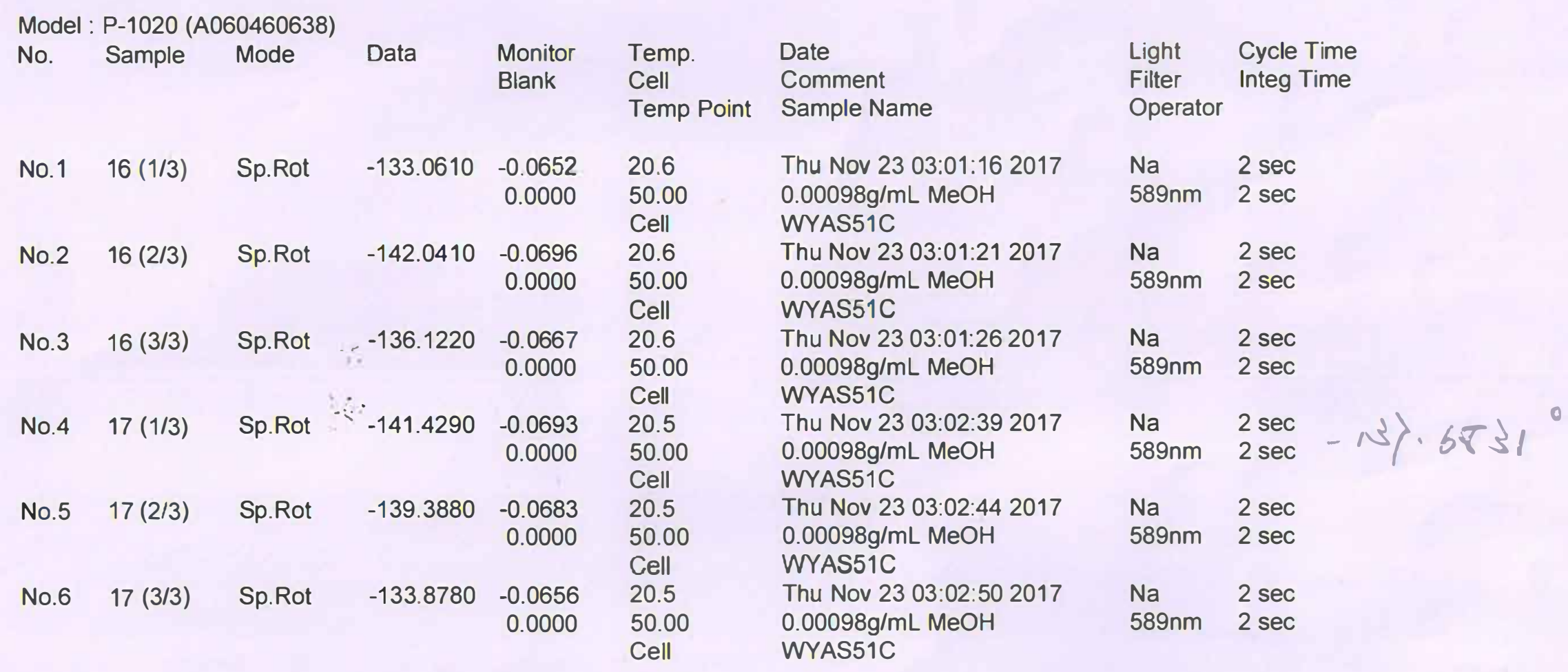




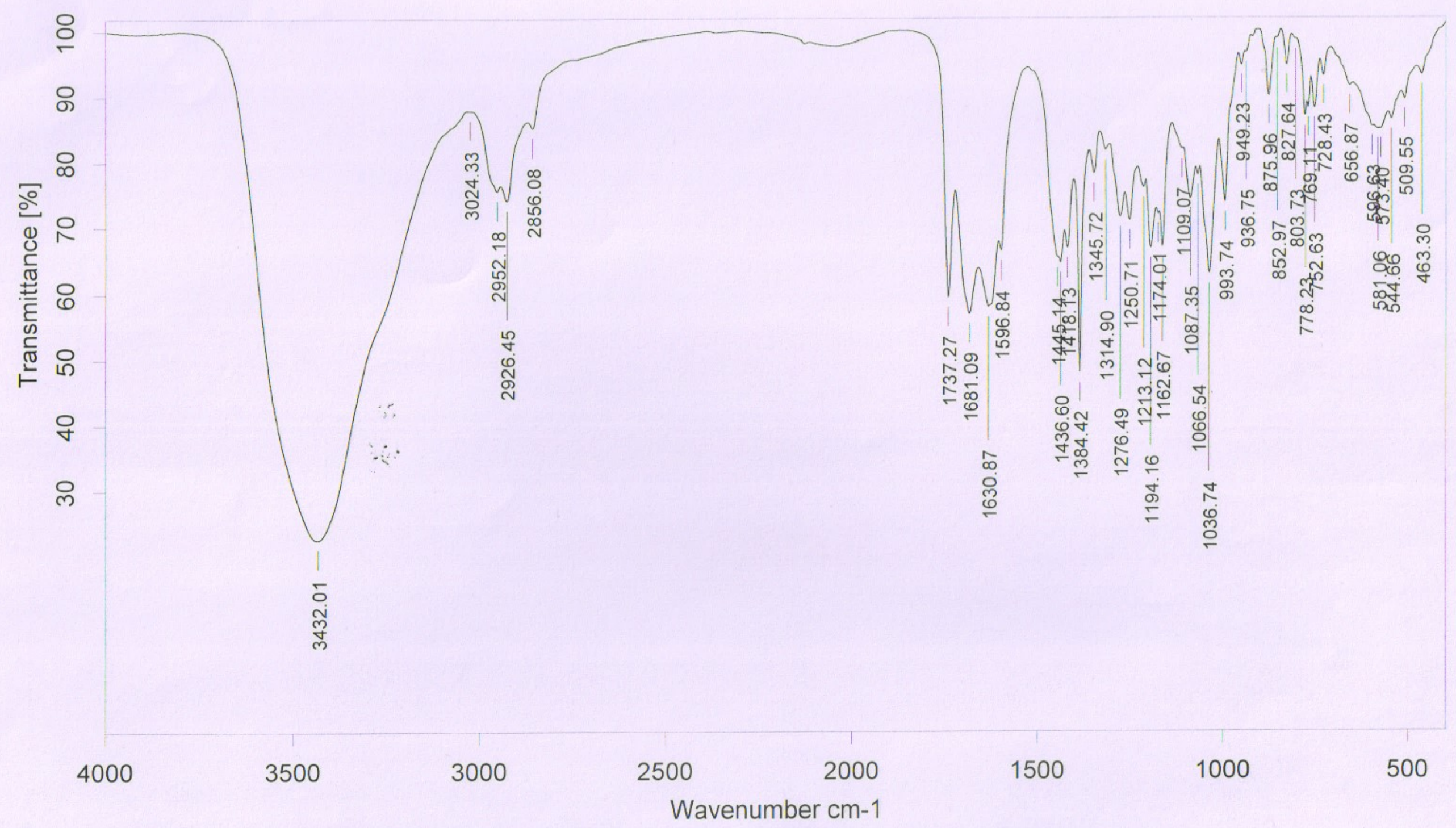

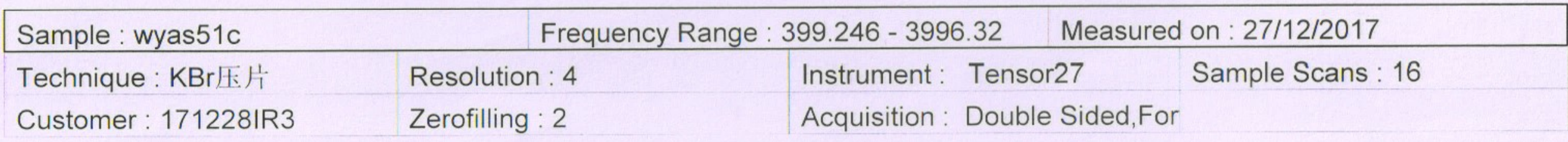

Figure S20. IR spectrum of alstoscholarisine K (1) 
$====$ LCMSsolution Data Report ====

\begin{tabular}{lll} 
& \multicolumn{1}{c}{$\quad$ Sample Information } & System Configuration \\
Acquired by & $:$ Admin & < Instrument $>>$ LC-IT-TOF \\
Date Acquired & $: 2017 / 8 / 213: 37: 29$ \\
Sample Name & $:$ wyas51c \\
Data File & $:$ wyas51c.lcd \\
Method File & $:$ 阻尼管一级20151028-100-1500.lcm
\end{tabular}

\section{$<$ Spectrum>}

Retention Time:0.450(Scan\#:92)

Spectrum:Averaged 0.340-0.570(69-115)

Background:Averaged 0.000-0.345(1-69) MS Stage:MS Polarity:Pos Segment1 - Eventl Precursor:----- Cutoff:

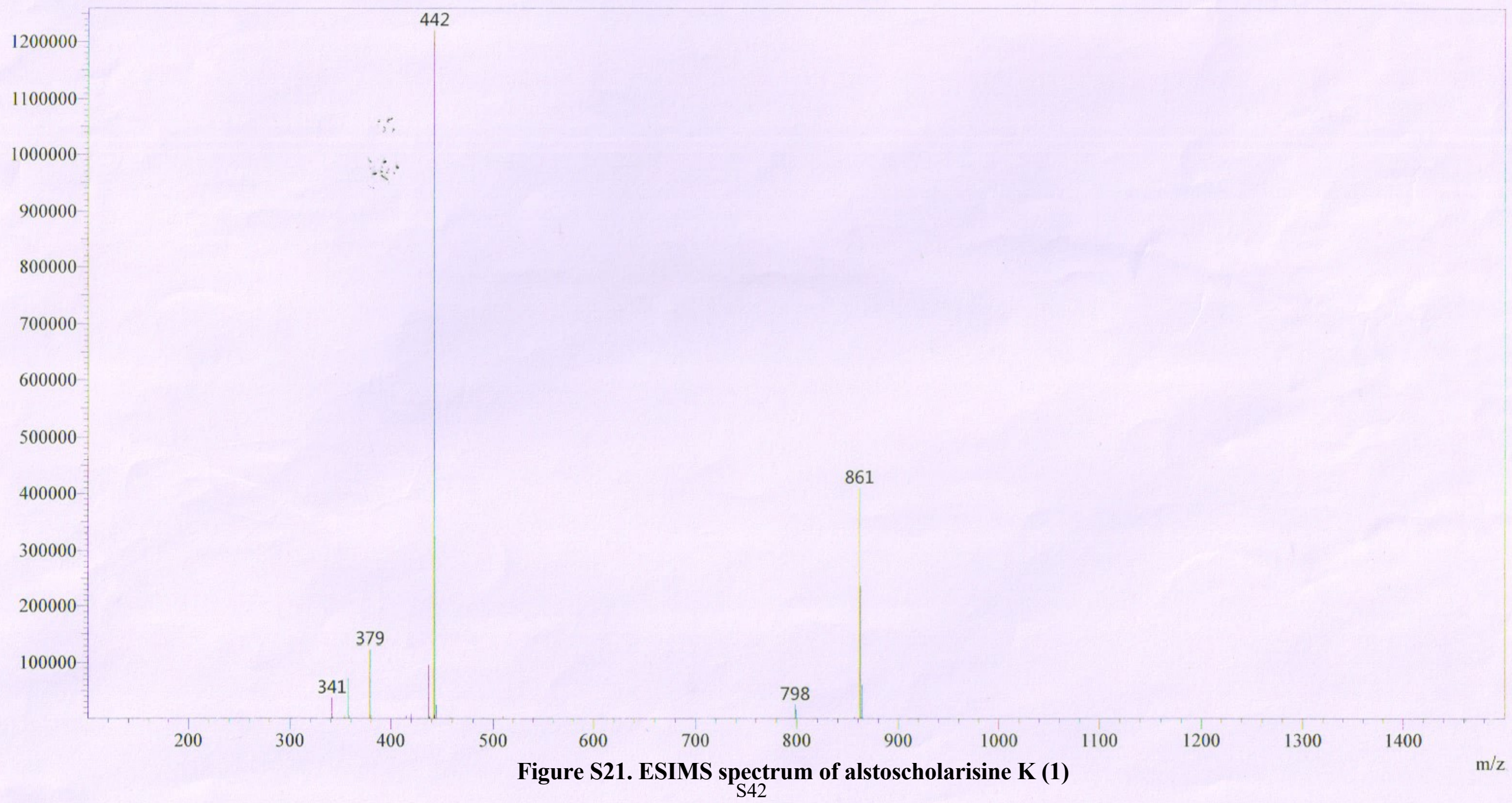


Figure S22. HR-ESI-MS spetrum of alstoscholarisine K (1)

Formula Predictor Report - wyas51c.lcd

Data File: E:IDATAl2017108021wyas51c.Icd

$\begin{array}{ccrrrrrrrrrr}\text { Elmt } & \text { Val. } & \text { Min } & \text { Max } & \text { Elmt } & \text { Val. } & \text { Min } & \text { Max } & \text { Elmt } & \text { Val. } & \text { Min } & \text { Max } \\ \mathrm{H} & 1 & 0 & 100 & \mathrm{O} & 2 & 0 & 50 & \mathrm{Cl} & 1 & 0 & 0 \\ \mathrm{C} & 4 & 0 & 50 & \mathrm{~F} & 1 & 0 & 0 & \mathrm{Br} & 1 & 0 & 0 \\ \mathrm{~N} & 3 & 0 & 10 & \mathrm{~S} & 2 & 0 & 0 & \mathrm{I} & 3 & 0 & 0\end{array}$

Error Margin (ppm): 5 HC Ratio: unlimited

Max Isotopes: all

DBE Range: $-2.0-100.0$

Apply N Rule: yes

Isotope RI (\%): 1.00

MSn Iso RI (\%): 75.00

MSn Logic Mode: AND

Use Adduct

Na

Electron lons: both

Use MSn Info: yes

Isotope Res: 10000

Max Results: 5

Event\#: $1 \mathrm{MS}(\mathrm{E}+)$ Ret. Time : 0.350 Scan\# : 71
$1.300 \mathrm{e} 5$
$1.200 \mathrm{e} 5$
$1.100 \mathrm{e} 5$
$1.000 \mathrm{e} 5$
$9.000 \mathrm{e} 4$
$8.000 \mathrm{e} 4$
$7.000 \mathrm{e} 4$
$6.000 \mathrm{e} 4$
$5.000 \mathrm{e} 4$
$4.000 \mathrm{e} 4$
$3.000 \mathrm{e} 4$
$2.000 \mathrm{e} 4$
$1.000 \mathrm{e} 4$

Measured region for $442.1734 \mathrm{~m} / \mathrm{z}$

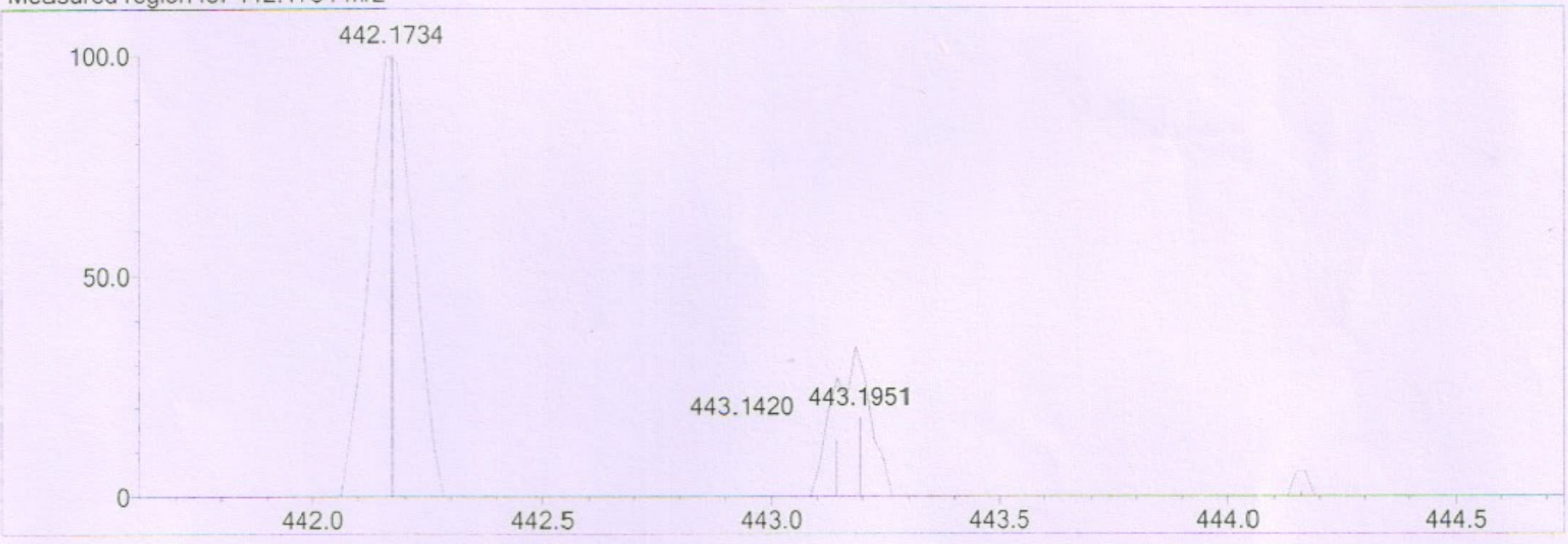

$\mathrm{C} 24 \mathrm{H} 25 \mathrm{~N} 3 \mathrm{O} 4 \mathrm{M}+\mathrm{Na}]+$ : Predicted region for $442.1737 \mathrm{~m} / \mathrm{z}$

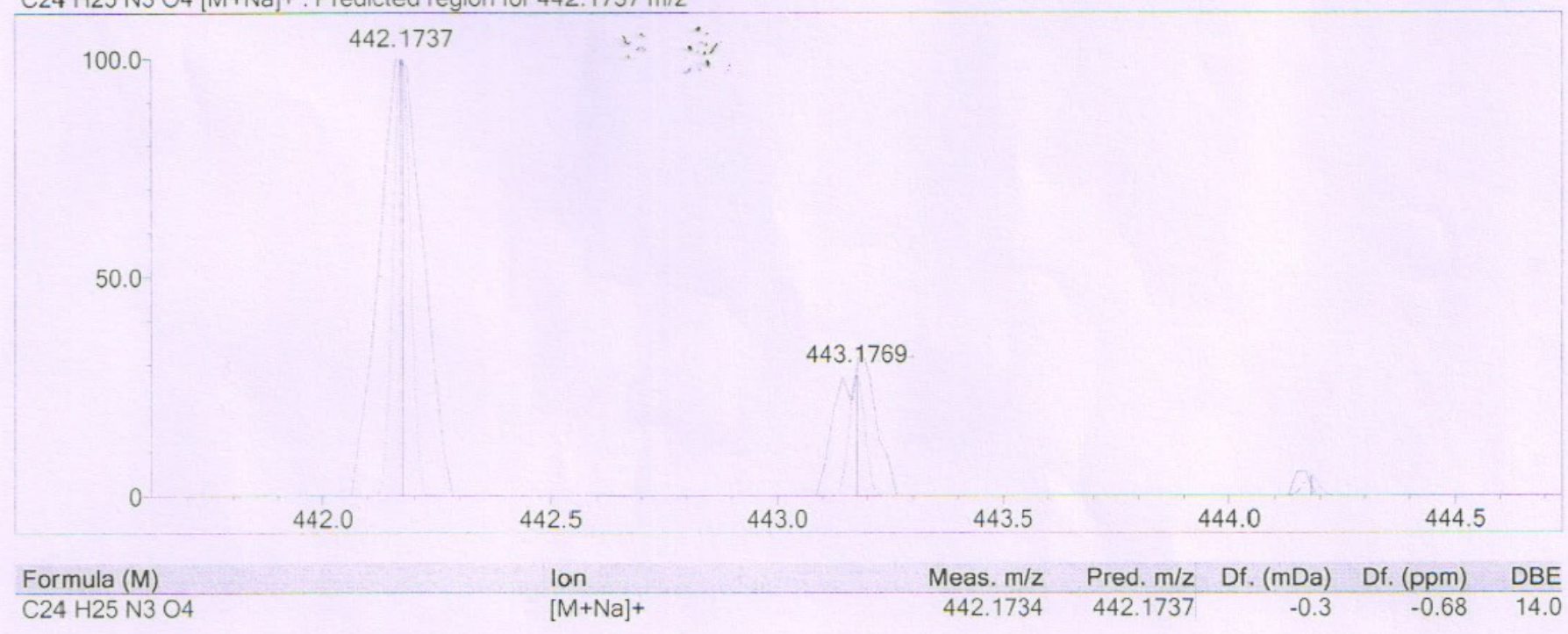


Figure 23 Crystal of alstoscholarisine K (1)

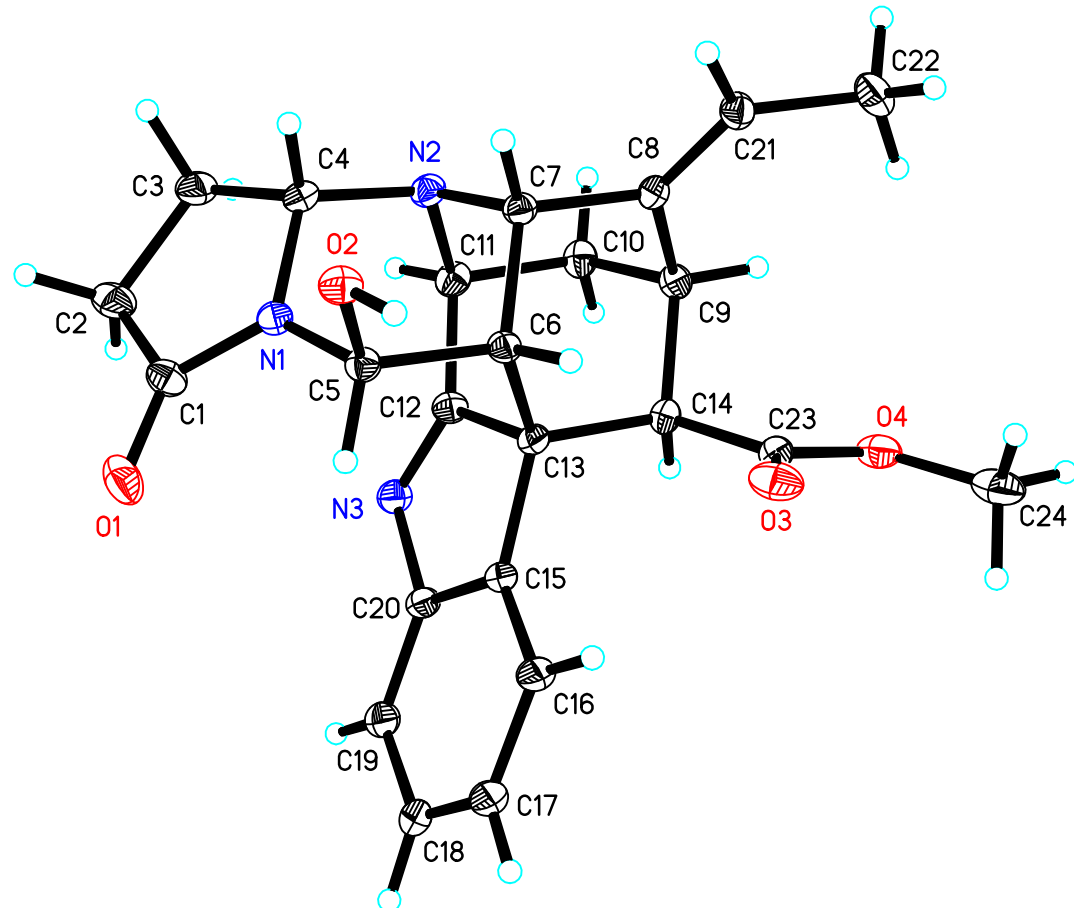

View of a molecule of compound (1) with the atom-labelling scheme.

Displacement ellipsoids are drawn at the $30 \%$ probability level.

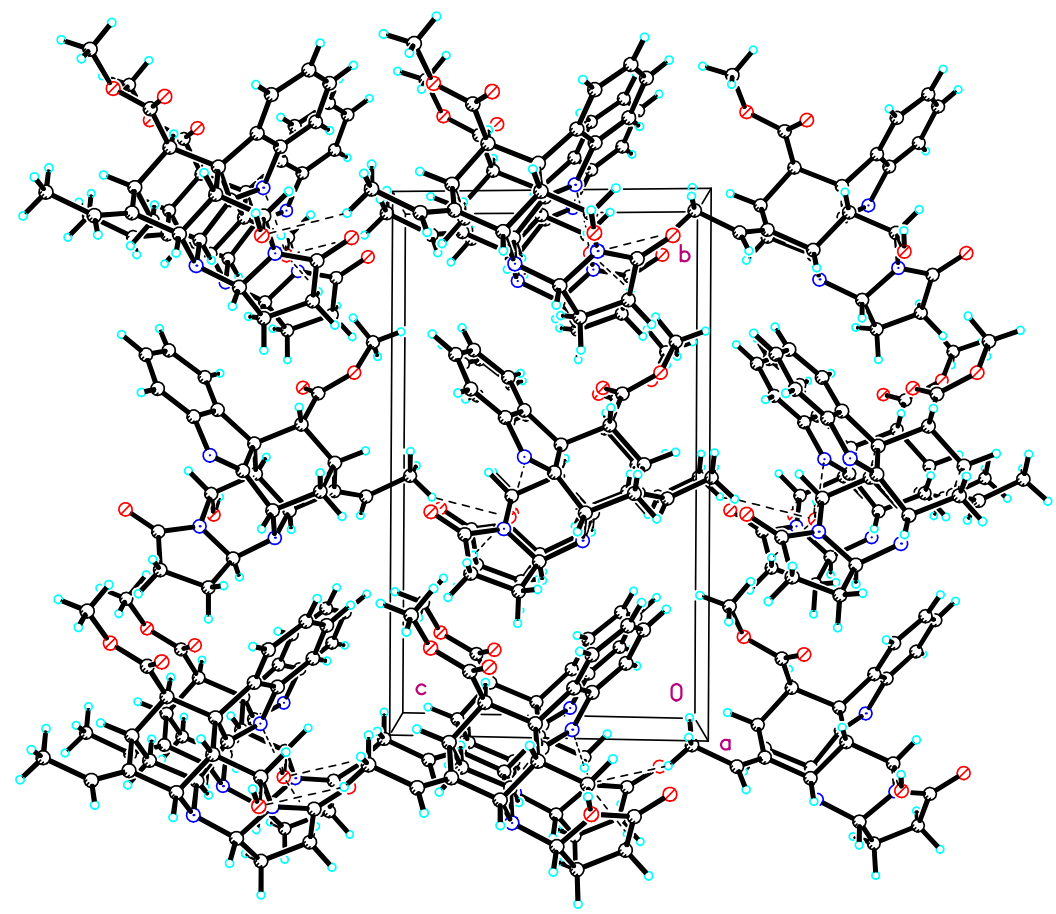


Table S7. Crystal data and structure refinement for compound (1).

Identification code

Empirical formula

Formula weight

Temperature

Wavelength

Crystal system

Space group

Unit cell dimensions

Volume

Z

Density (calculated)

Absorption coefficient

$\mathrm{F}(000)$

Crystal size

Theta range for data collection

Index ranges

Reflections collected

Independent reflections

Completeness to theta $=67.679^{\circ}$

Absorption correction

Max. and min. transmission

Refinement method

Data / restraints / parameters

Goodness-of-fit on $\mathrm{F}^{2}$

Final R indices [I $>2 \operatorname{sigma}(\mathrm{I})]$

$\mathrm{R}$ indices (all data)

Absolute structure parameter

Extinction coefficient

Largest diff. peak and hole compound (1)

C24 H25 N3 O4

419.47

173(2) K

$1.54178 \AA$

Monoclinic

P 21

$\mathrm{a}=6.83220(10) \AA$

$\alpha=90^{\circ}$.

$\mathrm{b}=16.0357(3) \AA$

$\beta=97.9690(10)^{\circ}$.

$\mathrm{c}=9.3673(2) \AA$

$\gamma=90^{\circ}$

2

$1.371 \mathrm{Mg} / \mathrm{m}^{3}$

$0.769 \mathrm{~mm}^{-1}$

444

$0.150 \times 0.120 \times 0.060 \mathrm{~mm}^{3}$

5.509 to $70.169^{\circ}$.

$-8<=\mathrm{h}<=8,-19<=\mathrm{k}<=19,-11<=\mathrm{l}<=11$

10869

$3749[\mathrm{R}(\mathrm{int})=0.0539]$

$99.4 \%$

Semi-empirical from equivalents

0.7533 and 0.5958

Full-matrix least-squares on $\mathrm{F}^{2}$

3749 / 1 / 284

1.038

$\mathrm{R} 1=0.0418, \mathrm{wR} 2=0.1074$

$\mathrm{R} 1=0.0462, \mathrm{wR} 2=0.1126$

$0.18(15)$

$0.0058(19)$

0.209 and -0.212 e. $\AA^{-3}$ 
Table S8. Atomic coordinates $\left(\times 10^{4}\right)$ and equivalent isotropic displacement parameters $\left(\AA^{2} \times 10^{3}\right)$ for compound (1). $\mathrm{U}(\mathrm{eq})$ is defined as one third of the trace of the orthogonalized $\mathrm{U}^{\mathrm{ij}}$ tensor.

\begin{tabular}{|c|c|c|c|c|}
\hline & $\mathrm{x}$ & $\mathrm{y}$ & $\mathrm{z}$ & $\mathrm{U}(\mathrm{eq})$ \\
\hline $\mathrm{N}(1)$ & 7323(4) & $3781(2)$ & $6444(3)$ & $23(1)$ \\
\hline $\mathrm{N}(2)$ & 7633(4) & $3576(2)$ & $3915(3)$ & $24(1)$ \\
\hline $\mathrm{N}(3)$ & $10780(4)$ & $5127(2)$ & $5772(3)$ & $25(1)$ \\
\hline $\mathrm{O}(1)$ & $8589(4)$ & $4100(2)$ & $8775(3)$ & $40(1)$ \\
\hline $\mathrm{O}(2)$ & 3942(3) & $3975(2)$ & $6302(3)$ & $26(1)$ \\
\hline $\mathrm{O}(3)$ & 4392(4) & $6462(2)$ & $3242(3)$ & $36(1)$ \\
\hline $\mathrm{O}(4)$ & 6099(4) & $6727(2)$ & 1416(3) & $33(1)$ \\
\hline $\mathrm{C}(1)$ & $8580(5)$ & $3686(2)$ & $7683(3)$ & $27(1)$ \\
\hline$C(2)$ & $10000(5)$ & 2988(3) & $7451(4)$ & $34(1)$ \\
\hline$C(3)$ & $9347(5)$ & $2658(2)$ & $5937(4)$ & $33(1)$ \\
\hline$C(4)$ & 7541(5) & $3178(2)$ & 5301(3) & $25(1)$ \\
\hline$C(5)$ & $5756(5)$ & $4392(2)$ & $6213(3)$ & $22(1)$ \\
\hline$C(6)$ & $5714(4)$ & $4782(2)$ & $4710(3)$ & $21(1)$ \\
\hline$C(7)$ & $5785(5)$ & $4080(2)$ & $3570(3)$ & $22(1)$ \\
\hline$C(8)$ & $5645(5)$ & $4462(2)$ & $2086(3)$ & $22(1)$ \\
\hline $\mathrm{C}(9)$ & 7424(4) & $5003(2)$ & 1962(3) & $23(1)$ \\
\hline$C(10)$ & $9288(5)$ & $4469(2)$ & 2313(3) & $26(1)$ \\
\hline$C(11)$ & 9399(5) & $4108(2)$ & $3848(4)$ & $25(1)$ \\
\hline$C(12)$ & 9381(4) & $4845(2)$ & $4830(3)$ & $23(1)$ \\
\hline$C(13)$ & 7497(5) & $5361(2)$ & $4620(3)$ & $21(1)$ \\
\hline$C(14)$ & $7466(4)$ & $5727(2)$ & $3068(3)$ & $22(1)$ \\
\hline$C(15)$ & 8019(5) & $5995(2)$ & $5799(3)$ & $22(1)$ \\
\hline$C(16)$ & $6947(5)$ & $6628(2)$ & $6333(4)$ & $29(1)$ \\
\hline $\mathrm{C}(17)$ & $7905(6)$ & $7123(2)$ & $7441(4)$ & $37(1)$ \\
\hline$C(18)$ & 9866(7) & $7003(2)$ & $7971(4)$ & $39(1)$ \\
\hline$C(19)$ & $10961(6)$ & $6354(2)$ & $7459(4)$ & $34(1)$ \\
\hline$C(20)$ & 9979(5) & $5849(2)$ & $6388(4)$ & $25(1)$ \\
\hline $\mathrm{C}(21)$ & 4091(5) & $4355(2)$ & 1105(3) & $25(1)$ \\
\hline$C(22)$ & $3682(6)$ & $4759(3)$ & $-352(4)$ & $36(1)$ \\
\hline$C(23)$ & 5794(5) & $6335(2)$ & $2630(3)$ & $24(1)$ \\
\hline $\mathrm{C}(24)$ & 4631(7) & $7337(3)$ & $873(5)$ & $43(1)$ \\
\hline
\end{tabular}


Table S9. Bond lengths $[\AA]$ and angles $\left[^{\circ}\right]$ for compound (1).

\begin{tabular}{|c|c|}
\hline $\mathrm{N}(1)-\mathrm{C}(1)$ & $1.353(4)$ \\
\hline $\mathrm{N}(1)-\mathrm{C}(5)$ & $1.445(4)$ \\
\hline $\mathrm{N}(1)-\mathrm{C}(4)$ & $1.466(4)$ \\
\hline $\mathrm{N}(2)-\mathrm{C}(4)$ & $1.456(4)$ \\
\hline $\mathrm{N}(2)-\mathrm{C}(11)$ & $1.486(4)$ \\
\hline $\mathrm{N}(2)-\mathrm{C}(7)$ & $1.496(4)$ \\
\hline $\mathrm{N}(3)-\mathrm{C}(12)$ & $1.290(4)$ \\
\hline $\mathrm{N}(3)-\mathrm{C}(20)$ & $1.435(4)$ \\
\hline $\mathrm{O}(1)-\mathrm{C}(1)$ & $1.219(4)$ \\
\hline $\mathrm{O}(2)-\mathrm{C}(5)$ & $1.420(4)$ \\
\hline $\mathrm{O}(2)-\mathrm{H}(2)$ & 0.8400 \\
\hline $\mathrm{O}(3)-\mathrm{C}(23)$ & $1.200(4)$ \\
\hline $\mathrm{O}(4)-\mathrm{C}(23)$ & $1.341(4)$ \\
\hline $\mathrm{O}(4)-\mathrm{C}(24)$ & $1.443(4)$ \\
\hline $\mathrm{C}(1)-\mathrm{C}(2)$ & $1.516(5)$ \\
\hline$C(2)-C(3)$ & $1.521(5)$ \\
\hline $\mathrm{C}(2)-\mathrm{H}(2 \mathrm{~A})$ & 0.9900 \\
\hline $\mathrm{C}(2)-\mathrm{H}(2 \mathrm{~B})$ & 0.9900 \\
\hline$C(3)-C(4)$ & $1.539(4)$ \\
\hline $\mathrm{C}(3)-\mathrm{H}(3 \mathrm{~A})$ & 0.9900 \\
\hline $\mathrm{C}(3)-\mathrm{H}(3 \mathrm{~B})$ & 0.9900 \\
\hline $\mathrm{C}(4)-\mathrm{H}(4)$ & 1.0000 \\
\hline$C(5)-C(6)$ & $1.537(4)$ \\
\hline $\mathrm{C}(5)-\mathrm{H}(5)$ & 1.0000 \\
\hline$C(6)-C(13)$ & $1.543(4)$ \\
\hline$C(6)-C(7)$ & $1.557(4)$ \\
\hline $\mathrm{C}(6)-\mathrm{H}(6)$ & 1.0000 \\
\hline $\mathrm{C}(7)-\mathrm{C}(8)$ & $1.509(4)$ \\
\hline $\mathrm{C}(7)-\mathrm{H}(7)$ & 1.0000 \\
\hline$C(8)-C(21)$ & $1.316(5)$ \\
\hline $\mathrm{C}(8)-\mathrm{C}(9)$ & $1.510(4)$ \\
\hline$C(9)-C(10)$ & $1.532(4)$ \\
\hline$C(9)-C(14)$ & $1.554(4)$ \\
\hline $\mathrm{C}(9)-\mathrm{H}(9)$ & 1.0000 \\
\hline $\mathrm{C}(10)-\mathrm{C}(11)$ & $1.542(5)$ \\
\hline $\mathrm{C}(10)-\mathrm{H}(10 \mathrm{~A})$ & 0.9900 \\
\hline
\end{tabular}




\begin{tabular}{|c|c|}
\hline $\mathrm{C}(10)-\mathrm{H}(10 \mathrm{~B})$ & 0.9900 \\
\hline $\mathrm{C}(11)-\mathrm{C}(12)$ & $1.498(5)$ \\
\hline $\mathrm{C}(11)-\mathrm{H}(11)$ & 1.0000 \\
\hline$C(12)-C(13)$ & $1.521(4)$ \\
\hline $\mathrm{C}(13)-\mathrm{C}(15)$ & $1.506(4)$ \\
\hline$C(13)-C(14)$ & $1.566(4)$ \\
\hline $\mathrm{C}(14)-\mathrm{C}(23)$ & $1.514(4)$ \\
\hline $\mathrm{C}(14)-\mathrm{H}(14)$ & 1.0000 \\
\hline$C(15)-C(16)$ & $1.385(5)$ \\
\hline$C(15)-C(20)$ & $1.396(5)$ \\
\hline$C(16)-C(17)$ & $1.397(5)$ \\
\hline $\mathrm{C}(16)-\mathrm{H}(16)$ & 0.9500 \\
\hline $\mathrm{C}(17)-\mathrm{C}(18)$ & $1.376(6)$ \\
\hline $\mathrm{C}(17)-\mathrm{H}(17)$ & 0.9500 \\
\hline$C(18)-C(19)$ & $1.404(6)$ \\
\hline $\mathrm{C}(18)-\mathrm{H}(18)$ & 0.9500 \\
\hline$C(19)-C(20)$ & $1.388(5)$ \\
\hline C(19)-H(19) & 0.9500 \\
\hline $\mathrm{C}(21)-\mathrm{C}(22)$ & $1.502(5)$ \\
\hline $\mathrm{C}(21)-\mathrm{H}(21)$ & 0.9500 \\
\hline $\mathrm{C}(22)-\mathrm{H}(22 \mathrm{~A})$ & 0.9800 \\
\hline $\mathrm{C}(22)-\mathrm{H}(22 \mathrm{~B})$ & 0.9800 \\
\hline $\mathrm{C}(22)-\mathrm{H}(22 \mathrm{C})$ & 0.9800 \\
\hline $\mathrm{C}(24)-\mathrm{H}(24 \mathrm{~A})$ & 0.9800 \\
\hline $\mathrm{C}(24)-\mathrm{H}(24 \mathrm{~B})$ & 0.9800 \\
\hline $\mathrm{C}(24)-\mathrm{H}(24 \mathrm{C})$ & 0.9800 \\
\hline $\mathrm{C}(1)-\mathrm{N}(1)-\mathrm{C}(5)$ & $125.0(3)$ \\
\hline $\mathrm{C}(1)-\mathrm{N}(1)-\mathrm{C}(4)$ & $115.8(3)$ \\
\hline $\mathrm{C}(5)-\mathrm{N}(1)-\mathrm{C}(4)$ & 119.1(3) \\
\hline $\mathrm{C}(4)-\mathrm{N}(2)-\mathrm{C}(11)$ & $115.1(3)$ \\
\hline $\mathrm{C}(4)-\mathrm{N}(2)-\mathrm{C}(7)$ & $106.9(2)$ \\
\hline $\mathrm{C}(11)-\mathrm{N}(2)-\mathrm{C}(7)$ & $110.3(3)$ \\
\hline $\mathrm{C}(12)-\mathrm{N}(3)-\mathrm{C}(20)$ & $105.7(3)$ \\
\hline $\mathrm{C}(5)-\mathrm{O}(2)-\mathrm{H}(2)$ & 109.5 \\
\hline $\mathrm{C}(23)-\mathrm{O}(4)-\mathrm{C}(24)$ & $115.8(3)$ \\
\hline $\mathrm{O}(1)-\mathrm{C}(1)-\mathrm{N}(1)$ & $125.9(3)$ \\
\hline $\mathrm{O}(1)-\mathrm{C}(1)-\mathrm{C}(2)$ & $126.4(3)$ \\
\hline
\end{tabular}




\begin{tabular}{|c|c|}
\hline $\mathrm{N}(1)-\mathrm{C}(1)-\mathrm{C}(2)$ & $107.7(3)$ \\
\hline $\mathrm{C}(1)-\mathrm{C}(2)-\mathrm{C}(3)$ & $106.2(3)$ \\
\hline $\mathrm{C}(1)-\mathrm{C}(2)-\mathrm{H}(2 \mathrm{~A})$ & 110.5 \\
\hline $\mathrm{C}(3)-\mathrm{C}(2)-\mathrm{H}(2 \mathrm{~A})$ & 110.5 \\
\hline $\mathrm{C}(1)-\mathrm{C}(2)-\mathrm{H}(2 \mathrm{~B})$ & 110.5 \\
\hline $\mathrm{C}(3)-\mathrm{C}(2)-\mathrm{H}(2 \mathrm{~B})$ & 110.5 \\
\hline $\mathrm{H}(2 \mathrm{~A})-\mathrm{C}(2)-\mathrm{H}(2 \mathrm{~B})$ & 108.7 \\
\hline$C(2)-C(3)-C(4)$ & $106.8(3)$ \\
\hline $\mathrm{C}(2)-\mathrm{C}(3)-\mathrm{H}(3 \mathrm{~A})$ & 110.4 \\
\hline $\mathrm{C}(4)-\mathrm{C}(3)-\mathrm{H}(3 \mathrm{~A})$ & 110.4 \\
\hline $\mathrm{C}(2)-\mathrm{C}(3)-\mathrm{H}(3 \mathrm{~B})$ & 110.4 \\
\hline $\mathrm{C}(4)-\mathrm{C}(3)-\mathrm{H}(3 \mathrm{~B})$ & 110.4 \\
\hline $\mathrm{H}(3 \mathrm{~A})-\mathrm{C}(3)-\mathrm{H}(3 \mathrm{~B})$ & 108.6 \\
\hline $\mathrm{N}(2)-\mathrm{C}(4)-\mathrm{N}(1)$ & $112.6(3)$ \\
\hline $\mathrm{N}(2)-\mathrm{C}(4)-\mathrm{C}(3)$ & $116.9(3)$ \\
\hline $\mathrm{N}(1)-\mathrm{C}(4)-\mathrm{C}(3)$ & $103.4(3)$ \\
\hline $\mathrm{N}(2)-\mathrm{C}(4)-\mathrm{H}(4)$ & 107.9 \\
\hline $\mathrm{N}(1)-\mathrm{C}(4)-\mathrm{H}(4)$ & 107.9 \\
\hline $\mathrm{C}(3)-\mathrm{C}(4)-\mathrm{H}(4)$ & 107.9 \\
\hline $\mathrm{O}(2)-\mathrm{C}(5)-\mathrm{N}(1)$ & $107.9(3)$ \\
\hline $\mathrm{O}(2)-\mathrm{C}(5)-\mathrm{C}(6)$ & $109.9(3)$ \\
\hline $\mathrm{N}(1)-\mathrm{C}(5)-\mathrm{C}(6)$ & $109.4(2)$ \\
\hline $\mathrm{O}(2)-\mathrm{C}(5)-\mathrm{H}(5)$ & 109.9 \\
\hline $\mathrm{N}(1)-\mathrm{C}(5)-\mathrm{H}(5)$ & 109.9 \\
\hline $\mathrm{C}(6)-\mathrm{C}(5)-\mathrm{H}(5)$ & 109.9 \\
\hline$C(5)-C(6)-C(13)$ & $112.4(2)$ \\
\hline $\mathrm{C}(5)-\mathrm{C}(6)-\mathrm{C}(7)$ & $109.6(3)$ \\
\hline$C(13)-C(6)-C(7)$ & $107.3(2)$ \\
\hline $\mathrm{C}(5)-\mathrm{C}(6)-\mathrm{H}(6)$ & 109.2 \\
\hline $\mathrm{C}(13)-\mathrm{C}(6)-\mathrm{H}(6)$ & 109.2 \\
\hline $\mathrm{C}(7)-\mathrm{C}(6)-\mathrm{H}(6)$ & 109.2 \\
\hline $\mathrm{N}(2)-\mathrm{C}(7)-\mathrm{C}(8)$ & $111.2(2)$ \\
\hline $\mathrm{N}(2)-\mathrm{C}(7)-\mathrm{C}(6)$ & $110.3(2)$ \\
\hline $\mathrm{C}(8)-\mathrm{C}(7)-\mathrm{C}(6)$ & $109.5(3)$ \\
\hline $\mathrm{N}(2)-\mathrm{C}(7)-\mathrm{H}(7)$ & 108.6 \\
\hline $\mathrm{C}(8)-\mathrm{C}(7)-\mathrm{H}(7)$ & 108.6 \\
\hline $\mathrm{C}(6)-\mathrm{C}(7)-\mathrm{H}(7)$ & 108.6 \\
\hline $\mathrm{C}(21)-\mathrm{C}(8)-\mathrm{C}(7)$ & $122.1(3)$ \\
\hline
\end{tabular}




\begin{tabular}{|c|c|}
\hline $\mathrm{C}(21)-\mathrm{C}(8)-\mathrm{C}(9)$ & $127.0(3)$ \\
\hline$C(7)-C(8)-C(9)$ & $110.8(3)$ \\
\hline$C(8)-C(9)-C(10)$ & $108.5(3)$ \\
\hline $\mathrm{C}(8)-\mathrm{C}(9)-\mathrm{C}(14)$ & $108.5(2)$ \\
\hline$C(10)-C(9)-C(14)$ & $109.7(3)$ \\
\hline $\mathrm{C}(8)-\mathrm{C}(9)-\mathrm{H}(9)$ & 110.0 \\
\hline $\mathrm{C}(10)-\mathrm{C}(9)-\mathrm{H}(9)$ & 110.0 \\
\hline $\mathrm{C}(14)-\mathrm{C}(9)-\mathrm{H}(9)$ & 110.0 \\
\hline$C(9)-C(10)-C(11)$ & $110.0(2)$ \\
\hline $\mathrm{C}(9)-\mathrm{C}(10)-\mathrm{H}(10 \mathrm{~A})$ & 109.7 \\
\hline $\mathrm{C}(11)-\mathrm{C}(10)-\mathrm{H}(10 \mathrm{~A})$ & 109.7 \\
\hline $\mathrm{C}(9)-\mathrm{C}(10)-\mathrm{H}(10 \mathrm{~B})$ & 109.7 \\
\hline $\mathrm{C}(11)-\mathrm{C}(10)-\mathrm{H}(10 \mathrm{~B})$ & 109.7 \\
\hline $\mathrm{H}(10 \mathrm{~A})-\mathrm{C}(10)-\mathrm{H}(10 \mathrm{~B})$ & 108.2 \\
\hline $\mathrm{N}(2)-\mathrm{C}(11)-\mathrm{C}(12)$ & $110.6(2)$ \\
\hline $\mathrm{N}(2)-\mathrm{C}(11)-\mathrm{C}(10)$ & $108.6(3)$ \\
\hline $\mathrm{C}(12)-\mathrm{C}(11)-\mathrm{C}(10)$ & $105.8(3)$ \\
\hline $\mathrm{N}(2)-\mathrm{C}(11)-\mathrm{H}(11)$ & 110.6 \\
\hline $\mathrm{C}(12)-\mathrm{C}(11)-\mathrm{H}(11)$ & 110.6 \\
\hline $\mathrm{C}(10)-\mathrm{C}(11)-\mathrm{H}(11)$ & 110.6 \\
\hline $\mathrm{N}(3)-\mathrm{C}(12)-\mathrm{C}(11)$ & $128.9(3)$ \\
\hline $\mathrm{N}(3)-\mathrm{C}(12)-\mathrm{C}(13)$ & $115.6(3)$ \\
\hline$C(11)-C(12)-C(13)$ & $115.4(3)$ \\
\hline$C(15)-C(13)-C(12)$ & $99.3(3)$ \\
\hline$C(15)-C(13)-C(6)$ & $118.3(2)$ \\
\hline $\mathrm{C}(12)-\mathrm{C}(13)-\mathrm{C}(6)$ & $109.0(3)$ \\
\hline $\mathrm{C}(15)-\mathrm{C}(13)-\mathrm{C}(14)$ & $113.5(3)$ \\
\hline$C(12)-C(13)-C(14)$ & $103.1(2)$ \\
\hline$C(6)-C(13)-C(14)$ & $111.5(2)$ \\
\hline $\mathrm{C}(23)-\mathrm{C}(14)-\mathrm{C}(9)$ & $110.9(3)$ \\
\hline $\mathrm{C}(23)-\mathrm{C}(14)-\mathrm{C}(13)$ & $113.9(2)$ \\
\hline$C(9)-C(14)-C(13)$ & $109.6(3)$ \\
\hline $\mathrm{C}(23)-\mathrm{C}(14)-\mathrm{H}(14)$ & 107.4 \\
\hline $\mathrm{C}(9)-\mathrm{C}(14)-\mathrm{H}(14)$ & 107.4 \\
\hline $\mathrm{C}(13)-\mathrm{C}(14)-\mathrm{H}(14)$ & 107.4 \\
\hline$C(16)-C(15)-C(20)$ & $120.5(3)$ \\
\hline$C(16)-C(15)-C(13)$ & $132.5(3)$ \\
\hline$C(20)-C(15)-C(13)$ & $107.1(3)$ \\
\hline
\end{tabular}




\begin{tabular}{|c|c|}
\hline$C(15)-C(16)-C(17)$ & $117.9(3)$ \\
\hline $\mathrm{C}(15)-\mathrm{C}(16)-\mathrm{H}(16)$ & 121.0 \\
\hline $\mathrm{C}(17)-\mathrm{C}(16)-\mathrm{H}(16)$ & 121.0 \\
\hline$C(18)-C(17)-C(16)$ & $121.4(3)$ \\
\hline $\mathrm{C}(18)-\mathrm{C}(17)-\mathrm{H}(17)$ & 119.3 \\
\hline $\mathrm{C}(16)-\mathrm{C}(17)-\mathrm{H}(17)$ & 119.3 \\
\hline$C(17)-C(18)-C(19)$ & $121.3(4)$ \\
\hline $\mathrm{C}(17)-\mathrm{C}(18)-\mathrm{H}(18)$ & 119.4 \\
\hline $\mathrm{C}(19)-\mathrm{C}(18)-\mathrm{H}(18)$ & 119.4 \\
\hline$C(20)-C(19)-C(18)$ & $116.9(3)$ \\
\hline $\mathrm{C}(20)-\mathrm{C}(19)-\mathrm{H}(19)$ & 121.6 \\
\hline $\mathrm{C}(18)-\mathrm{C}(19)-\mathrm{H}(19)$ & 121.6 \\
\hline$C(19)-C(20)-C(15)$ & $121.9(3)$ \\
\hline $\mathrm{C}(19)-\mathrm{C}(20)-\mathrm{N}(3)$ & $126.1(3)$ \\
\hline$C(15)-C(20)-N(3)$ & $112.0(3)$ \\
\hline $\mathrm{C}(8)-\mathrm{C}(21)-\mathrm{C}(22)$ & $127.5(3)$ \\
\hline $\mathrm{C}(8)-\mathrm{C}(21)-\mathrm{H}(21)$ & 116.3 \\
\hline $\mathrm{C}(22)-\mathrm{C}(21)-\mathrm{H}(21)$ & 116.3 \\
\hline $\mathrm{C}(21)-\mathrm{C}(22)-\mathrm{H}(22 \mathrm{~A})$ & 109.5 \\
\hline $\mathrm{C}(21)-\mathrm{C}(22)-\mathrm{H}(22 \mathrm{~B})$ & 109.5 \\
\hline $\mathrm{H}(22 \mathrm{~A})-\mathrm{C}(22)-\mathrm{H}(22 \mathrm{~B})$ & 109.5 \\
\hline $\mathrm{C}(21)-\mathrm{C}(22)-\mathrm{H}(22 \mathrm{C})$ & 109.5 \\
\hline $\mathrm{H}(22 \mathrm{~A})-\mathrm{C}(22)-\mathrm{H}(22 \mathrm{C})$ & 109.5 \\
\hline $\mathrm{H}(22 \mathrm{~B})-\mathrm{C}(22)-\mathrm{H}(22 \mathrm{C})$ & 109.5 \\
\hline $\mathrm{O}(3)-\mathrm{C}(23)-\mathrm{O}(4)$ & $123.6(3)$ \\
\hline $\mathrm{O}(3)-\mathrm{C}(23)-\mathrm{C}(14)$ & $127.0(3)$ \\
\hline $\mathrm{O}(4)-\mathrm{C}(23)-\mathrm{C}(14)$ & $109.4(3)$ \\
\hline $\mathrm{O}(4)-\mathrm{C}(24)-\mathrm{H}(24 \mathrm{~A})$ & 109.5 \\
\hline $\mathrm{O}(4)-\mathrm{C}(24)-\mathrm{H}(24 \mathrm{~B})$ & 109.5 \\
\hline $\mathrm{H}(24 \mathrm{~A})-\mathrm{C}(24)-\mathrm{H}(24 \mathrm{~B})$ & 109.5 \\
\hline $\mathrm{O}(4)-\mathrm{C}(24)-\mathrm{H}(24 \mathrm{C})$ & 109.5 \\
\hline $\mathrm{H}(24 \mathrm{~A})-\mathrm{C}(24)-\mathrm{H}(24 \mathrm{C})$ & 109.5 \\
\hline $\mathrm{H}(24 \mathrm{~B})-\mathrm{C}(24)-\mathrm{H}(24 \mathrm{C})$ & 109.5 \\
\hline
\end{tabular}

Symmetry transformations used to generate equivalent atoms: 
Table S10. Anisotropic displacement parameters $\left(\AA^{2} \times 10^{3}\right)$ for compound (1). The anisotropic displacement factor exponent takes the form: $\quad-2 \pi^{2}\left[\mathrm{~h}^{2} \mathrm{a}^{* 2} \mathrm{U}^{11}+\ldots \quad+2 \mathrm{~h} \mathrm{k} \mathrm{a}^{*} \mathrm{~b}^{*} \mathrm{U}^{12}\right]$

\begin{tabular}{|c|c|c|c|c|c|c|}
\hline & $\mathrm{U}^{11}$ & $\mathrm{U}^{22}$ & $\mathrm{U}^{33}$ & $\mathrm{U}^{23}$ & $\mathrm{U}^{13}$ & $\mathrm{U}^{12}$ \\
\hline $\mathrm{N}(1)$ & $23(1)$ & $22(2)$ & $24(1)$ & $0(1)$ & $2(1)$ & $3(1)$ \\
\hline $\mathrm{N}(2)$ & 24(1) & $21(1)$ & $27(1)$ & $-1(1)$ & $3(1)$ & $3(1)$ \\
\hline $\mathrm{N}(3)$ & $22(1)$ & $24(1)$ & $28(1)$ & $1(1)$ & $1(1)$ & $-2(1)$ \\
\hline $\mathrm{O}(1)$ & $36(1)$ & $54(2)$ & $26(1)$ & $-5(1)$ & $-5(1)$ & $10(1)$ \\
\hline $\mathrm{O}(2)$ & $22(1)$ & $27(1)$ & $31(1)$ & $3(1)$ & $4(1)$ & $1(1)$ \\
\hline $\mathrm{O}(3)$ & $33(1)$ & $40(2)$ & $37(1)$ & 11(1) & 10(1) & $14(1)$ \\
\hline $\mathrm{O}(4)$ & $40(1)$ & $29(1)$ & $30(1)$ & $8(1)$ & $8(1)$ & $6(1)$ \\
\hline$C(1)$ & $21(2)$ & $32(2)$ & $26(2)$ & $4(1)$ & $2(1)$ & $0(1)$ \\
\hline$C(2)$ & $29(2)$ & $39(2)$ & $34(2)$ & $7(2)$ & $-1(1)$ & $10(2)$ \\
\hline$C(3)$ & $34(2)$ & $29(2)$ & $34(2)$ & $4(2)$ & $2(1)$ & $10(2)$ \\
\hline $\mathrm{C}(4)$ & $28(2)$ & $18(2)$ & $27(2)$ & $1(1)$ & $3(1)$ & $4(1)$ \\
\hline$C(5)$ & $22(2)$ & $22(2)$ & $22(1)$ & $0(1)$ & $4(1)$ & $1(1)$ \\
\hline$C(6)$ & $20(1)$ & $21(2)$ & $21(1)$ & $0(1)$ & $2(1)$ & $4(1)$ \\
\hline$C(7)$ & 21(1) & $20(2)$ & $24(2)$ & $1(1)$ & $2(1)$ & $1(1)$ \\
\hline $\mathrm{C}(8)$ & $26(2)$ & $20(2)$ & $21(1)$ & $-3(1)$ & $3(1)$ & $2(1)$ \\
\hline C(9) & $23(2)$ & $26(2)$ & $21(1)$ & $-1(1)$ & $4(1)$ & $0(1)$ \\
\hline$C(10)$ & $24(2)$ & $30(2)$ & $27(2)$ & $-4(1)$ & $7(1)$ & $2(1)$ \\
\hline $\mathrm{C}(11)$ & $20(1)$ & $24(2)$ & $32(2)$ & $-2(1)$ & $4(1)$ & $3(1)$ \\
\hline$C(12)$ & 19(1) & $23(2)$ & $27(2)$ & $2(1)$ & $3(1)$ & $3(1)$ \\
\hline $\mathrm{C}(13)$ & $23(2)$ & $17(2)$ & $23(1)$ & $-1(1)$ & $1(1)$ & $2(1)$ \\
\hline$C(14)$ & $22(2)$ & $22(2)$ & $24(2)$ & $-3(1)$ & $3(1)$ & $-2(1)$ \\
\hline $\mathrm{C}(15)$ & $27(2)$ & $17(2)$ & $22(1)$ & $1(1)$ & $-1(1)$ & $0(1)$ \\
\hline$C(16)$ & $37(2)$ & $21(2)$ & $28(2)$ & 1(1) & $2(1)$ & $6(1)$ \\
\hline $\mathrm{C}(17)$ & $58(2)$ & $22(2)$ & $29(2)$ & $-1(1)$ & $-1(2)$ & $9(2)$ \\
\hline $\mathrm{C}(18)$ & 61(3) & $21(2)$ & $30(2)$ & $-4(2)$ & $-9(2)$ & $-1(2)$ \\
\hline C(19) & $39(2)$ & $25(2)$ & $34(2)$ & $1(2)$ & $-11(2)$ & $-3(1)$ \\
\hline$C(20)$ & $27(2)$ & $19(2)$ & $27(2)$ & $2(1)$ & $-1(1)$ & $-1(1)$ \\
\hline $\mathrm{C}(21)$ & $26(2)$ & $26(2)$ & $24(2)$ & $-3(1)$ & $2(1)$ & $1(1)$ \\
\hline$C(22)$ & $37(2)$ & $45(2)$ & $24(2)$ & $2(2)$ & $-2(1)$ & $-2(2)$ \\
\hline$C(23)$ & $25(2)$ & $21(2)$ & $26(2)$ & $1(1)$ & $0(1)$ & $-1(1)$ \\
\hline$C(24)$ & $47(2)$ & $41(2)$ & $40(2)$ & $13(2)$ & $4(2)$ & $16(2)$ \\
\hline
\end{tabular}


Table S11. Hydrogen coordinates $\left(\mathrm{x} 10^{4}\right)$ and isotropic displacement parameters $\left(\AA^{2} \times 10^{3}\right)$ for compound (1).

\begin{tabular}{|c|c|c|c|c|}
\hline & $\mathrm{x}$ & $\mathrm{y}$ & z & $\mathrm{U}(\mathrm{eq})$ \\
\hline $\mathrm{H}(2)$ & 3012 & 4322 & 6192 & 40 \\
\hline $\mathrm{H}(2 \mathrm{~A})$ & 9941 & 2541 & 8173 & 41 \\
\hline $\mathrm{H}(2 \mathrm{~B})$ & 11371 & 3201 & 7540 & 41 \\
\hline $\mathrm{H}(3 \mathrm{~A})$ & 8989 & 2061 & 5971 & 39 \\
\hline $\mathrm{H}(3 \mathrm{~B})$ & 10427 & 2718 & 5340 & 39 \\
\hline $\mathrm{H}(4)$ & 6359 & 2804 & 5193 & 29 \\
\hline $\mathrm{H}(5)$ & 5977 & 4835 & 6968 & 26 \\
\hline $\mathrm{H}(6)$ & 4465 & 5108 & 4466 & 25 \\
\hline $\mathrm{H}(7)$ & 4622 & 3704 & 3596 & 26 \\
\hline $\mathrm{H}(9)$ & 7343 & 5232 & 963 & 28 \\
\hline $\mathrm{H}(10 \mathrm{~A})$ & 10473 & 4814 & 2244 & 32 \\
\hline $\mathrm{H}(10 \mathrm{~B})$ & 9263 & 4008 & 1608 & 32 \\
\hline $\mathrm{H}(11)$ & 10639 & 3777 & 4102 & 30 \\
\hline $\mathrm{H}(14)$ & 8733 & 6037 & 3053 & 27 \\
\hline $\mathrm{H}(16)$ & 5601 & 6721 & 5957 & 35 \\
\hline $\mathrm{H}(17)$ & 7189 & 7553 & 7837 & 44 \\
\hline $\mathrm{H}(18)$ & 10490 & 7365 & 8698 & 47 \\
\hline $\mathrm{H}(19)$ & 12312 & 6266 & 7827 & 41 \\
\hline $\mathrm{H}(21)$ & 3115 & 3978 & 1347 & 30 \\
\hline $\mathrm{H}(22 \mathrm{~A})$ & 4586 & 5229 & -398 & 54 \\
\hline $\mathrm{H}(22 \mathrm{~B})$ & 2315 & 4960 & -511 & 54 \\
\hline $\mathrm{H}(22 \mathrm{C})$ & 3879 & 4351 & -1098 & 54 \\
\hline $\mathrm{H}(24 \mathrm{~A})$ & 3315 & 7083 & 781 & 64 \\
\hline $\mathrm{H}(24 \mathrm{~B})$ & 4890 & 7534 & -74 & 64 \\
\hline $\mathrm{H}(24 \mathrm{C})$ & 4690 & 7809 & 1542 & 64 \\
\hline
\end{tabular}


Table S12. Torsion angles $\left[{ }^{\circ}\right]$ for compound (1).

\begin{tabular}{|c|c|}
\hline $\mathrm{C}(5)-\mathrm{N}(1)-\mathrm{C}(1)-\mathrm{O}(1)$ & $-0.5(5)$ \\
\hline $\mathrm{C}(4)-\mathrm{N}(1)-\mathrm{C}(1)-\mathrm{O}(1)$ & $-177.0(3)$ \\
\hline $\mathrm{C}(5)-\mathrm{N}(1)-\mathrm{C}(1)-\mathrm{C}(2)$ & $-179.2(3)$ \\
\hline $\mathrm{C}(4)-\mathrm{N}(1)-\mathrm{C}(1)-\mathrm{C}(2)$ & $4.4(4)$ \\
\hline $\mathrm{O}(1)-\mathrm{C}(1)-\mathrm{C}(2)-\mathrm{C}(3)$ & $178.7(4)$ \\
\hline $\mathrm{N}(1)-\mathrm{C}(1)-\mathrm{C}(2)-\mathrm{C}(3)$ & $-2.7(4)$ \\
\hline$C(1)-C(2)-C(3)-C(4)$ & $0.2(4)$ \\
\hline $\mathrm{C}(11)-\mathrm{N}(2)-\mathrm{C}(4)-\mathrm{N}(1)$ & $65.6(3)$ \\
\hline $\mathrm{C}(7)-\mathrm{N}(2)-\mathrm{C}(4)-\mathrm{N}(1)$ & $-57.2(3)$ \\
\hline $\mathrm{C}(11)-\mathrm{N}(2)-\mathrm{C}(4)-\mathrm{C}(3)$ & $-53.8(4)$ \\
\hline $\mathrm{C}(7)-\mathrm{N}(2)-\mathrm{C}(4)-\mathrm{C}(3)$ & $-176.7(3)$ \\
\hline $\mathrm{C}(1)-\mathrm{N}(1)-\mathrm{C}(4)-\mathrm{N}(2)$ & $-131.1(3)$ \\
\hline $\mathrm{C}(5)-\mathrm{N}(1)-\mathrm{C}(4)-\mathrm{N}(2)$ & $52.2(4)$ \\
\hline $\mathrm{C}(1)-\mathrm{N}(1)-\mathrm{C}(4)-\mathrm{C}(3)$ & $-4.1(4)$ \\
\hline$C(5)-N(1)-C(4)-C(3)$ & $179.2(3)$ \\
\hline $\mathrm{C}(2)-\mathrm{C}(3)-\mathrm{C}(4)-\mathrm{N}(2)$ & $126.3(3)$ \\
\hline $\mathrm{C}(2)-\mathrm{C}(3)-\mathrm{C}(4)-\mathrm{N}(1)$ & $2.0(4)$ \\
\hline $\mathrm{C}(1)-\mathrm{N}(1)-\mathrm{C}(5)-\mathrm{O}(2)$ & $-103.0(3)$ \\
\hline $\mathrm{C}(4)-\mathrm{N}(1)-\mathrm{C}(5)-\mathrm{O}(2)$ & $73.4(3)$ \\
\hline$C(1)-N(1)-C(5)-C(6)$ & $137.5(3)$ \\
\hline$C(4)-N(1)-C(5)-C(6)$ & $-46.1(4)$ \\
\hline $\mathrm{O}(2)-\mathrm{C}(5)-\mathrm{C}(6)-\mathrm{C}(13)$ & $170.7(2)$ \\
\hline $\mathrm{N}(1)-\mathrm{C}(5)-\mathrm{C}(6)-\mathrm{C}(13)$ & $-71.0(3)$ \\
\hline $\mathrm{O}(2)-\mathrm{C}(5)-\mathrm{C}(6)-\mathrm{C}(7)$ & $-70.0(3)$ \\
\hline $\mathrm{N}(1)-\mathrm{C}(5)-\mathrm{C}(6)-\mathrm{C}(7)$ & $48.3(3)$ \\
\hline $\mathrm{C}(4)-\mathrm{N}(2)-\mathrm{C}(7)-\mathrm{C}(8)$ & $-175.1(3)$ \\
\hline $\mathrm{C}(11)-\mathrm{N}(2)-\mathrm{C}(7)-\mathrm{C}(8)$ & $59.1(3)$ \\
\hline$C(4)-N(2)-C(7)-C(6)$ & $63.2(3)$ \\
\hline $\mathrm{C}(11)-\mathrm{N}(2)-\mathrm{C}(7)-\mathrm{C}(6)$ & $-62.6(3)$ \\
\hline $\mathrm{C}(5)-\mathrm{C}(6)-\mathrm{C}(7)-\mathrm{N}(2)$ & $-59.9(3)$ \\
\hline $\mathrm{C}(13)-\mathrm{C}(6)-\mathrm{C}(7)-\mathrm{N}(2)$ & $62.3(3)$ \\
\hline$C(5)-C(6)-C(7)-C(8)$ & $177.3(2)$ \\
\hline $\mathrm{C}(13)-\mathrm{C}(6)-\mathrm{C}(7)-\mathrm{C}(8)$ & $-60.4(3)$ \\
\hline $\mathrm{N}(2)-\mathrm{C}(7)-\mathrm{C}(8)-\mathrm{C}(21)$ & $125.9(3)$ \\
\hline$C(6)-C(7)-C(8)-C(21)$ & $-111.9(3)$ \\
\hline $\mathrm{N}(2)-\mathrm{C}(7)-\mathrm{C}(8)-\mathrm{C}(9)$ & $-57.7(3)$ \\
\hline
\end{tabular}




\begin{tabular}{|c|c|}
\hline$C(6)-C(7)-C(8)-C(9)$ & $64.5(3)$ \\
\hline$C(21)-C(8)-C(9)-C(10)$ & $-126.7(3)$ \\
\hline $\mathrm{C}(7)-\mathrm{C}(8)-\mathrm{C}(9)-\mathrm{C}(10)$ & $57.1(3)$ \\
\hline $\mathrm{C}(21)-\mathrm{C}(8)-\mathrm{C}(9)-\mathrm{C}(14)$ & 114.2(4) \\
\hline $\mathrm{C}(7)-\mathrm{C}(8)-\mathrm{C}(9)-\mathrm{C}(14)$ & $-62.0(3)$ \\
\hline$C(8)-C(9)-C(10)-C(11)$ & $-58.9(3)$ \\
\hline $\mathrm{C}(14)-\mathrm{C}(9)-\mathrm{C}(10)-\mathrm{C}(11)$ & $59.4(3)$ \\
\hline $\mathrm{C}(4)-\mathrm{N}(2)-\mathrm{C}(11)-\mathrm{C}(12)$ & $-65.2(4)$ \\
\hline $\mathrm{C}(7)-\mathrm{N}(2)-\mathrm{C}(11)-\mathrm{C}(12)$ & $55.8(3)$ \\
\hline $\mathrm{C}(4)-\mathrm{N}(2)-\mathrm{C}(11)-\mathrm{C}(10)$ & 179.1(3) \\
\hline $\mathrm{C}(7)-\mathrm{N}(2)-\mathrm{C}(11)-\mathrm{C}(10)$ & $-59.9(3)$ \\
\hline $\mathrm{C}(9)-\mathrm{C}(10)-\mathrm{C}(11)-\mathrm{N}(2)$ & $60.7(3)$ \\
\hline $\mathrm{C}(9)-\mathrm{C}(10)-\mathrm{C}(11)-\mathrm{C}(12)$ & $-58.0(3)$ \\
\hline $\mathrm{C}(20)-\mathrm{N}(3)-\mathrm{C}(12)-\mathrm{C}(11)$ & 179.1(3) \\
\hline $\mathrm{C}(20)-\mathrm{N}(3)-\mathrm{C}(12)-\mathrm{C}(13)$ & $3.3(4)$ \\
\hline $\mathrm{N}(2)-\mathrm{C}(11)-\mathrm{C}(12)-\mathrm{N}(3)$ & $131.4(3)$ \\
\hline $\mathrm{C}(10)-\mathrm{C}(11)-\mathrm{C}(12)-\mathrm{N}(3)$ & $-111.2(4)$ \\
\hline $\mathrm{N}(2)-\mathrm{C}(11)-\mathrm{C}(12)-\mathrm{C}(13)$ & $-52.8(4)$ \\
\hline $\mathrm{C}(10)-\mathrm{C}(11)-\mathrm{C}(12)-\mathrm{C}(13)$ & $64.6(3)$ \\
\hline $\mathrm{N}(3)-\mathrm{C}(12)-\mathrm{C}(13)-\mathrm{C}(15)$ & $-5.6(3)$ \\
\hline $\mathrm{C}(11)-\mathrm{C}(12)-\mathrm{C}(13)-\mathrm{C}(15)$ & $178.0(3)$ \\
\hline $\mathrm{N}(3)-\mathrm{C}(12)-\mathrm{C}(13)-\mathrm{C}(6)$ & $-130.1(3)$ \\
\hline $\mathrm{C}(11)-\mathrm{C}(12)-\mathrm{C}(13)-\mathrm{C}(6)$ & $53.6(3)$ \\
\hline $\mathrm{N}(3)-\mathrm{C}(12)-\mathrm{C}(13)-\mathrm{C}(14)$ & 111.3(3) \\
\hline $\mathrm{C}(11)-\mathrm{C}(12)-\mathrm{C}(13)-\mathrm{C}(14)$ & $-65.0(3)$ \\
\hline $\mathrm{C}(5)-\mathrm{C}(6)-\mathrm{C}(13)-\mathrm{C}(15)$ & $-47.5(4)$ \\
\hline$C(7)-C(6)-C(13)-C(15)$ & $-168.1(3)$ \\
\hline $\mathrm{C}(5)-\mathrm{C}(6)-\mathrm{C}(13)-\mathrm{C}(12)$ & $64.8(3)$ \\
\hline $\mathrm{C}(7)-\mathrm{C}(6)-\mathrm{C}(13)-\mathrm{C}(12)$ & $-55.7(3)$ \\
\hline $\mathrm{C}(5)-\mathrm{C}(6)-\mathrm{C}(13)-\mathrm{C}(14)$ & $178.0(2)$ \\
\hline$C(7)-C(6)-C(13)-C(14)$ & $57.4(3)$ \\
\hline $\mathrm{C}(8)-\mathrm{C}(9)-\mathrm{C}(14)-\mathrm{C}(23)$ & $-69.7(3)$ \\
\hline $\mathrm{C}(10)-\mathrm{C}(9)-\mathrm{C}(14)-\mathrm{C}(23)$ & $172.0(3)$ \\
\hline $\mathrm{C}(8)-\mathrm{C}(9)-\mathrm{C}(14)-\mathrm{C}(13)$ & $57.0(3)$ \\
\hline $\mathrm{C}(10)-\mathrm{C}(9)-\mathrm{C}(14)-\mathrm{C}(13)$ & $-61.3(3)$ \\
\hline $\mathrm{C}(15)-\mathrm{C}(13)-\mathrm{C}(14)-\mathrm{C}(23)$ & $-68.7(3)$ \\
\hline $\mathrm{C}(12)-\mathrm{C}(13)-\mathrm{C}(14)-\mathrm{C}(23)$ & $-175.1(3)$ \\
\hline $\mathrm{C}(6)-\mathrm{C}(13)-\mathrm{C}(14)-\mathrm{C}(23)$ & $68.1(3)$ \\
\hline
\end{tabular}




$\begin{array}{lc}C(15)-C(13)-C(14)-C(9) & 166.3(2) \\ C(12)-C(13)-C(14)-C(9) & 59.9(3) \\ C(6)-C(13)-C(14)-C(9) & -56.9(3) \\ C(12)-C(13)-C(15)-C(16) & -173.9(3) \\ C(6)-C(13)-C(15)-C(16) & -56.3(5) \\ C(14)-C(13)-C(15)-C(16) & 77.3(4) \\ C(12)-C(13)-C(15)-C(20) & 5.5(3) \\ C(6)-C(13)-C(15)-C(20) & 123.1(3) \\ C(14)-C(13)-C(15)-C(20) & -103.3(3) \\ C(20)-C(15)-C(16)-C(17) & 1.8(5) \\ C(13)-C(15)-C(16)-C(17) & -178.9(3) \\ C(15)-C(16)-C(17)-C(18) & 1.4(5) \\ C(16)-C(17)-C(18)-C(19) & -2.6(6) \\ C(17)-C(18)-C(19)-C(20) & 0.5(6) \\ C(18)-C(19)-C(20)-C(15) & 2.7(5) \\ C(18)-C(19)-C(20)-N(3) & -176.3(3) \\ C(16)-C(15)-C(20)-C(19) & -3.9(5) \\ C(13)-C(15)-C(20)-C(19) & 176.6(3) \\ C(16)-C(15)-C(20)-N(3) & 175.2(3) \\ C(13)-C(15)-C(20)-N(3) & -4.3(3) \\ C(12)-N(3)-C(20)-C(19) & 179.8(3) \\ C(12)-N(3)-C(20)-C(15) & 0.7(4) \\ C(7)-C(8)-C(21)-C(22) & 174.0(3) \\ C(9)-C(8)-C(21)-C(22) & -1.9(6) \\ C(24)-O(4)-C(23)-O(3) & 0.9(5) \\ C(24)-O(4)-C(23)-C(14) & -179.3(3) \\ C(9)-C(14)-C(23)-O(3) & 112.7(4) \\ C(13)-C(14)-C(23)-O(3) & -11.5(5) \\ C(9)-C(14)-C(23)-O(4) & -67.1(3) \\ C(13)-C(14)-C(23)-O(4) & 168.6(3) \\ & \\ C & \end{array}$

Symmetry transformations used to generate equivalent atoms: 
Table S13. Hydrogen bonds for compound (1) [ $\AA^{\AA}$ and $\left.{ }^{\circ}\right]$.

\begin{tabular}{lcccc}
\hline D-H...A & d(D-H) & d(H...A & $d(\mathrm{D} \ldots \mathrm{A})$ & $<(\mathrm{DHA})$ \\
\hline $\mathrm{C}(10)-\mathrm{H}(10 \mathrm{~B}) \ldots \mathrm{O}(1) \# 1$ & 0.99 & 2.63 & $3.335(4)$ & 128.0 \\
$\mathrm{C}(6)-\mathrm{H}(6) \ldots \mathrm{O}(3)$ & 1.00 & 2.45 & $3.101(4)$ & 122.0 \\
$\mathrm{C}(2)-\mathrm{H}(2 \mathrm{~B}) \ldots \mathrm{O}(2) \# 2$ & 0.99 & 2.56 & $3.424(4)$ & 146.2 \\
$\mathrm{O}(2)-\mathrm{H}(2) \ldots \mathrm{N}(3) \# 3$ & 0.84 & 1.99 & $2.833(4)$ & 175.7 \\
& & & & \\
\hline
\end{tabular}

Symmetry transformations used to generate equivalent atoms:

\#1 x,y,z-1 \#2 x+1,y,z \#3 x-1,y,z 